
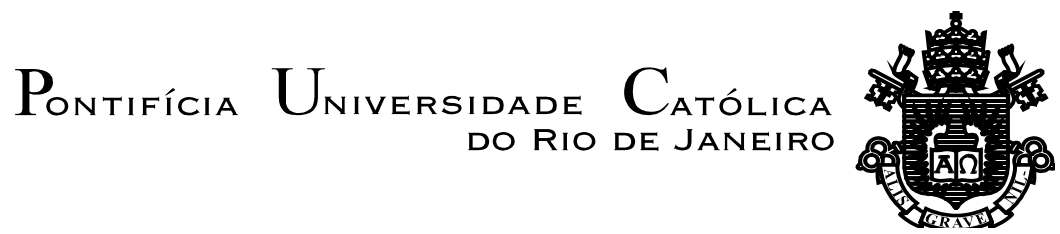

MARIANA DO NASCIMENTO SILVA

\title{
Grafeno como Nanoaditivo em Compósitos para Proteção Anticorrosiva
}

Dissertação de Mestrado

Dissertação apresentada como requisito parcial para obtenção do grau de Mestre pelo Programa de Pós-graduação em Engenharia de Materiais e de Processos Químicos e Metalúrgicos da PUC-Rio.

Orientadora: Profa. Ivani de Souza Bott Co-Orientadora: Elisa Janzen Kassab

Rio de Janeiro

Agosto de 2018 
Pontifícia Universidade Católica $_{\text {a }}$

DO RIO DE JANEIRO

\section{MARIANA DO NASCIMENTO SILVA}

\section{Grafeno como Nanoaditivo em Compósitos para Proteção \\ Anticorrosiva}

Dissertação apresentada como requisito parcial para obtenção do grau de Mestre pelo Programa de Pós-graduação em Engenharia de Materiais e de Processos Químicos e Metalúrgicos da PUC-Rio. Aprovado pela Comissão Examinadora abaixo assinada.

Profa. Ivani de Souza Bott

Orientadora

Departamento de Engenharia Química e de Materiais - PUC-Rio

Dra. Elisa Janzen Kassab

Co-Orientadora

Departamento de Engenharia Química e de Materiais - PUC-Rio

Prof. Alexander Hiroshi Kasama

Petrobras - CENPES

Prof. Omar Ginoble Pandoli

Departamento de Química- PUC-Rio

Profa. Glaura Goulart Silva

CTNANO - UFMG

Prof. Marcio da Silveira Carvalho

Coordenador Setorial do Centro Técnico Científico - PUC-Rio

Rio de Janeiro, 17 de Agosto de 2018. 
Todos os direitos reservados. É proibida a reprodução total ou parcial do trabalho sem autorização do autor, do orientador e da universidade.

\section{Mariana do Nascimento Silva}

Graduou-se em Engenharia de Petróleo na Universidade Federal de Sergipe (UFS) em 2016. Atuou como estagiária na PETREC- Petróleo Tecnologia Ltda (RJ), onde obteve experiência com geologia do petróleo. Ingressou no curso de mestrado em Engenharia de Materiais no ano de 2016. Realizou pesquisa na área corrosão em revestimentos aditivados com grafeno.

Ficha Catalográfica

Silva, Mariana do Nascimento

Grafeno como nanoaditivo em compósitos para proteção anticorrosiva / Mariana do Nascimento Silva ; orientadora: Ivani de Souza Bott ; co-orientadora: Elisa Janzen Kassab. - 2018.

127 f. : il. color. ; $30 \mathrm{~cm}$

Dissertação (mestrado)-Pontifícia Universidade Católica do Rio de Janeiro, Departamento de Engenharia Química e de Materiais, 2018.

Inclui bibliografia

1. Engenharia de Materiais - Teses. 2. Engenharia Química Teses. 3. Grafeno. 4. Nanocompósitos. 5. Revestimentos. 6. Polímero epóxi. 7. Corrosão. I. Bott, Ivani de Souza. II. Kassab, Elisa Janzen. III. Pontifícia Universidade Católica do Rio de Janeiro. Departamento de Engenharia Química e de Materiais. IV. Título. 


\section{Agradecimentos}

A Deus, pelo dom da vida e por me capacitar a correr atrás dos meus objetivos e nunca desistir de mim. Humildemente, agradeço.

A minha orientadora, Ivani Bott, pela confiança e disposição, reconheço toda dedicação, apoio e preocupação durante todas as etapas do mestrado, desde a escolha do tema até a correção do trabalho final. Muito obrigada por tudo!

A minha co-orientadora Elisa Janzen Kassab, pela disposição e pelo conhecimento compartilhado durante a fase experimental.

A Dra. Adriana Lopes Barros, pela oportunidade e pela disposição em contribuir no direcionamento dos meus experimentos.

Aos professores, pelos conhecimentos compartilhados, utilizados como base na elaboração deste trabalho. Em especial, aos professores Omar Pandoli e Marco Cremona, pela contribuição direta nos meus ensaios de caracterização.

A equipe do CTNano, em especial à Profa. Glaura Goulart Silva, pela contribuição direta na pesquisa.

A CAPES e PUC/Rio, pela concessão dos auxílios, imprescindíveis na realização desta tese de Mestrado.

Aos funcionários dos laboratórios da PUC/Rio, Asafe, Raphael, Jesica, Sônia, Antônio, Marcos, Loren obrigada por todo auxílio e paciência.

A Petrobras, em especial Joaquim Pereira Quintela e o Jeferson Leite de Oliveira, pela intensa colaboração experimental e conhecimentos que agregaram conteúdo neste trabalho.

A WEG Tintas, pelo material concedido.

Ao CENPES - Laboratório de Revestimentos Anticorrosivos, em especial o Silvio e o André, pelo acompanhamento nos meus ensaios de corrosão. Muito obrigada pelos ensinamentos e pela paciência

Aos meus pais queridos (Maria Irlan e Antônio José), minha irmã (Isis) e toda a minha família, pelo apoio incansável e pelo amor incondicional. Vocês são o meu porto seguro, agradecida demais.

Ao meu namorado (André Luiz) e sua família, pelo apoio, compreenssão e hospitalidade. Eternamente grata por tudo.

Aos meus amigos que contribuíram e torceram pelo sucesso do trabalho, vocês são a família que eu escolhi. 


\section{Resumo}

Silva, Mariana do Nascimento Silva; Bott, Ivani de Souza; Kassab, Elisa Janzen. Grafeno como Nanoaditivo em Compósitos para Proteção Anticorrosiva. Rio de Janeiro, 2018. 127p. Dissertação de Mestrado Departamento de Engenharia de Materiais e Processos Químicos e Metalúrgicos, Pontifícia Universidade Católica do Rio de Janeiro.

O nanocompósito estudado com função de revestimento anticorrosivo é constituído de Epóxi Novolac Tipo II aditivado com grafeno, sintetizado através do processo de esfoliação/redução do grafite empregando microondas. $\mathrm{O}$ sistema epóxi utilizado é composto pelos componentes: A, baseado em bisfenol F e cargas inorgânicas, e o B, endurecedor baseado em um polímero aminado. A síntese do grafeno e sua aditivação no componente A, foram realizadas pelo CTNano UFMG. O principal objetivo desta dissertação é o estudo da aplicabilidade do nanocompósito, onde o grafeno é utilizado como aditivo complementar em matriz polimérica (epóxi), como alternativa de maximizar a proteção anticorrosiva. Foram estudadas diferentes aditivações: CR (sem aditivo), e aditivadas $(0.1 \%$ e $0.5 \%)$. O substrato utilizado foi o aço carbono 1020, cuja superfície foi preparada com jateamento abrasivo e em seguida revestida com uma pistola de ar comprimido e com solvente para auxiliar o processo. Para avaliar a eficiência destes revestimentos foram realizados ensaios de corrosão (Célula Atlas e Ensaios Cíclicos), teste de aderência (Pull Off), medida de espessura (MEV) e rugosidade do substrato através do rugosímetro analógico e microscopia óptica. Para a dispersão do grafeno foi adicionado diglidil éter de bisfenol A (DGEBA) como um diluente. Os resultados obtidos indicaram que o grafeno apresentava boa dispersão na matriz polimérica. Concentrações de grafeno acima de 0,1 \% em massa levam à falha da proteção anticorrosiva. Este comportamento pode estar relacionado à presença de solvente residual ou DGEBA não reagido no sistema com grafeno, além de possível atuação de grafeno agregado como ponto de tensão. O mecanismo de adesão revestimento/substrato permaneceu inalterado para todas as aditivações estudadas.

\section{Palavras-chave}

Grafeno; Nanocompósitos; Revestimentos; Polímero Epóxi; Corrosão; Caracterização. 


\section{Abstract}

Silva, Mariana do Nascimento Silva; Bott, Ivani de Souza; Kassab, Elisa Janzen. Graphene as Nanofiller in Composites for Anticorrosive Protection. Rio de Janeiro, 2018. 127p. Dissertação de Mestrado Departamento de Engenharia de Materiais e Processos Químicos e Metalúrgicos, Pontifícia Universidade Católica do Rio de Janeiro.

The studied nanocomposite with anticorrosive coating function is composed of Novolac Type II epoxy added with graphene, synthesized through the process of exfoliation / reduction of graphite using microwaves. The epoxy system used consists of the following components: A, based on bisphenol $\mathrm{F}$ and inorganic fillers, and B, hardener based on an amino polymer. The synthesis of graphene and its additivation in component A were performed by CTNano UFMG. The main objective of this dissertation is the study of the applicability of the nanocomposite, where graphene is used as complementary additive in polymer matrix (epoxy), as an alternative to maximize anticorrosive protection. Different additives were studied: CR (without additive), and additives $(0.1 \%$ and $0.5 \%$ ). The substrate used was carbon steel 1020, the surface of which was prepared with abrasive blasting and then coated with a compressed air and solvent gun to aid the process. To evaluate the efficiency of these coatings were performed corrosion tests (Atlas Cell and Cyclic Tests), Pull Off test, thickness measurement (MEV) and roughness of the substrate through the analogous rugosimeter and optical microscopy. For the dispersion of graphene, diglycidyl ether of bisphenol A (DGEBA) was added as a diluent. The results indicated that graphene showed good dispersion in the polymer matrix. Concentrations of graphene above $0.1 \%$ by mass lead to failure of the anticorrosive protection. This behavior may be related to the presence of residual solvent or unreacted DGEBA in the graphene system, in addition to the possibility of aggregated graphene as voltage point. The coating / substrate adhesion mechanism remained unchanged for all additives studied.

\section{Keywords}

Graphene; Nanocomposites; Coatings; Epoxy Polymer; Corrosion; Characterization. 


\section{Sumário}

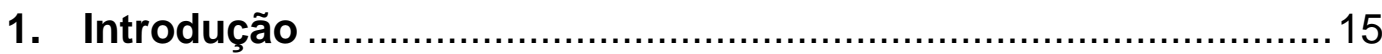

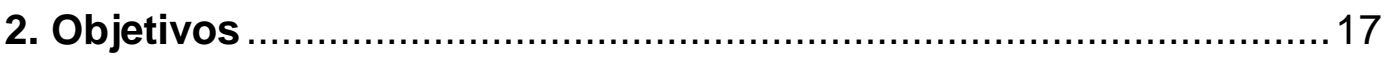

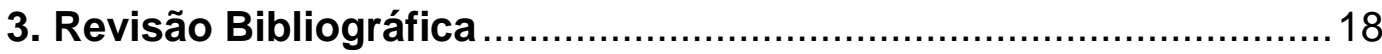

3.1. Corrosão …...................................................................... 18

3.1.1. Formas de Corrosão ....................................................22

3.2. Revestimento como Proteção Anticorrosiva ................................23

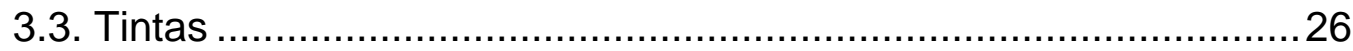

3.3.1. Componentes básicos .................................................26

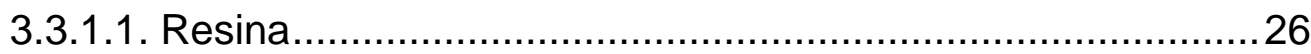

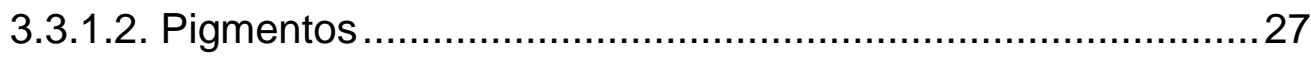

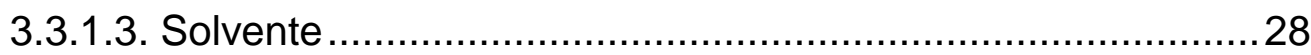

3.3.1.4. Aditivos ............................................................... 28

3.3.2. Tipos de tintas.......................................................... 29

3.3.2.1. Sistema EPOXÍDICO ..................................................29

3.3.2.2. Tinta epóxi NOVOLAC .............................................. 32

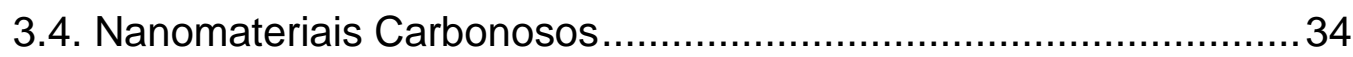

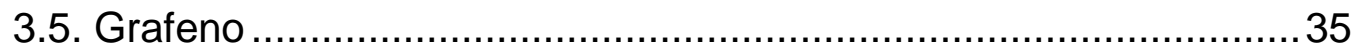

3.5.1. Propriedades do Grafeno............................................... 38

3.5.2. Técnicas de obtenção do grafeno .......................................39

3.5.2.1. Óxido de grafeno ........................................................40

3.5.2.2. Óxido de grafeno reduzido ........................................41

3.5.3. Funcionalização química do grafeno ..................................42

3.5.4. Aplicações .............................................................. 44

3.6. Nanocompósitos Poliméricos aditivados com Grafeno .................46 46

4. Materias e métodos ............................................................... 49

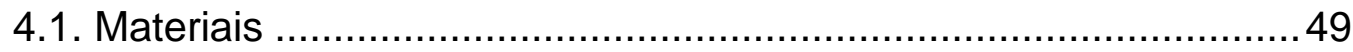

4.1.1. Grafeno ....................................................................... 49

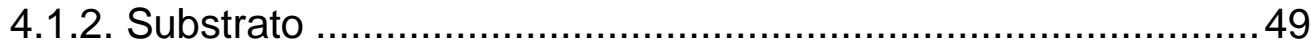

4.1.3. Revestimento .......................................................... 50

4.2. Matriz de Ensaios................................................................. 52 


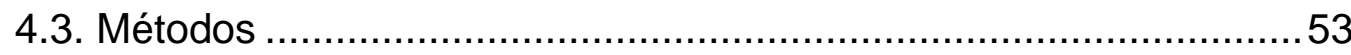

4.3.1. Caracterização do óxido de grafeno reduzido (OGR) ..............53

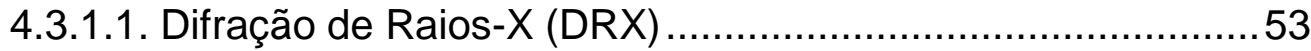

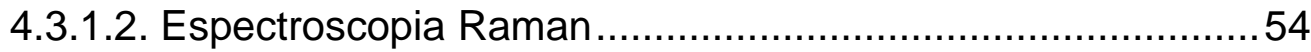

4.3.1.3. Microscopia de Força Atômica (AFM) ………………….......55

4.3.1.4. Microscopia Eletrônica de Varredura

com Emissão de Campo (MEV-FEG) ...............................................55

4.3.1.5. Espectroscopia no Infravermelho

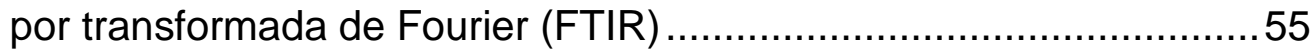

4.3.1.6. Condutividade Elétrica (Efeito Hall) ....................................56

4.3.1.7. Microscopia Eletrônica de Varredura (MEV) ........................56

4.3.2. Medida de Aderência (Pull Off) ............................................56

4.3.3. Preparação das amostras de metal

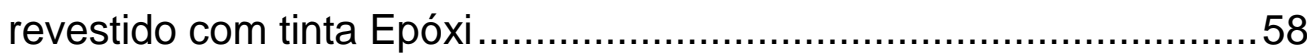

4.3.3.1. Rugosidade Superficial do Substrato ..................................58

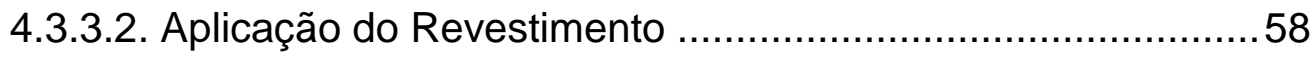

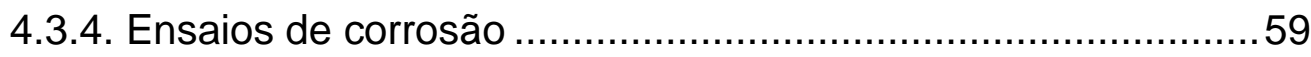

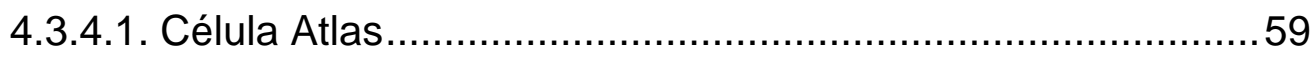

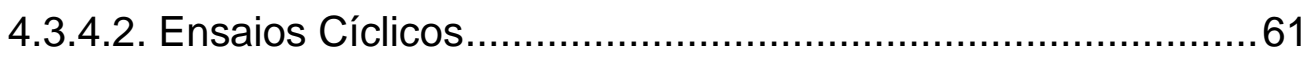

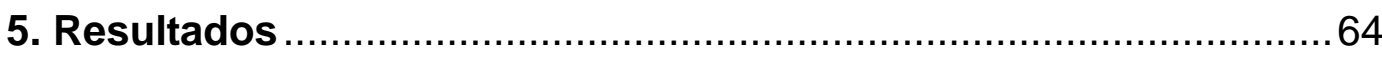

5.1. Caracterização do óxido de grafeno reduzido (OGR) ....................64

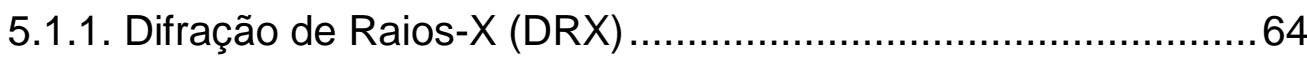

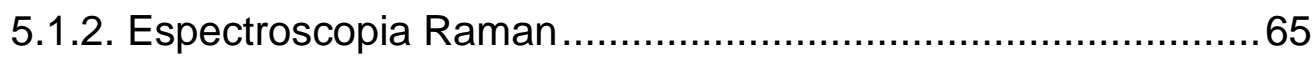

5.1.3. Microscopia de Força Atômica (AFM) ……………..................66

5.1.4. Microscopia Eletrônica de Varredura com Emissão de Campo (FEG) ………………........................ 70

5.2. Caracterização dos Nanocompósitos...........................................71

5.2.1. Microscopia Eletrônica de Varredura (MEV) ...........................71

5.2.2. Espectroscopia Raman ...................................................... 72

5.2.3. Espectroscopia no Infravermelho por Transformada de Fourier (FTIR) ...............................................

5.2.4. Condutividade Elétrica (Efeito Hall) ……………………....... 74

5.3. Medidas de Rugosidade da Superfície ……………………........ 75

5.4. Teste de Aderência (Pull off) ..................................................... 78 


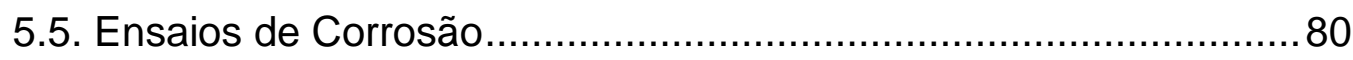

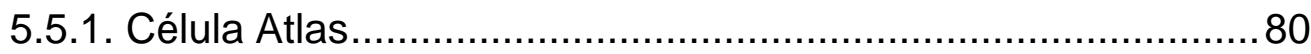

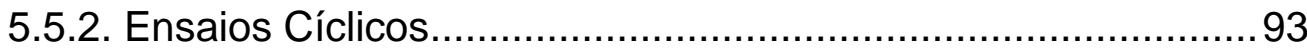

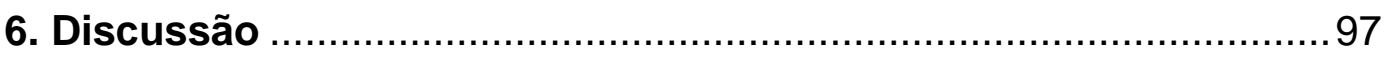

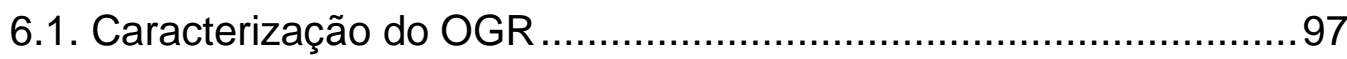

6.2. Caracterização dos Nanocompósitos........................................... 100

6.3. Aderência do Sistema (Nanocompósito + Substrato) ...................104

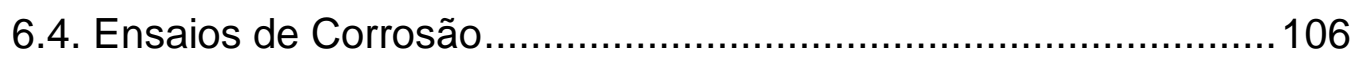

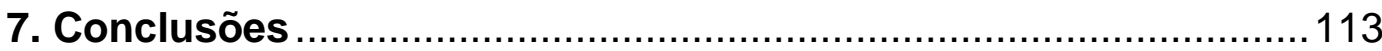

8. Sugestões para trabalhos futuros …………..........................114

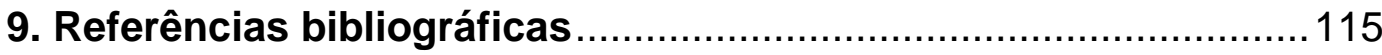




\section{Lista de Figuras}

Figura 01: Diagrama de Pourbaix do Ferro em $\mathrm{H} 2 \mathrm{O}$ a $25^{\circ} \mathrm{C} \ldots \ldots \ldots \ldots \ldots . . . .21$

Figura 02: Ilustração representativa dos tipos de corrosão ......................23

Figura 03: Revestimento de proteção por barreira ................................25

Figura 04: Composição geral das tintas ..............................................26

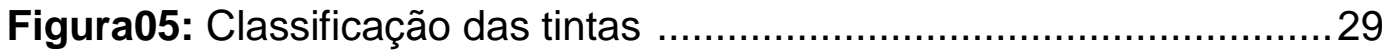

Figura 06: Estrutura química da resina epóxi a base de Bisfenol A .......30

Figura 07: Disposição dos componentes A e $B$ das tintas Epóxi .............31

Figura 08: Estrutura química da resina epóxi NOVOLAC …..................32

Figura 09: Estruturas derivadas do grafeno

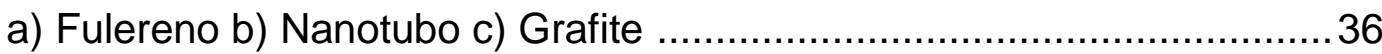

Figura 10: Representação da estrutura hexagonal e planar do grafeno..37

Figura 11: Bandas de energia do grafeno

próximo ao ponto de Dirac em $\mathrm{t}(\mathrm{t}=2.7 \mathrm{eV})$.

Figura 12: Esquema de produção do Grafeno nas abordagens Bottom Up e Top Down 39

Figura 13: Representação esquemática do processo

de oxidação do grafite para formação do óxido de

grafite, seguido da exfoliação para formação de

folhas individuais de óxido de grafeno, seguido

de redução para formação de grafeno

(ou óxido de grafeno reduzido)

Figura 14: Aspecto do Óxido de Grafeno Reduzido

(OGR) utilizado nesta dissertação.

Figura 15: Dimensões dos corpos de prova

para a a) primeira e b) segunda configurações.

Figura 16: Aspecto visual da tinta

após aditivação nas concentrações I, II e III

Figura 17: Esquema das camadas envolvidas no teste. 
Figura 18: Esquema das camadas suscetíveis a falhas

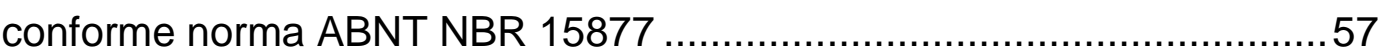

Figura 19: Instrumento portátil para medição de aderência Pull Off........57 Figura 20: Configuração estrtural da Célula Atlas

I) Revestimentos II) Sistema em funcionamento.....................................61

Figura 21: Difratograma da amostra de OGR......................................64

Figura 22: Espectro Raman para amostra de OGR. ..............................65

Figura 23: Micrografias de AFM para amostras de OGR. ......................67

Figura 24: Distância interplanar entre folhas de grafeno.........................68

Figura 25: Distância interplanar entre folhas de grafeno..........................69

Figura 26: Micrografias de MEV/FEG

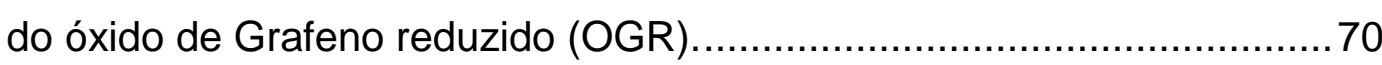

Figura 27: Micrografias de MEV da interface substrato/resina

(I) CR (sem aditivo) e (II) Imagem representativa

para resinas aditivadas.

Figura 28: Espectros Raman para as condições

(a)CR, (b) $0.1 \%$ e (c) $0.5 \%$.

Figura 29: Espectros Raman sobrepostos

para todas as condições estudadas.

Figura 30: Espectro no FTIR para o nanocompósito

nas condições $\mathrm{CR}, 0.1 \%$ e $0.5 \%$.

Figura 313: Posição dos parafusos (dollys) para execução do teste. .....79

Figura 32: Placas $0.1 \%$ aditivada

durante o ensaio de 504h ( 3 semanas).

Figura 33: Interface da placa $0.1 \%$ após o ensaio de $504 \mathrm{~h}$.

Figura 34: Aparência das Placas $0.25 \%$ aditivada

durante o ensaio de 504h (3semanas).

Figura 35: Detalhe da interface da placa $0.25 \%$

após o ensaio de 504h.

Figura 36: Placas $0.5 \%$ aditivada durante o ensaio de 504h (3 semanas).

Figura 37: Progressão da interface da placa $0.5 \%$ após o ensaio de 504h.

Figura 38: Placas $0.25 \%$ aditivada 
durante o ensaio de 1000h (6 semanas).

Figura 39: Progressão da interface da placa $0.25 \%$

durante o ensaio de 504h.

Figura 40: Placas $0.5 \%$ aditivada

durante o ensaio de 1000h (6 semanas).

Figura 41: Progressão da interface durante o ensaio de 1000h.

Figura 42: Placas com revestimento

na condição de como recebida (sem aditivos)

durante o ensaio de 2000h (12 semanas).

90

Figura 43: Placas $0.5 \%$ aditivada

durante o ensaio de 2000h (12 semanas).

Figura 44: Progressão da corrosão interface liquido-vapor

durante o ensaio de $2000 \mathrm{~h}$ para o revestimento

aditivado com $0,5 \%$ de grafeno.

Figura 45: Aspecto Visual da superfície dos corpos de prova

ao longo do ensaio cíclico.

Figura 46: Aspecto do entalhe após 25 ciclos.

Figura 47: Difratograma do OGR para ângulos

entre $10^{\circ}$ e $50^{\circ}$

Figura 48: llustração esquemática de dispersão/distribuição

a) má dispersão e boa distribuição b) má distribuição e dispersão

c) má distribuição e boa dispersão d) boa distribuição

e dispersão

Figura 49: Espectro de FTIR para os nanocompósitos nas condições CR (Verde), AD0.1\% (Amarelo) e AD0.5\%(Rosa).

Figura 50: Representação da dependência da condutividade

elétrica de um polímero condutor em função

da concentração de carga condutora 103

Figura 51: Superfície das placas após o ensaio de 504h...................... 109

Figura 52: Interfaces após o ensaio de 504h.

Figura 53: Avanço da corrosão pós-ensaio cíclico nas condições CR, AD0.1\% e AD0.5\%. 


\section{Lista de Tabelas}

Tabela 01: Propriedades e aplicações do grafeno monocamada 45

Tabela 02: Composição química em percentual do aço AISI 1020 utilizado 50

Tabela 03: Matriz de caracterização físico-química do grafeno e nanocompósitos. 52

Tabela 04: Parâmetros utilizados nos ensaios de corrosão. …………....53

Tabela 05: Configurações dos pares de amostras na célula atlas............61

Tabela 06: Distâncias interplanares para picos do OGR.........................65

Tabela 07: Resultados do ensaio de condutividade elétrica.....................75

Tabela 08: Resultado da análise quantitativa do ensaio cíclico...............96

Tabela 09: Resultados do teste de aderência pull off após os ensaios cíclicos.

Tabela 10: Principais bandas de absorção da resina epoxídica curada e não curada. 102

Tabela 11: Perfil de Rugosidade baseado na geometria da granalha de aço. 


\section{Lista de Abreviaturas}

AISI American Iron and Steel Institute

AFM Microscopia de Força Atômica

AD $0.1 \% \quad$ Tinta aditivada com $0.1 \% \mathrm{~m} / \mathrm{m}$ de grafeno

AD $0.5 \% \quad$ Tinta aditivada com $0.5 \% \mathrm{~m} / \mathrm{m}$ de grafeno

CR Tinta como recebida sem aditivo

CP Corpo de prova

DEQM Departamento de Engenharia Química e de Materiais

DGEBA Diglicidil Éter de Bisfenol A

DRX Difração de Raios $X$

EIS Espectroscopia de Impedância Eletroquímica

FTIR Espectroscopia no Infravermelho por Transformada de Fourier

$\mathrm{I}_{\mathrm{D}} \quad$ Intensidade da banda $\mathrm{D}$ no espectro Raman

$I_{G} \quad$ Intensidade da banda $G$ no espectro Raman

MEV/FEG Microscópio Eletrônico de Varredura com Efeito de Campo

MO Microscopia Óptica

$\mathrm{Na}(\mathrm{BH})_{4} \quad$ Borohidreto de Sódio

OG Óxido de grafeno

OGE Óxido de grafeno Expandido

OGR Óxido de grafeno Reduzido

Ppm Partes por milhão

TEPA Tetraetilenopentamina 


\section{Introdução}

No cenário industrial um dos principais desafios é a redução dos prejuízos econômicos causados pela corrosão metálica e degradação dos materiais, os quais promovem acidentes e reduzem a segurança. No longo prazo, a deterioração das ligas metálicas é quase inevitável, podendo ser retardada através da modificação da composição química da liga, utilização de inibidores de corrosão, ou aplicação de barreiras como tintas ou revestimentos anti-corrosivos. A utilização de revestimentos para o controle da corrosão é um método que envolve baixo custo e aplicação relativamente simples, tornando-o bastante atraente para aplicações anticorrosivas (FRAUSHES-SANTOS et al., 2013; HARB, 2015).

As principais exigências para um revestimento são: resistência química ao meio agressivo, baixa permeabilidade, dilatação térmica compatível com o substrato e propriedades físicas adequadas aos esforços que receberá. Não devem possuir emendas, de modo a evitar infiltrações, aceitar reparos locais e possuir baixo custo entre outras propriedades (BAYER, 2001; FRAUCHES-SANTOS et al., 2013).

Nos últimos anos, a utilização de nanocompósitos atraiu bastante interesse cientifico e tecnológico, pois a presença de nanoreforços em pequenas quantidades provocam melhorias substanciais nas propriedades físico-químicas da matriz polimérica, além de promover redução do peso final e criar novas aplicações para os polímeros. As propriedades finais do nanocompósito estão fortemente relacionadas à natureza química do nanomaterial, dispersão do nanoreforço na matriz, além de outros parâmetros, como por exemplo, tamanho e forma do reforço, orientação e concentração na matriz (FIEDLER et al., 2006 \& KIM et al., 2010).

Os dois principais pré-requisitos para obtenção de nanocompósitos com propriedades consideradas ótimas são a adesão interfacial matriz/reforço e dispersão do reforço na matriz. Embora apresentem uma elevada tendência à aglomeração, dificultando a dispersão na matriz polimérica, de um modo geral os 
nanoreforços apresentam mais vantagens em relação aos outros tipos de reforço, por possuirem maior área específica e razão de aspecto, favorecendo a adesão interfacial (NGUYEN et al., 2009; POTTS et al., 2011; DA SILVA et al., 2013).

As resinas epoxídicas apresentam excelentes propriedades químicas e mecânicas, como por exemplo: alta resistência à tração e compressão, excelente resistência química na presença de solventes, baixa retração pós-cura, baixo custo e facilidade no processamento, tornando-as atraente para diversas aplicações industriais. No entanto, são consideradas frágeis e com baixa resistência à propagação de trincas, devido à formação de estruturas altamente reticuladas póscura. $\mathrm{Na}$ tentativa de minimizar essa fragilidade, são utilizados reforços em sua matriz (RAFIEE et al., 2009; DA SILVA et al., 2013).

O grafeno apresenta propriedades excelentes como: grande área específica, alta razão área/massa, elevada condutividade elétrica e térmica, excelente resistência mecânica, dentre outras. Porém, vale ressaltar que estas propriedades do grafeno estão associadas ao grafeno isolado (monocamada), no entanto ao ser incorporado a outros materiais, essas propriedades mudam. Para a obtenção do rendimento máximo das propriedades do grafeno é necessário entender como suas propriedades variam, quando em contato com outros materiais, nesse caso polímero (RAFIEE et al., 2010; FIM, 2012; DA SILVA et al., 2013). O principal objetivo desta dissertação de Mestrado é o estudo da aplicabilidade de um nanocompósito onde o grafeno é utilizado como aditivo em tinta epóxi (Novolac II), como alternativa para maximizar a proteção anticorrosiva produzindo um nanocompósito de matriz polimérica. 


\section{Objetivos}

- Caracterizações físico-químicas das nanofolhas de grafeno em pó, da tinta como recebida (sem aditivo) curada e dos nanocompósitos curados aditivados com grafeno nas concentrações: $0.1 \%$ e $0.5 \% \mathrm{~m} / \mathrm{m}$;

- Determinação quantitativa e qualitativa da rugosidade do substrato aço carbono AISI 1020 e o impacto na propriedade de aderência do sistema (substrato + revestimento);

- Comparar o desempenho anticorrosivo da tinta como recebida e aditivada com as proporções em massa de grafeno de $0.1 \%, 0.25 \%$ e $0.5 \%$. 


\section{Revisão Bibliográfica}

\subsection{Corrosão}

A corrosão pode ser definida como o processo de deterioração de um material metálico por meio de ação química ou eletroquímica do meio ambiente, atrelada ou não a esforços mecânicos. A interação físico-química entre o material e o meio no qual se encontra provoca alterações indesejáveis, que podem ser tanto de natureza mecânica, como desgastes e modificações estruturais, quanto de natureza química. Essas mudanças refletem na interface entre material/meio, podendo tornar o material inadequado para o uso. Entretanto, existem alguns processos corrosivos que podem ser utilizados e possuem relativa importância industrial, como por exemplo, a oxidação de aços inoxidáveis, resultando na formação de uma película protetora de óxido de cromo $\left(\mathrm{Cr}_{2} \mathrm{O}_{3}\right)$ e a fosfatização do alumínio, cuja presença melhora a aderência das tintas à superfícies metálicas (GENTIL, 2007; ASSIS, 2000).

Nos processos corrosivos em metais, as propriedades físicas e químicas dos produtos de corrosão podem influenciar diretamente na taxa de corrosão. Se os produtos forem insolúveis e aderentes, funcionam como barreira na interface entre meio/metal, reduzindo a taxa de corrosão, e até interromper o processo corrosivo. No entanto, grande parte dos produtos de corrosão é solúvel, se formam distantes da interface meio/metal, impossibilitando a proteção anticorrosiva (ASSIS, 2000).

Do ponto de vista eletroquímico, a corrosão metálica consiste na combinação de duas reações químicas que ocorrem simultaneamente, a oxidação (anódica) com perda de elétrons e a redução (catódica) com ganho de elétrons. O metal, agente redutor, cede elétrons que serão recebidos por uma substância, o agente oxidante. Sendo assim, à medida que o metal cede elétrons, perde massa, caracterizando o fenômeno da corrosão. De um modo geral, os metais possuem uma elevada tendência de perder elétrons, sofrer oxidação e consequentemente corrosão. No caso dos metais ferrosos, quando expostos ao ar e umidade, há maior 
tendência a se oxidar e sofrer corrosão. Em termos de reações, ocorre a conversão do ferro para o óxido de ferro hidratado, a ferrugem $\left(\mathrm{Fe}_{2} \mathrm{O}_{3} \cdot \mathrm{H}_{2} \mathrm{O}\right)$. A força motriz da reação é a forte tendência do ferro de se combinar com oxigênio dissolvido em água. As reações abaixo expressam o comportamento do ferro na presença de água e oxigênio, e podem ser escritas em termos de semi-reações ou a reação global (ASSIS, 2000; GENTIL, 2007; TRIDAPALLI, 2011).

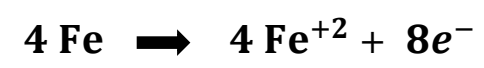

(Reação Catódica)

$2 \mathrm{O}_{2}+4 \mathrm{H}_{2} \mathrm{O}+8 e^{-} \rightarrow 8 \mathrm{OH}^{-}$

(Reação Anódica)

$$
4 \mathrm{Fe}+2 \mathrm{O}_{2}+4 \mathrm{H}_{2} \mathrm{O} \rightarrow 4 \mathrm{Fe}(\mathrm{OH})_{2}
$$

(Reação Global)

Quando um metal é imerso em solução, a diferença de potencial químico entre o metal e a solução promove um fluxo iônico, onde os íons metálicos se dissolvem na solução e os íons da solução penetram na superfície metálica. Em contrapartida, a diferença de potencial elétrico entre o eletrodo e a solução eletrolítica, gera um fluxo de corrente elétrica no sistema. Esse comportamento explica o fenômeno de corrosão eletroquímica (GEMELLI, 2001).

Todos os metais estão sujeitos a desenvolver corrosão, dependendo do meio e do material. Quase todos os metais possuem uma elevada tendência em reagir com o meio nos quais se encontram, podendo formar óxidos, hidróxidos e outros compostos químicos. Portanto, para se garantir a eficácia no emprego de certo material, é necessário fazer um estudo prévio do conjunto que inclui o material metálico, condições operacionais e o meio corrosivo, com o objetivo de indicar métodos adequados de proteção anticorrosiva ou até mesmo sugerir modificações de projeto (CARBÓ, 2001; GENTIL, 2007).

O metal sofre reações espontâneas e libera energia através de processos corrosivos, quando ocorrem as transformações em compostos mais estáveis na forma de óxidos, hidróxidos e sais desses metais. Energeticamente, o metal sai da sua condição metaestável e se transforma espontaneamente em sua forma iônica, adquirindo estabilidade, porém sofre alterações estruturais que geram desgaste e perda de propriedades.

Termodinamicamente, a corrosão está associada à energia de Gibbs do sistema, como um processo inverso aquele no qual uma liga retorna a sua 
condição natural, provocando por uma redução na Energia de Gibbs do sistema. Esse fenômeno é explicado pela segunda lei da Termodinâmica, onde os processos espontâneos são caracterizados por possuírem $\Delta \mathrm{G}<0$ (FREIRE, 2005).

$\mathrm{Na}$ corrosão eletroquímica, os meios corrosivos são eletrólitos, os quais são uma solução eletricamente condutora constituída de água com sais, ácidos ou bases. Os principais meios corrosivos são: atmosfera, cujo eletrólito é constituído de água condensada na superfície metálica com presença de sais ou gases; solos, com características ácidas ou básicas dissolvidos em água; águas naturais que apresentam sais, resíduos industriais e outros poluentes dissolvidos; água do mar, devido à presença abundante de sais minerais dissolvidos; e determinados produtos químicos, desde que estejam em contato com água ou umidade (MAGNAN, 2011; GENTIL, 2007).

$\mathrm{Na}$ indústria, os efeitos corrosivos causam elevados danos estruturais em diversos materiais. Isso ocorre devido à baixa resistência à corrosão de um determinado material ao meio ao qual foi exposto. Para evitar a proliferação de danos, tanto estruturais como econômicos, se realiza a adequação do tipo de material ao meio e utilizam-se técnicas para controle da corrosão. O controle pode ser efetuado através da: a) alteração do metal, adicionando-se elementos de liga ou através da modificação microestrutural por meio de um tratamento térmico; b) alteração do meio onde o metal está exposto, através da utilização de inibidores químicos, além de técnicas de desaeração e controle de $\mathrm{pH}$; c) alteração do potencial de corrosão, por meio da proteção catódica ou anódica; d) alteração da interface metal/substrato com a aplicação de revestimentos protetores de natureza orgânica ou inorgânica (GENTIL,2007; ASSIS, 2000; MAGNAN, 2011).

Um dos métodos mais efetivos no combate a corrosão é o da proteção catódica, que pode ser utilizado no combate a quase todos os tipos de corrosão. O mecanismo de proteção se dá por meio do fornecimento de elétrons, através de uma fonte externa, transformando $\mathrm{o}$ metal a ser protegido em cátodo. Normalmente, os elétrons são produzidos no anôdo e se deslocam para serem consumidos no cátodo. Porém, como os elétrons estão sendo fornecidos externamente, o anôdo não produzirá os elétrons, transferindo as reações anódicas da superfície metálica para o novo anôdo, neutralizando a corrosão do metal.

Embora o método de proteção catódica possa ser utilizado com eficiência na proteção de superfícies metálicas livres, a aplicação desta técnica se torna mais 
simples e econômica quando as superfícies estão previamente revestidas. Nestes casos, a finalidade é complementar a ação protetora dos revestimentos, já que é grande a possibilidade de possuir poros e falhas. A ação combinada da proteção catódica e revestimento pode garantir, de maneira econômica e segura, uma maior integridade das estruturas metálicas ao longo dos anos (GENTIL, 2007; SIMONI, 2014).

$\mathrm{O}$ diagrama de Pourbaix do ferro em água a $25^{\circ} \mathrm{C}$ e 1 atm (Figura 01) relaciona os valores de $\mathrm{pH}$ com os valores de potencial do eletrodo de ferro, com referência ao eletrodo padrão de hidrogênio. No diagrama é possível prever condições sob os quais pode haver corrosão, imunidade ou passivação. Estas curvas representam os diversos equilíbrios químicos e eletroquímicos possíveis entre o metal e o eletrólito líquido. No entanto não é possível prever as reações de corrosão. Para o elemento ferro, a região de imunidade ocorre onde se encontra o elemento $\mathrm{Fe}$, a região de corrosão, onde se encontram os íons $\mathrm{Fe}^{2+}, \mathrm{Fe}^{3+}$ ou $\mathrm{FeO}_{2} \mathrm{H}^{-}$e a região de passivação, onde se encontram os produtos insolúveis, $\mathrm{Fe}_{2} \mathrm{O}_{3}$ e $\mathrm{Fe}_{3} \mathrm{O}_{4}$. Portanto, para que ocorra a proteção catódica, o metal deve ser polarizado até que o seu potencial de eletrodo atinja a região de imunidade mostrada no gráfico (GENTIL, 2007; SIMONI, 2014).

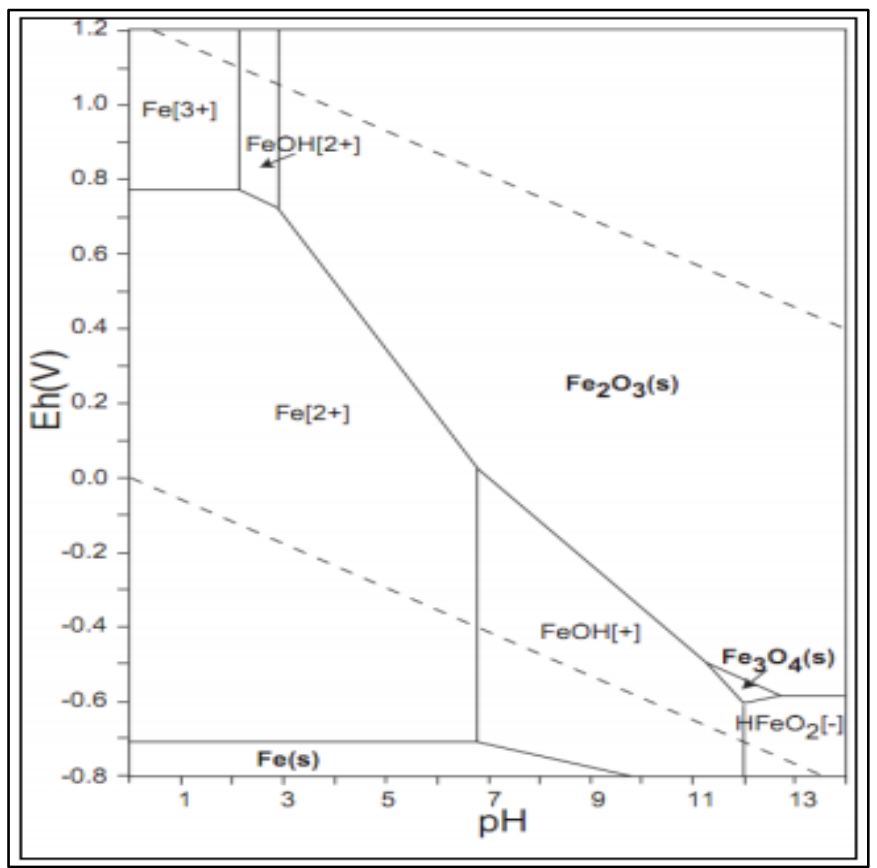

Figura 01: Diagrama de Pourbaix do Ferro em H2O a $25^{\circ} \mathrm{C}$ (POURBAIX, 1987). 


\subsubsection{Formas de Corrosão}

Existem inúmeras formas de classificar os tipos de corrosão. Podendo ser classificadas quanto: a morfologia (uniforme, por placas, alveolar, por pite, intergranular, intragranular, filiforme, por esfoliação, grafítica entre outras); aos mecanismos/causas (por aeração diferencial, eletrolítica, galvânica, associadas a esforços mecânicos, ao redor do cordão de solda, empolamento, seletiva ou fragilização pelo hidrogênio); aos fatores mecânicos (sob fadiga, sob tensão, por atrito, associada a erosão); ao meio corrosivo (atmosférica, solo, induzida por microrganismos, pela água do mar); a localização do ataque (uniforme, por pite, intergranular, intragranular) (GENTIL,2007; TRIDAPALLI, 2011).

Um pequeno sumário das principais formas de corrosão (Figura 02) e mecanismos será descrito a seguir.

Corrosão Uniforme: A corrosão se propaga por toda extensão da superfície, provocando perda uniforme da espessura. Comum em metais que não formam películas protetoras, quando expostos a meios corrosivos.

Corrosão por placas: A corrosão é localizada em pontos específicos da superfície metálica, formando placas com pequenas depressões.

Corrosão Alveolar: A corrosão se processa localmente, produzindo sulcos semelhantes a alvéolos, com o fundo arredondado e a profundidade, geralmente, menor que o seu diâmetro.

Corrosão por pite: Desgaste intenso e local em pequenas áreas da superfície, formando os pites. Estas cavidades possuem fundo anguloso e profundidade, geralmente, maior que o seu diâmetro.

Corrosão Intergranular: $O$ ataque ocorre entre os grãos da microestrutura, ou seja, nos contornos de grão do material, promovendo a perda de propriedades mecânicas e deixando o material suscetível a fraturas mediante esforços mecânicos.

Corrosão Intragranular: A corrosão se propaga nos grãos da rede cristalina que forma o material metálico, podendo fraturar a pequenos esforços mecânicos.

Corrosão Filiforme: A corrosão se processa na forma de finos filamentos, não profundos, que se propagam em diferentes sentidos e direções.

(GENTIL, 2007; MAGAN, 2011; SCHIAVETTO, 2009). 


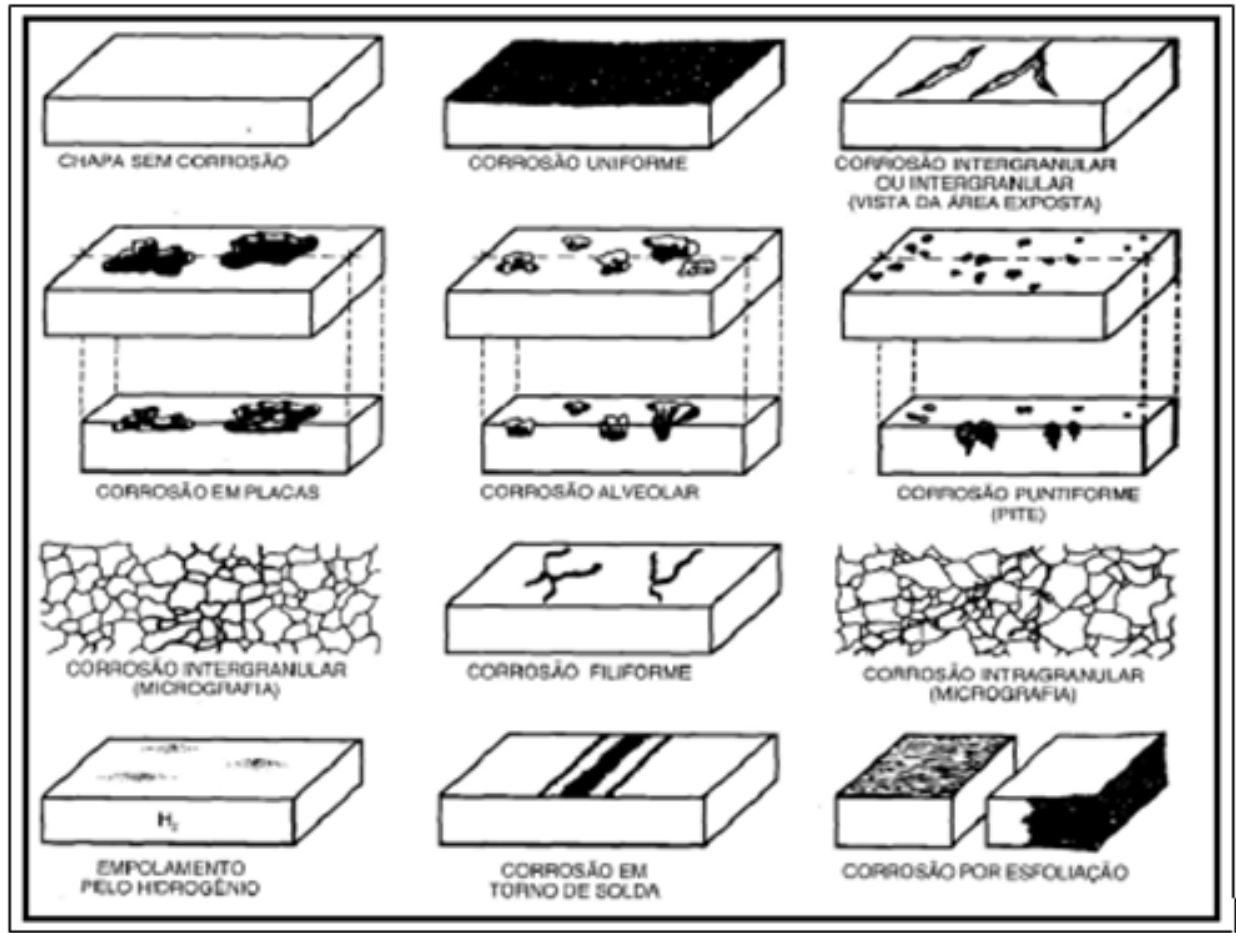

Figura 02: Ilustração representativa dos tipos de corrosão (GENTIL, 2007).

\subsection{Revestimento como Proteção Anticorrosiva}

A utilização de revestimentos para controle da corrosão é um método que envolve baixo custo e é de aplicação relativamente simples. Os revestimentos utilizados na proteção anticorrosiva funcionam como barreiras protetoras devido à formação de películas de óxidos, hidróxidos e outros compostos químicos através das reações entre os metais e os agentes oxidantes do meio corrosivo. Sendo, portanto constituídos por películas interpostas entre o metal e o meio corrosivo, atribuindo ao material um comportamento de metal mais nobre, ou simplesmente protegendo-o da ação corrosiva do meio (ASSIS, 2000; GENTIL, 2007; MAGNAN, 2011; FRAUSHES-SANTOS et al., 2013).

As principais exigências para um revestimento são: resistência química ao meio agressivo, baixa permeabilidade, dilatação térmica compatível com o substrato e propriedades físicas adequadas aos esforços que receberá. Além de ser monolíticas (não possuir emendas), não devem permitir infiltrações, deve aceitar reparos locais, ter baixo custo, e baixa ocorrência de fissuras ou trincas (BAYER, 2001; FRAUCHES-SANTOS et al., 2013). 
Quanto a sua natureza, os principais tipos de revestimentos são classificados como: metálicos, não metálicos (orgânico e inorgânico) e compósitos.

Revestimentos Metálicos: São compostos por partículas de metais, no estado líquido, aplicados sobre a superfície rugosa do aço, por exemplo. Ao tocar a superfície do metal a ser protegido, o metal líquido solidifica, formando uma camada levemente porosa que se acumula na superfície metálica, promovendo máxima resistência à corrosão, sem formação de ligas intermetálicas. Não é um método muito empregado devido os seus elevados custos e exigências especiais em termos de preparo e limpeza da superfície (PANNONI, 2015).

Revestimentos Compósitos: São compósitos de base polimérica que podem ser constituídos de materiais cerâmicos, geralmente flocos ou fibras de vidro. A durabilidade desse revestimento é influenciada pela dureza dos flocos/fibras de vidro, assim como depende da integridade da interface com o metal e a matriz polimérica do compósito. Os requisitos principais para os compósitos são boa estabilidade dimensional em elevadas faixas de temperatura, baixa permeabilidade e alta mobilidade elétrica. No entanto a aplicabilidade e desempenho de materiais compósitos ainda não está consolidada (OLIVEIRA et al., 2009).

Os revestimentos não metálicos inorgânicos são formados por compostos inorgânicos e depositados diretamente na superfície metálica. Os mais empregados na proteção anticorrosiva são: vidros, porcelanas, esmaltes vitrosos, cimentos, óxidos, nitretos, boretos, carbetos e siliciletos (GENTIL, 2007).

Os revestimentos não metálicos orgânicos, também conhecidos como tintas, onde material líquido é aplicado sobre a superfície metálica, e após curar e secar forma um filme fino, sólido, aderente, flexível e impermeável. É considerado o método anticorrosivo mais utilizado, cerca de $90 \%$ de todos os substratos metálicos são revestidos por tintas (VÉRGES, 2005). Possuem elevada relevância no cenário de proteção anticorrosiva devido à variedade dos tipos de pintura, disponibilidade de cores, métodos de aplicação e possibilidade de combinação com os revestimentos metálicos. Antes da aplicação de qualquer revestimento não metálico orgânico, faz-se necessário à avaliação prévia do meio corrosivo, modo de preparação da superfície, composição da tinta utilizada, o 
método de aplicação, tempo para a alternância entre as aplicações, dentre outros (MAINIER, 2006; FERNANDES et al., 2003).

As tintas, ou revestimentos orgânicos, atuam como protetores anticorrosivos de três maneiras: a) como uma barreira, impossibilitando o contato entre o meio e o substrato metálico; b) através de metais de sacrifício presentes na composição da tinta, por exemplo, pigmentos de zinco impedem a reação do substrato metálico com o meio agressivo; c) por inibição, interferindo nas reações eletroquímicas da corrosão. Além da função protetora, as tintas desempenham: funções decorativas, criando uma aparência visualmente mais agradável às superfícies metálicas, sinalização de estruturas e equipamentos, auxílio na segurança industrial, identificação de fluidos em tanques ou tubulações, entre outras (ASSIS, 2000; MAGNAN, 2011).

No método de proteção por barreiras, é comum a corrosão ocorrer entre o revestimento e o substrato. Isso ocorre devido à porosidade do revestimento, com o tempo, o eletrólito penetra por dentro do revestimento, ocasionando a corrosão. Além disso, os revestimentos podem ser danificados por ação mecânica ou serem atacados pelo meio corrosivo, danificando o revestimento e provocando a corrosão. O mecanismo de proteção por barreiras pode ser visto na Figura $\mathbf{0 3}$ (NUNES et al., 2007).

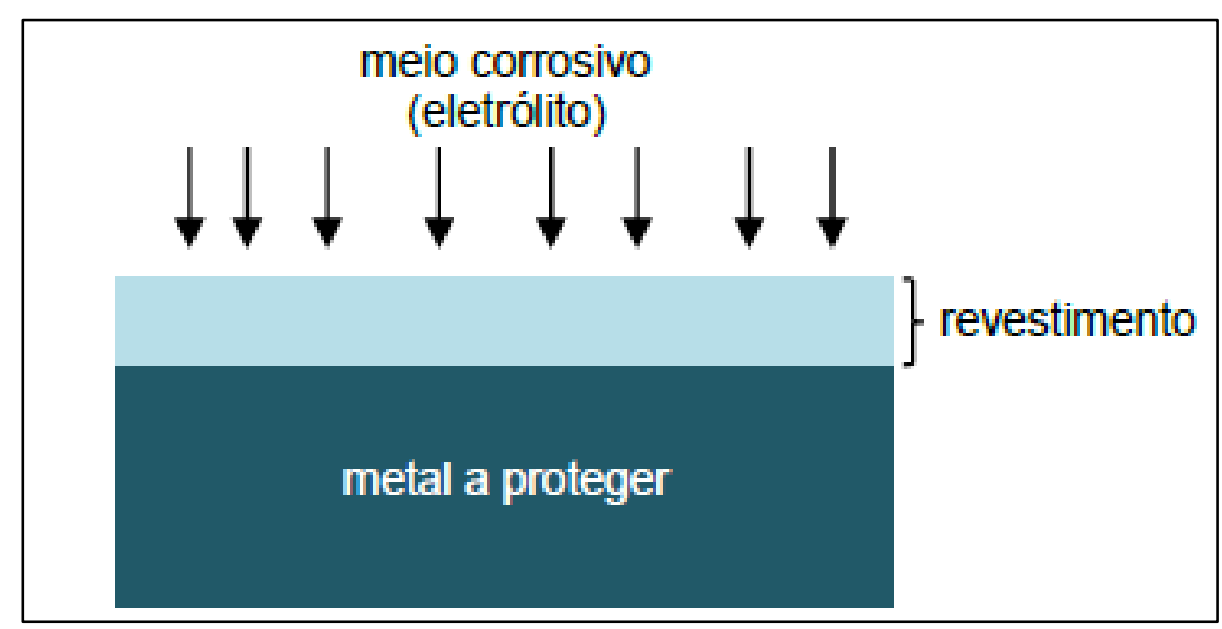

Figura 03: Revestimento de proteção por barreira (NUNES et al., 2007). 


\subsection{Tintas}

A tinta pode ser considerada como uma solução ou suspensão contendo pigmentos, elementos ligantes, um solvente mineral (ou água), a qual após ser depositada sobre uma superfície e secar, forma um filme aderente com objetivos cosmético ou de proteção. De modo geral, os componentes das tintas são resinas ou polímeros, pigmentos, solventes e aditivos. Vale ressaltar que nem todas as tintas são compostas por todos esses componentes e a formulação pode variar a de acordo com o tipo de aplicação. Geralmente, uma tinta líquida possui quatro componentes básicos: resinas, solventes, pigmentos e aditivos, como podem ser visto na Figura 04 (ANGHINETTI, 2012).

\subsubsection{Componentes básicos}

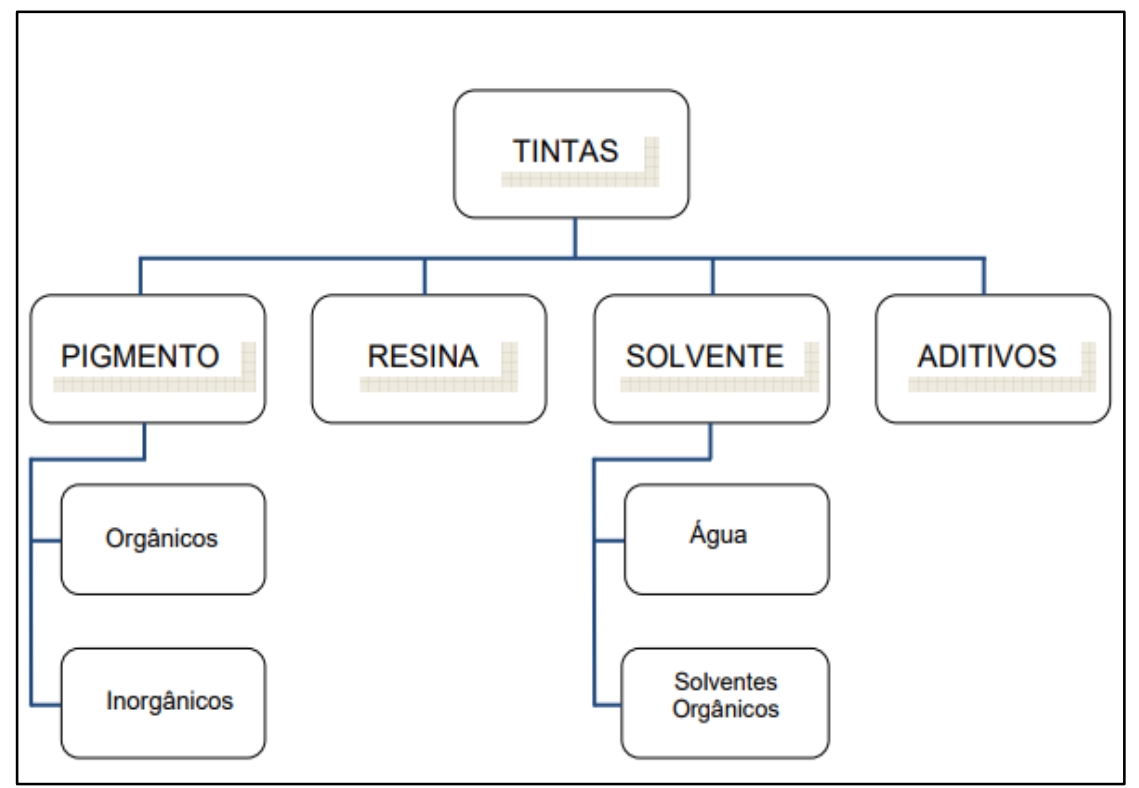

Figura 04: Composição geral das tintas (ANGHINETTI, 2012).

\subsubsection{Resina}

Este componente é um veículo não volátil, aglutinante das partículas do pigmento, além de ser o agente formador do filme. A composição da resina está diretamente ligada com as propriedades da película formada, a qual é também influenciada pelo tipo e teor de pigmento presente. Sendo assim, a resina determina a maior parte das propriedades físico-químicas no processo de 
formulação das tintas. Atualmente, as resinas são obtidas nas indústrias química e petroquímica, através de reações complexas, gerando polímeros com propriedades de durabilidade e resistência superior às resinas a base de compostos naturais, vegetais ou animais. As resinas podem ser classificadas como termofixas, obtidas por reações de polimerização do sistema de resinas simultaneamente à evaporação dos solventes, e as termoplásticas obtidas exclusivamente pela evaporação do solvente (GENTIL, 1996; SANTOS et al., 2012).

No que diz respeito às propriedades dos filmes, como: brilho, resistência química e mecânica e durabilidade, as resinas termofixas têm propriedades superiores às termoplásticas. Também chamada de veículo sólido, a resina é o componente mais importante da tinta. São por meio das especificações das resinas, que se classificam os nomes das tintas, sendo que as tintas mais utilizadas são: vinílicas, alquídicas, acrílicas, poliuretânicas, epóxi, poliéster, nitrocelulose e borracha clorada (BATISTA, 2004; ANGHINETTI, 2012).

\subsubsection{Pigmentos}

São partículas sólidas extremamente finas, com tamanho entre $0,05 \mu \mathrm{m}$ e 5 $\mu \mathrm{m}$, com elevado índice de refração e praticamente insolúveis nas resinas formadoras do filme. A adição de pigmentos na formulação da tinta é realizada com a finalidade de promover cor, opacidade, consistência, durabilidade e resistência à tinta. São classificados em pigmentos coloridos (conferem cor), não coloridos e anticorrosivos, que promovem proteção ao substrato metálico (UEMOTO, 2004; FAZENDA et al., 2005; ANGHINETTI, 2012).

As partículas sólidas presentes na tinta refletem muitos raios de luz prejudiciais, ajudando a prolongar a durabilidade da tinta. Geralmente, os pigmentos devem ser opacos, para garantir um bom poder de cobertura; quimicamente inertes, assegurando estabilidade; atóxicos ou com toxidade muito baixa, por questões de segurança, possuindo alta mobilidade em relação aos componentes formadores da película e, por fim, baixo custo (SANTOS et al., 2012). 


\subsubsection{Solvente}

É o componente volátil, com baixo ponto de ebulição, neutro e incolor. São compostos cuja base é orgânica ou água, capazes de conferir aspecto líquido ou viscoso em tintas ou vernizes. São largamente utilizados no processo de solubilização da resina, no equilíbrio da viscosidade, auxilia e facilita o processo de aplicação das tintas, aumentando a adesão à superfície trabalhada. Além disso, pode apresentar forte odor, inflamabilidade, toxicidade e não reagem com os componentes da tinta. São definidos de acordo com o tipo da tinta, levando em consideração a solubilidade, grau de viscosidade e tipo de aplicação das respectivas resinas. Após a aplicação da tinta, o solvente evapora gradualmente, variando em função do seu ponto de ebulição. Vale ressaltar a importância no controle da evaporação do solvente, pois auxilia na minimização de pequenas imperfeições, além de evitar o escorrimento da tinta (UEMOTO, 2006; ANGHINETTI, 2012; CUNHA, 2012).

Os solventes são classificados de acordo com o grau de solubilização na resina, podem ser: verdadeiros, solventes miscíveis em qualquer proporção; falsos, solventes que possuem baixo grau de solubilização na resina; auxiliares, são aqueles que não solubilizam na resina, porém auxiliam o solvente verdadeiro e os falsos- $\mathrm{Na}$ indústria, os solventes mais utilizados são: álcool etílico, acetato de etila, acetato de butila, butil glicol, toluol e xilol (GENTIL, 1996; SANTOS et al., 2012).

\subsubsection{Aditivos}

São substâncias líquidas, sólidas ou viscosas solubilizadas nos veículos voláteis, adicionadas em pequenas quantidades (concentrações menores que 5\%) com o objetivo de conferir mudanças específicas nas características das tintas, agregando propriedades especiais às mesmas.

Os aditivos não são nomeados de acordo com a sua composição química e sim pelo nome da função que desempenham nas tintas. Os mais utilizados no processo de produção das tintas são os molhantes e os dispersantes, pois facilitam as interações interfaciais entre os componentes da tinta; além dos ativos reológicos, que auxiliam no processo de estabilização das emulsões, mantendo os 
pigmentos em suspensão, facilitando a aplicação da tinta (UEMOTO, 2004; MAIO, 2010).

Os principais aditivos usados em tintas são: plastificantes; secantes; antipeles ou antinatas; espessantes, geleificantes ou tixotrópicos; surfactantes, antiespumantes; desaerantes; tensoativos ou umectantes e nivelantes.

\subsubsection{Tipos de tintas}

A classificação e nomeação das tintas são realizadas em acordo com a base utilizada (resina ou cerâmica) sendo as principais características reflexos da presença destes componentes. O esquema da Figura 05 ilustra essa classificação.

O enfoque desta dissertação de mestrado será na tinta epóxi NOVOLAC Tipo II, a qual será abordada nos próximos tópicos.

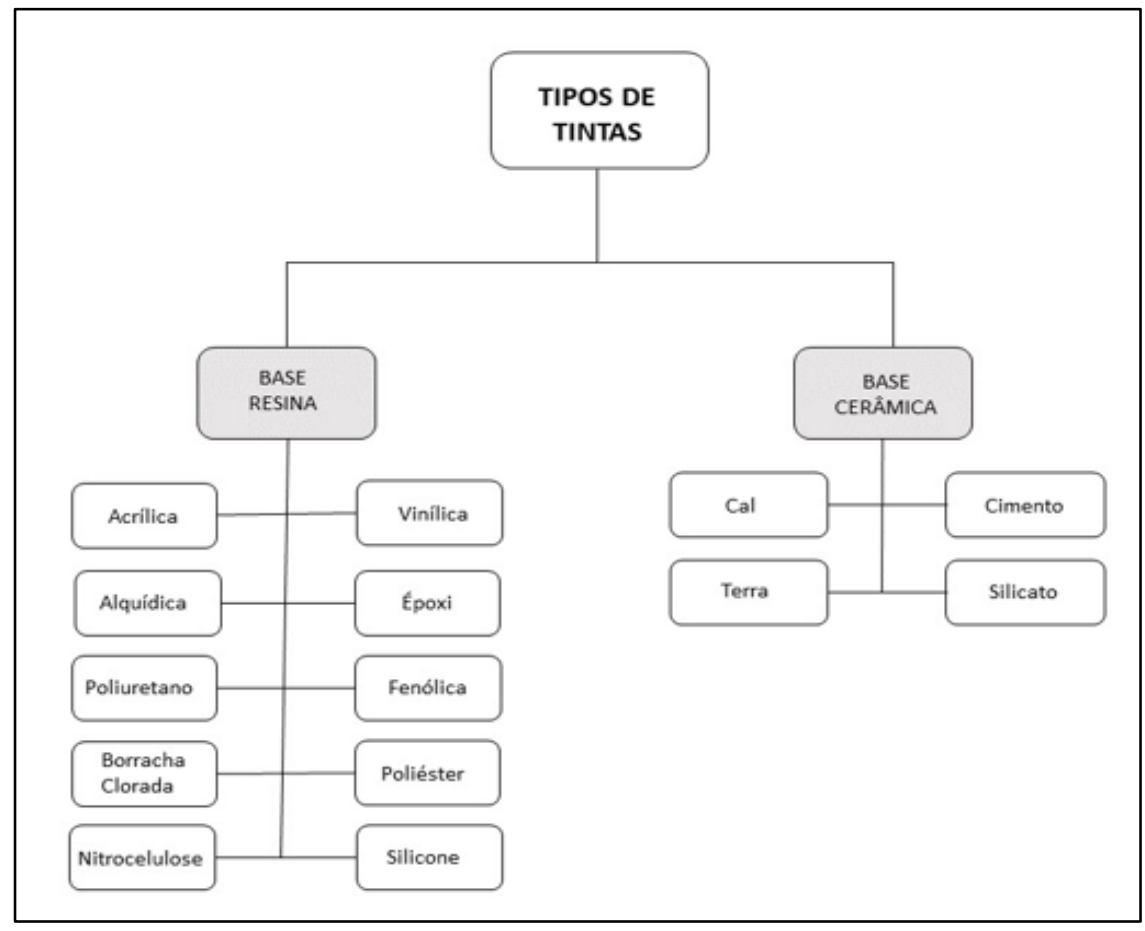

Figura05: Classificação das tintas (ANGHINETTI, 2012).

\subsubsection{Sistema EPOXÍDICO}

O epóxi é uma das resinas mais importantes na classe de polímeros termorígidos já utilizados. Apresentam multifuncionalidades e podem ser usados como adesivos, reforços mecânicos, recobrimentos e materiais de 
encapsulamento, além de serem bastante utilizados como material reparador em estruturas metálicas e de concreto. Estes polímeros apresentam características particulares, quando comparados aos demais, como: estabilidade dimensional, bom comportamento térmico, boa impregnação e alta resistência à abrasão. Em aplicações que requerem alta durabilidade, é fundamental o controle rígido da proporção estequiométrica resina/catalisador, estabelecendo um padrão de cura adequado, proporcionando uma transformação máxima, levando em conta um tempo específico de manipulação e garantindo uma melhor utilização da formulação final (GONZÁLEZ et al., 2003; PETRIE, 2006).

As tintas epóxi são tintas de alto desempenho utilizadas em aplicações anticorrosivas com excelente relação custo benefício, e podem ser formadas através da reação entre a epicloridrina e o bisfenol A (DGEBA), um pré-polímero de baixa massa molecular. A Figura 06 ilustra a estrutura química da resina epóxi baseada no diglicidil éter do bisfenol A (DGEBA).

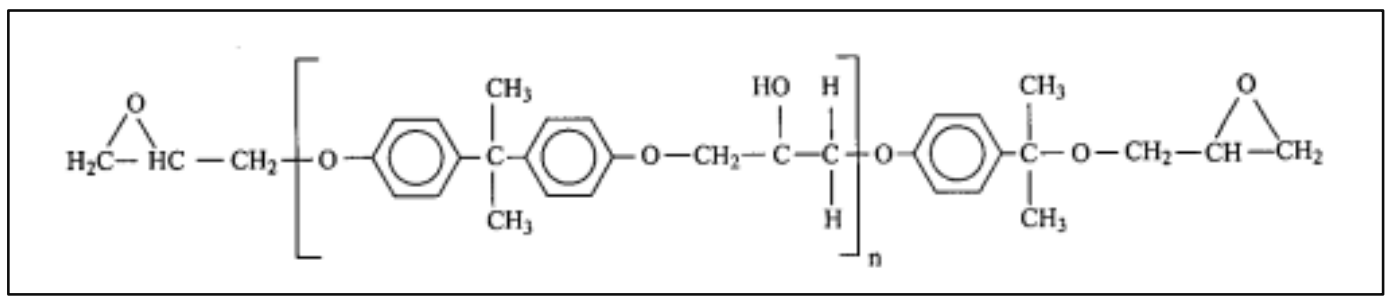

Figura 06: Estrutura química da resina epóxi a base de Bisfenol A (PARDINI et al., 1996).

Geralmente as tintas epóxi são fornecidas em dois componentes (Figura 07), o pré-polímero epóxi (Componente A) e o agente de cura (Componente B), os quais podem ser poliaminas, poliamidas ou isocianatos alifáticos. Os prépolímeros ou resinas epóxis isoladas não tem valor comercial, é necessário misturá-las, em proporções pré-definidas pelo fabricante, com outra resina, também chamada de catalisador, agente de cura ou endurecedor. Vale ressaltar que o excesso da resina ou do agente de cura pode comprometer o aspecto final do filme formador, refletindo nas propriedades finais (NUNES, 2007; ANGHINETTI, 2012). 


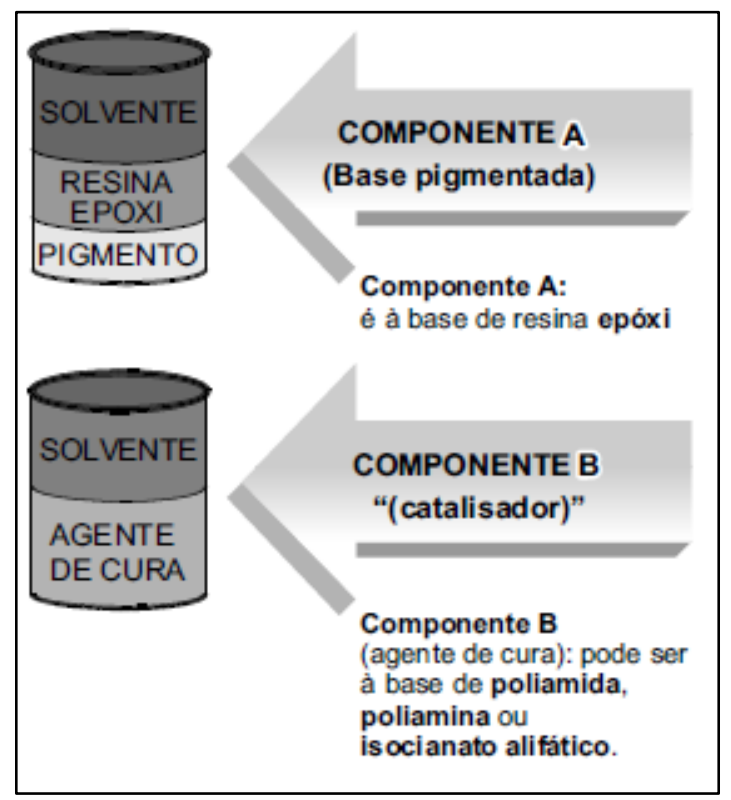

Figura 07: Disposição dos componentes A e B das tintas Epóxi (GNECCO et al., 2003).

Usualmente, as tintas epóxis são formuladas para serem utilizadas em alta espessura (entre 120 e $150 \mu$ m por demão), além de conter pigmentos lamelares, do tipo óxido de ferro, micáceo ou alumínio, maximizando sua proteção por barreira. Como característica geral, estas tintas possuem elevada resistência química de acordo com o sistema resina epóxi / agente de cura, alta dureza e boa resistência à abrasão e ao impacto, fraca resistência à radiação solar, em especial aos raios ultravioletas, gerando perdas de brilho e cor. Além disso, são consideradas mais impermeáveis à água que o esmalte sintético (GNECCO, 2003; ANGHINETTI, 2012).

As resinas epóxi são polímeros caracterizados pela presença de grupos glicidila (epóxi) em sua molécula, além de outros grupos funcionais como a hidroxila. É uma resina utilizada em revestimentos para ação anticorrosiva em áreas de armazenamento químico, poços, tanques e áreas que podem entrar em contato com produtos químicos.

As resinas epóxi são frequentemente utilizadas em revestimentos anticorrosivos, pois são polímeros que asseguram uma boa aderência na superfície metálica de vários substratos, estabilidade química e facilidade na aplicação. Após a cura, os sistemas epóxi necessitam de pequena contração (aproximadamente $2 \%$ ) resultando num pequeno rearranjo molecular. A alta aderência dessas resinas está associada à polaridade dos grupos éteres e hidroxilas alifáticas presentes na cadeia inicial da resina e na rede do sistema epóxi pós-cura. Esta polarização 
induz o surgimento de forças de interação entre a molécula epóxi e seus adjacentes, potencializando sua aplicação como revestimento. Na aplicação em compósitos, o efeito da polarização maximiza a interação resina/reforço, reduzindo os problemas na interface do mesmo (PIRES et al., 2005).

Em contrapartida, revestimentos à base de resinas epóxi são hidrofóbicos, possuem baixa tenacidade, baixa resistência mecânica à fratura, estabilidade térmica relativamente baixa e podem ser degradados quando expostos a radiação solar. Por isso, as resinas epóxi são regularmente modificadas com o intuito de potencializar suas propriedades, aumentando a sua aplicabilidade (SHU-YONG et al.,2002; ROCHA et al., 2017; CASTRO, 2017).

\subsubsection{Tinta epóxi NOVOLAC}

Em aplicações industriais de alto desempenho como revestimentos de dutos e tanques, faz-se necessário a obtenção de propriedades específicas. Para suprir essa necessidade, existem vários tipos e formulações de resinas epóxis comerciais. Resinas à base de Bisfenol F, também conhecida como Novolac, apresentam maior resistência térmica e química, devido um maior número de ligações cruzadas (ramificações e/ou reticulações) em sua estrutura (MOREIRA, 2009).

A estrutura química da resina epóxi Novolac (Figura 08) é sintetizada pela reação de uma resina fenólica Novolac com a epicloridrina. Os grupos epóxi (oxigênio entre carbonos) presentes na estrutura refletem na alta densidade de reticulação, resultando em excelentes propriedades de resistência térmica e química (GUO et al., 2003; PARK et al., 2006).

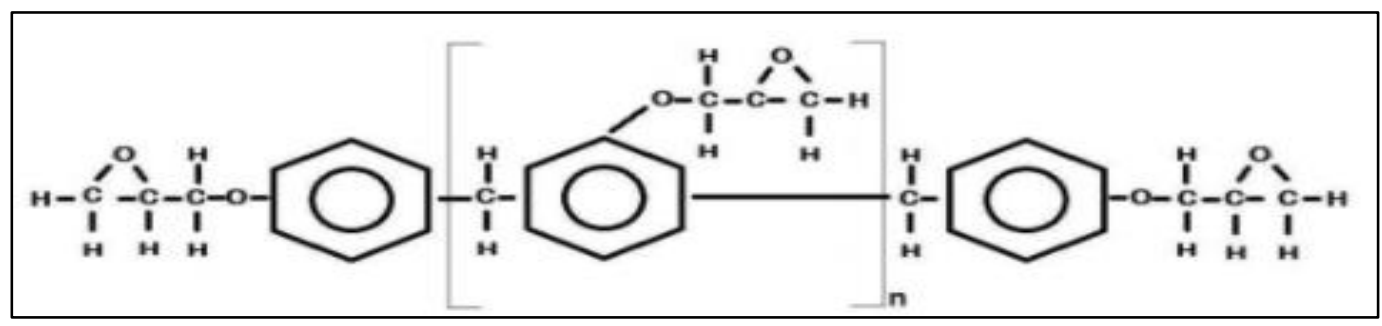

Figura 08: Estrutura química da resina epóxi NOVOLAC (PIPER et al., 2015).

A tinta epóxi NOVOLAC, possui as mesmas propriedades das tintas epóxi comum, com uma única diferença, utiliza o bisfenol $\mathrm{F}$ no lugar do bisfenol A. 
Essa substituição (bisfenol F) proporciona as resinas epóxi uma maior densidade de ligações cruzadas ("Cross-link”), maximizando o desempenho químico, mecânico e térmico. Resinas epóxi a base de bisfenol $\mathrm{F}$ normalmente são misturadas com diluentes reativos, com o objetivo de diminuir a viscosidade dos ligantes, possibilitando a incorporação de altos teores de carga (SCHMIDT, 2005).

As tintas epóxi NOVOLAC são classificadas em tipo I, II e III:

Tipo I: É uma tinta com um alto teor de sólidos e baixos teores de compostos orgânicos voláteis. É apropriada para ser utilizada como revestimento interno e externo de tubulações e equipamentos. Apresenta película com aspecto final liso, com a finalidade de redução do atrito, por exemplo, para o transporte de gás em tubos. Além de apresentar ótima resistência química a solventes orgânicos e produtos derivados do petróleo.

Tipo II: Este tipo de tinta é isento de solventes orgânicos voláteis, reforçado com cargas cerâmicas, servindo para uso como revestimento interno ou externo de tanques de armazenamento para produtos de petróleo, tais como: óleo cru, diesel, maioria dos solventes aromáticos, salmouras e muitos outros produtos do petróleo. Apresenta película com aspecto final liso e semibrilhante. Altamente recomendado para revestimento interno e externo de equipamentos onde a resistência química é principal requisito

Tipo III: Demonstra alto desempenho contendo flocos de vidro, proporcionando superior impermeabilidade e resistência química em aplicações com imersão total de líquidos e exposição a gases ou vapores corrosivos. Durante a aplicação, não emite solventes voláteis, portanto, não oferece riscos de incêndio ou explosão em locais confinados. Possui alta resistência química a álcalis, solventes e ácidos fortes para estruturas de aço carbono ou de concreto. Este tipo de tinta foi testado para equipamentos de processos (Separadores de Gases e Tratadores de Óleo) que operam com água produzida do processo de extração de petróleo, em temperaturas entre $120^{\circ} \mathrm{C} \mathrm{e} 150^{\circ} \mathrm{C}$. 


\subsection{Nanomateriais Carbonosos}

O uso de nanomateriais e nanotecnologias é uma opção estrategicamente inovadora que confere aos materiais produzidos um comportamento multifuncional. Os nanocompósitos poliméricos com partículas orgânicas ou inorgânicas de diferentes dimensões e com diferentes comportamentos químicos são atualmente tema de várias linhas de pesquisa científica. Os diferentes "nanoacabamentos" funcionais possíveis, como antimicrobiano, proteção UV, retardamento à chama, entre outros, surgem da eficiente combinação do sistema "compósito polimérico - nanopartículas orgânica ou inorgânica", uma vez que diferentes combinações deste sistema levam a um número adicional de funcionalidades (VENTURA et al., 2011).

Nanopartículas de carbono, nanotubos e grafeno, estão sendo utilizados como aditivos em diversas matrizes poliméricas. O objetivo é gerar compósitos com propriedades físico-químicas superiores ao polímero puro. Na literatura científica, existem muitos trabalhos envolvendo o sistema epóxi/nanoaditivos de carbono. Dentre os mais importantes, Ribeiro e colaboradores (2015) estudaram a influência do grupo TEPA (tetraetilenopentamina) ligado ao óxido de grafeno (OG) nas propriedades mecânicas e térmicas dos nanocompósitos em matriz epoxídica DGEBA. Através de medidas de nanoindentação, observaram aumentos consideráveis no módulo de elasticidade (73\%) e na dureza (140\%) em nanocompósitos contendo 0,5\% em massa de GO-TEPA. Yu e colaboradores (2010) constataram um aumento de quatro vezes na condutividade térmica do compósito em relação ao polímero puro, devido à adição de $5 \% \mathrm{~m} / \mathrm{m}$ de óxido de grafeno em matriz epoxídica. Em outro estudo, Da Silva e colaboradores (2013) caracterizaram as propriedades morfológicas, térmicas e mecânicas do grafite sonificado, óxido de grafite (OG) e OG expandido (OGE), dispersos em matriz epóxi DGEBA. Foi observado um incremento de aproximadamente $37 \%$ na resistência a tração, sendo o OGE o mais promissor. Hack, 2013 produziu o grafeno pelo método de Hummers modificado, além de produzir nanocompósitos de matriz epoxídica aditivadas com grafeno produzido (GP) e grafeno comercial (GC). 


\subsection{Grafeno}

Em escala nanométrica, o carbono pode ser encontrado em diferentes arquiteturas, originando uma variedade de estruturas estáveis com configurações poliatômicas diferentes, designadas como formas alotrópicas. As estruturas são diferenciadas de acordo com o número e a natureza das ligações ao átomo central de carbono, determinando sua geometria e propriedades. Desde o início da década de 20, as únicas estruturas organizadas conhecidas de carbono eram o diamante (hibridização $s p^{3}$ ) e o grafite (hibridização $s p^{2}$ ). O elevado interesse científico na investigação do elemento carbono e suas variadas estruturas, atrelados ao desenvolvimento de novos equipamentos de caracterização de superfícies, como microscópios eletrônicos e espectroscópios, levaram à descoberta de novas formas alotrópicas do carbono com hibridização $s p^{2}$. Dentre essas novas formas se encontram: os fulerenos (C60), descobertos em 1985 por Robert F. Curl Jr., Sir Harold Kroto e Richard E. Smalley, os nanotubos de carbono, observados em 1991 por Sumio Iijima, e o grafeno, até o momento considerado termodinamicamente instável em condições ambientes, foi isolado e identificado em 2004 por Andre Geim e Konstantin Novoselov através do processo de microesfoliação mecânica do grafite (KROTO et al., 1985; IIJIMA, 1991; NOVOSELOV et al., 2004; GEIM \& NOVOSELOV, 2007; PESTRANAMARTÍNEZ et al., 2013).

Dentre os alótropos do carbono (Figura 09), o grafeno é considerado a unidade básica estrutural para a construção de nanoestruturas de carbono, com exceção do diamante. Uma folha de grafeno manipulada de diferentes formas pode se transformar em outras estruturas de carbono, os fulerenos em formato esférico, os nanotubos de carbono que podem ser visualizados como uma folha de grafeno enrolada em formato cilíndrico e o grafite, descrito como um empilhamento de folhas de grafeno dispostos alternadamente (BALUCH et al. 2008; ZARBIN et al., 2013). 


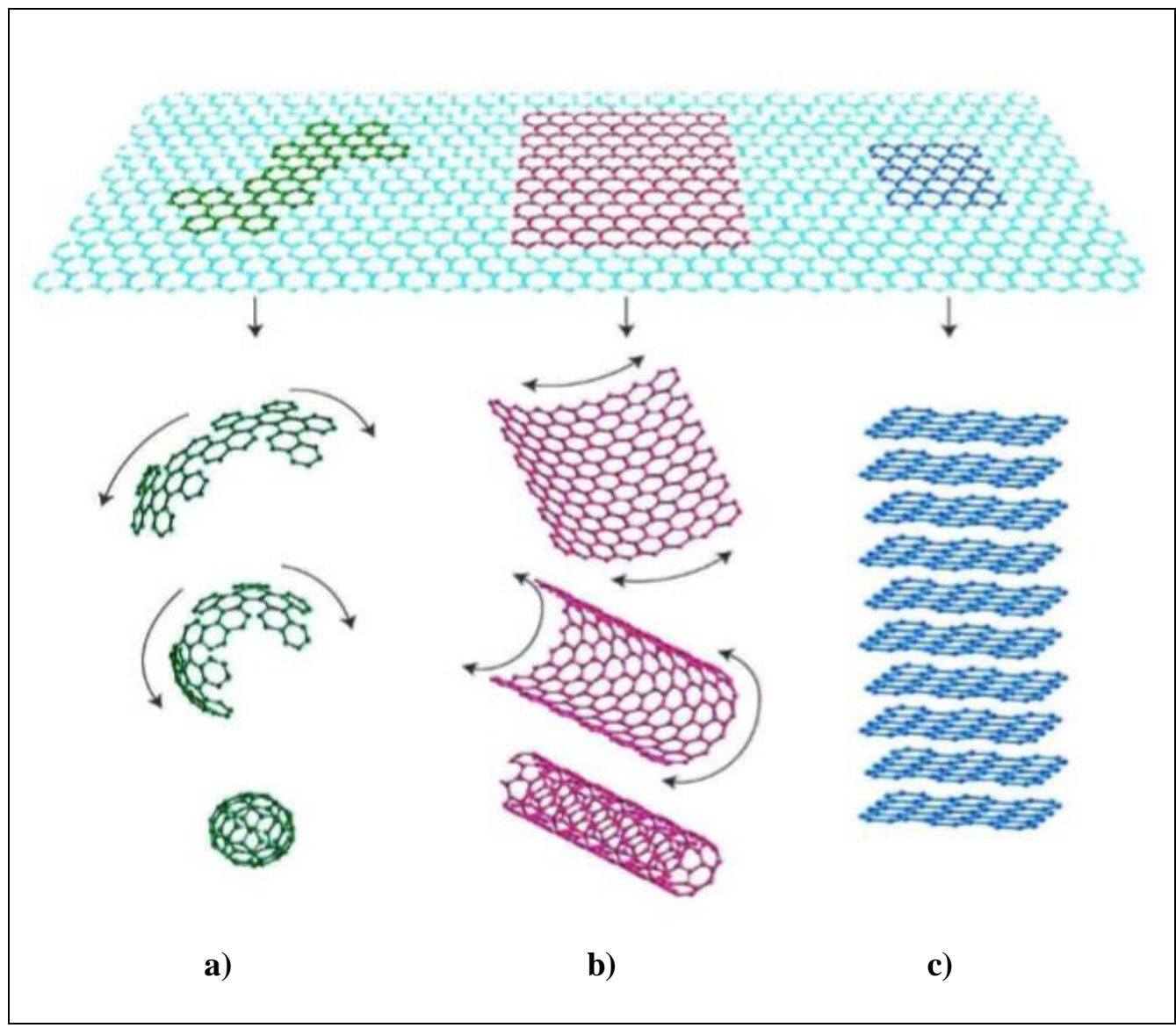

Figura 09: Estruturas derivadas do grafeno a) Fulereno b) Nanotubo c) Grafite (NOVOSELOV, 2005).

A definição científica do grafeno é de um material constituído por monocamadas de carbono puro, com espessura de um átomo (aproximadamente $0,34 \mathrm{~nm}$ ), possui uma rede bidimensional constituída por uma estrutura hexagonal de átomos de carbono com hibridização $s p^{2}$, com distâncias entre carbonos $(\mathrm{C}-\mathrm{C})$ de 0,142 $\mathrm{nm}$. Além de possuir uma estrutura densa em forma de "honeycomb" (colméia). A representação da estrutura planar e hexagonal pode ser vista na Figura 10 (D GHUGE et al. 2016). 


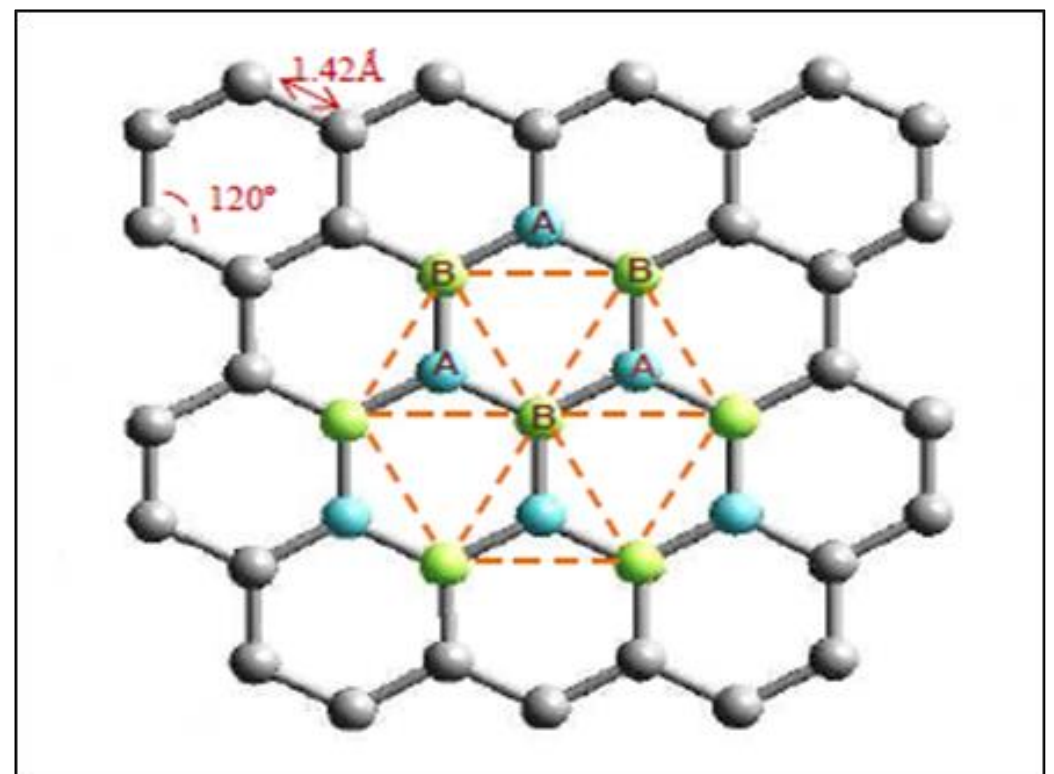

Figura 10: Representação da estrutura hexagonal e planar do grafeno (DE LIMA, 2012).

O grafeno vem chamando muita atenção devido às suas propriedades físicas excepcionais, oferecendo a possibilidade de fabricação de uma grande diversidade de materiais que vem sendo utilizado em aplicações para células solares, transistores, supercapacitores e dispositivos de memória. Entre estes materiais, estão os materiais compósitos, onde o grafeno é utilizado como aditivo em matrizes cerâmicas ou poliméricas, de modo que, estas possuam propriedades especiais feitas sob medida (tailor made), podendo ser empregados em vários setores da indústria, como por exemplo, a eletrônica, mecânica, aeroespacial, automotiva, para citar algumas (ALLEN et al., 2010; KHOLMANOV et al., 2010; KUILA et al., 2012; SHEN et al., 2013; TANG et al., 2013; WAN et al., 2013; YANG et al., 2013; CHUA et al., 2014).

Todavia, o desafio na pesquisa de nanoestruturas de grafeno depende da capacidade de se produzir nanofolhas independentes, como também tentar moldálas em diferentes estruturas químicas. As propriedades do nanocompósitos dependem, principalmente, do grau de dispersão desses materiais em diferentes tipos de matrizes, que podem ser: poliméricas, cerâmicas ou sistemas de solventes e líquidos iônicos. A eficiente interação entre a nanocarga e a matriz receptora é reflexo da transformação das nanofolhas de grafeno, determinando as propriedades finais do compósito processado (RIBEIRO, 2015). 


\subsubsection{Propriedades do Grafeno}

Uma das propriedades mais importantes do grafeno é a espessura. Quando se compara o grafeno a todos os outros materiais, o grafeno é o material mais fino, flexível e extremamente duro, assim como também é considerado mais forte que o diamante. As propriedades eletrônicas do grafeno são únicas, devido ao fato dos portadores de carga no grafeno ser considerados como "Fermiões de Dirac", elétrons sem massa, com uma elevadíssima mobilidade, possibilitando a observação de fenômenos quânticos à temperatura ambiente. Na Figura11, é possível perceber que na estrutura eletrônica de uma monocamada de grafeno, dois pontos cônicos da zona de Brillouin se sobrepõem. A diferença infinitesimal entre as bandas de condução e valência facilita e acelera a mobilidade dos elétrons no grafeno, quando comparados a materiais como, por exemplo, os semicondutores. Sendo assim, a condução da corrente elétrica no grafeno também é a mais eficaz em comparação com todos os outros materiais. Outra característica é a transparência, absorvendo apenas $2.3 \%$ da luz incidente, onde parte da sua translucidez advém do fato do grafeno possuir espessura monoatômica. A combinação dessas propriedades, como flexibilidade, alta resistência e potencial para alteração química vem despertando um elevado interesse nas aplicações do Grafeno (GEIN et al. 2007; R.R et al. 2008; PESTRANA-MARTÍNEZ et al., 2013; BARBOSA, 2014).

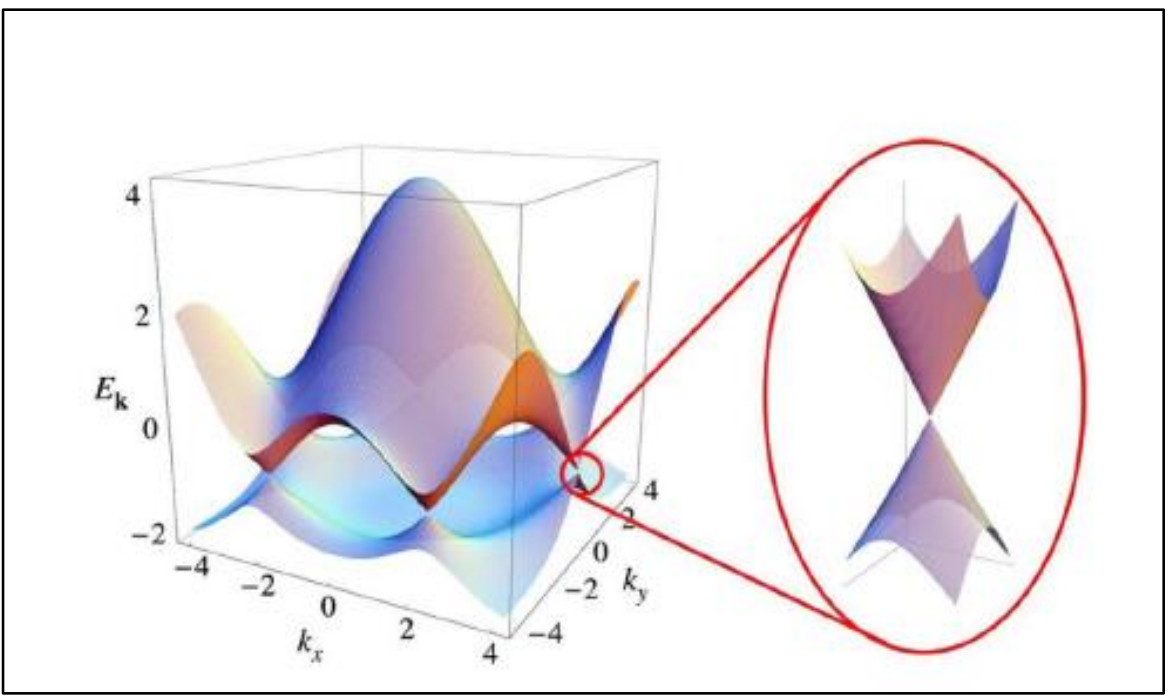

Figura 11: Bandas de energia do grafeno próximo ao ponto de Dirac em $\mathrm{t}(\mathrm{t}=2.7 \mathrm{eV}$ ) (CASTRO NETO et al., 2009). 


\subsubsection{Técnicas de obtenção do grafeno}

No processo de síntese do grafeno, várias técnicas de fabricação são delineadas a partir da esfoliação mecânica de grafeno de alta qualidade para o crescimento direto em carbeto de silício ou substratos metálicos e das rotas químicas usando óxido de grafeno. Os mecanismos de síntese do grafeno se dividem em duas abordagens principais: bottom-up e top-down. Sendo que a primeira promove a síntese do grafeno a partir de moléculas de carbono simples (metanol e etanol), já a segunda envolve a separação das camadas empilhadas de grafite, produzindo folhas individuais ou empilhamentos de grafeno. Na Figura 12 é possível ilustrar o esquema genérico das abordagens Bottom Up e Top Down.

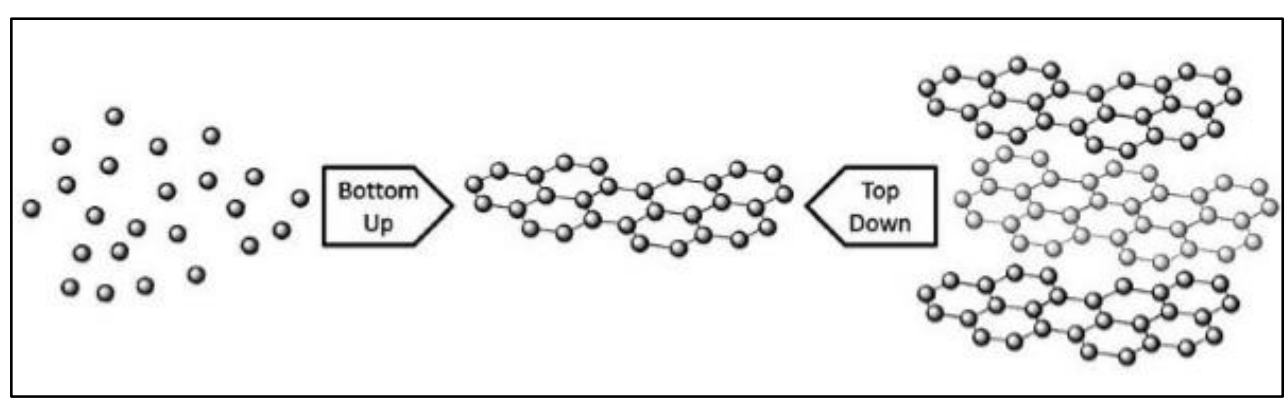

Figura 12: Esquema de produção do Grafeno nas abordagens Bottom Up e Top Down (EDWARDS, 2013).

Os principais métodos de obtenção do grafeno são: I) Microesfoliação mecânica; II) Esfoliação por oxidação química seguida de redução; III) Deposição química a vapor (CVD).

O método I envolve a separação mecânica das folhas de grafeno a partir de placas de $1 \mathrm{~mm}$ de espessura de grafite pirolítico altamente orientado. No processo, esfolia-se o grafite altamente puro com uma fita adesiva e em seguida gruda-se a fita adesiva num substrato com 100 ou $300 \mathrm{~nm}$ de óxido de silício. Não é um método reprodutivo em larga escala, já que o grafeno é obtido ao acaso, além da possibilidade de contaminação da cola presente na fita (NOVOSELOV et al., 2004).

No método II a obtenção das folhas de grafeno é feita a partir do óxido de grafite (OG) e tem se mostrado bastante promissor, devido ao seu elevado potencial na produção em larga escala, além de possuir baixo custo em relação aos 
demais, e também não necessita de equipamentos e reagentes caros para a produção em larga escala.

O método III baseia-se na obtenção do grafeno diretamente sobre o substrato sólido. É considerado um método de baixo custo e com alto desempenho, excelente para produzir grafeno em alta escala. É o método mais utilizado para a obtenção do grafeno em quantidades relevantes. Neste método, camadas de grafeno cristalizam em superfícies de carbetos metálicos, principalmente carbeto de silício (SiC), por sublimação. Ou se forma diretamente sobre superfícies metálicas, onde ocorre a passagem de hidrocarbonetos gasosos a baixas pressões $(<1 \mathrm{~atm})$ e altas temperaturas $\left(800\right.$ a $\left.1100{ }^{\circ} \mathrm{C}\right)$. Estes substratos metálicos podem ser de cobre, níquel, rutênio ou irídio, resultando na formação de filmes ultrafinos de grafite sobre a superfície. O grafeno depositado sobre esses materiais pode ser facilmente recuperado e transferido para outro substrato, já que alguns metais de transição podem ser dissolvidos em soluções ácidas (LAMMERT et al. 2009; SOLDANO et al. 2010; KUILA et al, 2012; LI et $a l, 2014$; GHUGE et al.2016 e GARNICA et al.2017).

Portanto, os métodos bottom-up processam grafeno com menor grau de defeitos, fator indispensável em eletrônicos, no caso dos nanocompósitos poliméricos, não é aplicável por questões de quantidade de material. Sendo assim, os métodos top-down são os mais apropriados, devido o seu elevado rendimento e baixo custo (BADHULIKA, 2015; DING, 2012; SHAH, 2015).

\subsubsection{1. Óxido de grafeno}

A oxidação do grafite pode ser feita utilizando várias condições e reagentes, através do uso de ácidos e óxidos fortes, devido à presença de defeitos pontuais na estrutura cristalina do grafite. Os métodos são classificados de acordo com o reagente utilizado, à base de clorato, foram criados por Brodie, Staudenmaier e Hofmann ou os métodos à base de Permanganato, estudadados por Hummers e Offeman. Ambos com poucas diferenças.

O óxido de grafeno (OG), quimicamente semelhante ao óxido de grafite, consiste em estruturas grafíticas formadas por uma camada de grafeno funcionalizada por grupos como: hidroxila, epóxi, carboxílicos e carbonilas. Por ele ser obtido pela oxidação do grafite, apresenta características semelhantes de 
hidrofilicidade, compatibilidade e dispersibilidade em diferentes matrizes poliméricas. A diferença entre o óxido de grafite e óxido de grafeno é apenas estrutural, o óxido de grafite sofre esfoliação para formar o óxido de grafeno (EDWARDS, 2013; POTTS, 2011; MARASCHIN, 2016).

As propriedades do OG estão atreladas a natureza dos grupos funcionais e a morfologia do óxido resultante. Visto que tudo isso depende da natureza do grafite precursor e das condições de reação os quais foram submetidos. As consequências da adição de grupos funcionais (epóxi e hidroxila) são: o aumento do espaçamento interlaminar, alteração da hibridização dos átomos de carbono $\left(s p^{2}\right.$ para $\left.s p^{3}\right)$, alterando a sua geometria planar para tetraédrica, além de quebras das forças de Van der Waals (MCALLISTER, 2007; BOTAS, 2012; CISZEWSKI, 2014; GAO, 2015; SHAH, 2015; MARASCHIN, 2016; SHAMAILA, 2016).

\subsubsection{2. Óxido de grafeno reduzido}

O óxido de grafeno reduzido (OGR) pode ser obtido por duas vias: a redução química ou a redução térmica. Na redução química utilizam-se agentes redutores (hidrazina, dimetilhidrazina, hidroquinona ou $\mathrm{NaBH}_{4}$ ). A redução térmica ocorre através de um aquecimento abrupto, promovendo a liberação de $\mathrm{CO}, \mathrm{CO}_{2}$ e água, elevando a pressão interna e forçando a separação das folhas. Após temperaturas de aproximadamente $200{ }^{\circ} \mathrm{C}$, os grupos são total ou parcialmente eliminados das folhas de grafeno. Portanto, a redução térmica é considerada mais vantajosa que a redução química, por ser mais rápida, podendo promover simultaneamente a esfoliação e a redução do OG, por não precisar do uso de solventes, facilitando o uso em materiais secos; por não precisar da etapa de purificação, tornando o processo mais barato; dentre outros. Sua estrutura diferenciada é compatível com aplicações em nanocompósitos poliméricos (MCALLISTER et al., 2007; POTTS, 2011; BOTAS, 2013; CHUA, 2014; SANTOSH, 2015; MARASCHIN, 2016).

Quimicamente, o grafeno é produzido através de duas rotas principais, primeiro oxidando o grafite com oxidantes fortes seguido de esfoliação via ultrassom, formando o óxido de grafeno, seguido de uma redução térmica ou química, obtendo o óxido de grafeno reduzido (OGR). Outro caminho utilizado é 
a oxidação do grafite com adição de oxidantes fortes, seguido de um tratamento térmico em microondas para posterior esfoliação e redução simultânea do óxido de grafite, obtendo o óxido de grafeno reduzido. É considerada uma rota simples e versátil, promissora para produção econômica em escala de grafenos, além de ser a rota utilizada na síntese do grafeno utilizado nesta tese de mestrado (SCHNIEPP et al., 2006; MCALLISTER et al., 2007; DING, 2012; ZHU et al., 2010; RIBEIRO, 2015).

A Figura 13 mostra de forma esquematicamente todas as etapas para obtenção do grafeno por meio da esfoliação química.

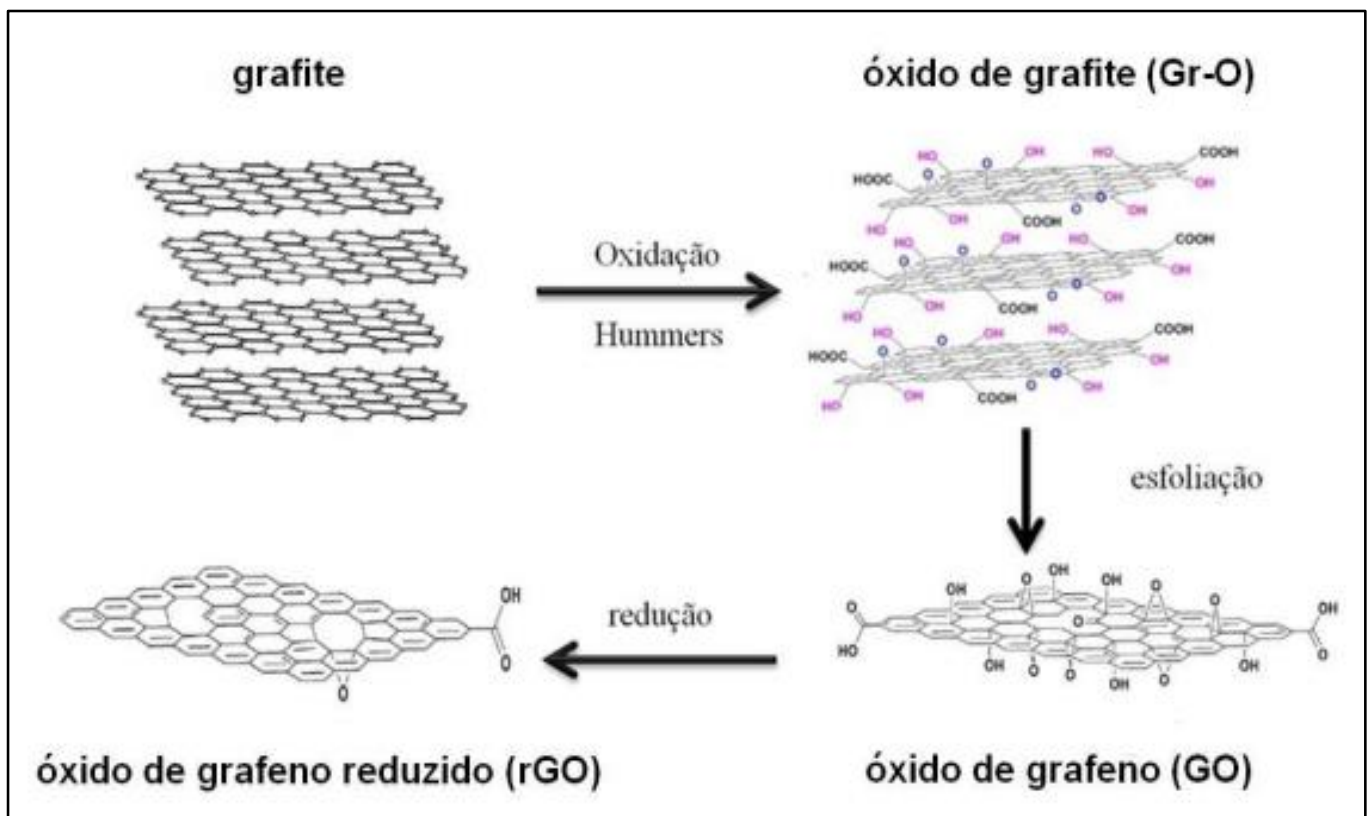

Figura 13: Representação esquemática do processo de oxidação do grafite para formação do óxido de grafite, seguido da exfoliação para formação de folhas individuais de óxido de grafeno, seguido de redução para formação de grafeno (ou óxido de grafeno reduzido) (Adaptado de ZARBIN \& OLIVEIRA, 2013).

\subsubsection{Funcionalização química do grafeno}

A funcionalização química e dispersão das folhas de grafeno são de extrema importância em suas aplicações. Um grafeno quimicamente funcionalizado pelo processo adequado possui uma menor tendência à aglomeração e consequente manutenção das suas propriedades. Na abordagem química, a superfície cristalina sem defeitos do grafeno aparenta ser intensamente inerte. Podendo interagir com outras moléculas por meio do processo de fisiossorção (ligações $\pi$ - $\pi$ ), onde as moléculas aderem na superfície do adsorvente 
através das forças de Van der Waals, interações intermoleculares fracas incapazes de formar ligações químicas. Para aumentar a reatividade da superfície do grafeno são adicionados defeitos ou grupos funcionais de superfície. Por exemplo, a adição de grupos funcionais do tipo: carboxila, carbonila e grupos amina podem ajustar as propriedades de superfície e as propriedades eletrônicas do grafeno (XU et al., 2013; SEGUNDO et al., 2016).

Os defeitos desempenham um papel importantíssimo nas propriedades cristalinas das nanoestruturas grafíticas. A versatilidade estrutural do grafeno implica em maiores capacidades em acomodar diferentes tipos de defeitos, que podem alterar a sua estrutura (topologia ou curvatura) e suas propriedades físicoquímicas. Todavia, identificar quantitativamente esses defeitos não é uma tarefa simples. Muitos estudos estão sendo desenvolvidos com o desafio futuro de utilizar defeitos para projetar nanoestruturas grafíticas com aplicações diversas, dentre elas: estruturas modificadas e capazes de ancorar cadeias poliméricas específicas, com o objetivo de processar compósitos mais estáveis e dispersos (TERRONES et al., 2010; BATZILL, 2012).

A produção de grafeno em monocamadas não é uma tarefa simples. Isso ocorre porque as nanofolhas de grafeno apresentam uma elevada área superficial e possuem uma forte tendência de se aglomerarem, reempilhando-se pela interação das forças de Van der Waals. Entretanto, o reempilhamento destas camadas pode ser minimizado com a adição química de outras moléculas ou por recobrimento com polímeros. A presença de grupos funcionais hidrofóbicos/hidrofílicos dificulta a aglomeração de nanofolhas de grafeno por interações dipolares ou por impedimento estérico, através da produção de ligações covalentes, permitindo a dispersão do grafeno em diferentes meios. A funcionalização química do grafeno está associada ao processo de hibridização de um ou mais átomos de carbono $s p^{2}$ para $s p^{3}$, aliada à perda total ou parcial da distribuição eletrônica (PARK et al., 2006; LI et al., 2008; SHAN et al., 2009; KUILA et al., 2012; CHUA et al., 2014).

Considerando os compósitos de base epóxi, os grupos funcionais do tipo amina podem estabilizar a dispersão do grafeno, devido à forte interação gerada com a matriz polimérica. Sendo, portanto, o reflexo do aumento da polaridade e a possibilidade de reação entre os grupos amino com o grupo epóxi da resina. Tudo isso influencia na dispersão do grafeno devido ao surgimento das ligações 
covalentes estáveis entre a amina, presente na estrutura do grafeno funcionalizado e o grupo epóxi, presente na matriz polimérica (GOJNY et al., 2004; RIBEIRO, 2015).

\subsubsection{Aplicações}

Como já foi mencionada, a definição científica do grafeno consiste de uma monocamada plana de átomos de carbono, organizada em células hexagonais, com átomos hibridizados na forma $s p^{2}$. Essa estrutura única fornece ao grafeno excelentes propriedades, como pode ser vista na Tabela 01. Inicialmente, o grafeno foi obtido pelo método de esfoliação mecânica, devido às suas ótimas propriedades comprovadas para a configuração em monocamada, outras técnicas para obtenção do grafeno foram criadas, abrindo o leque para o estudo experimental das suas propriedades.

Atualmente, o termo grafeno corresponde a uma família de compostos que abrange desde a folha monoatômica até dez folhas de grafeno empilhadas ordenadamente. Suas propriedades são diretamente influenciadas pelo processo de síntese utilizado e pelo número de camadas constituintes. As propriedades eletrônicas são distintas, considerando grafenos com diferentes números de camadas, devido às inúmeras possibilidades de acoplamento eletrônico entre as folhas de cada estrutura.

Esse comportamento ratifica o princípio básico que norteia a nanociência e nanotecnologia, de que as propriedades da matéria não dependem, somente, da sua estrutura e composição química, como também do seu tamanho e formato (ZARBIN et al., 2013). 
Tabela 01: Propriedades e aplicações do grafeno monocamada.

\section{Propriedades Físico-Químicas}

\begin{tabular}{|c|c|}
\hline $\begin{array}{l}\text { Alta condutividade e mobilidade elétrica } \\
\left(\rho \simeq \mathbf{1 5 0} \Omega / \mathbf{c m}, \boldsymbol{\mu} \simeq \mathbf{2 0 0 . 0 0 0} \mathrm{cm}^{\mathbf{2}} / \mathrm{Vs}\right)\end{array}$ & $\begin{array}{l}\text { Condutores elétricos (fios e fitas) de alta } \\
\text { eficiência, transistores de alta frequência, } \\
\text { padrões de resistência elétrica }\end{array}$ \\
\hline $\begin{array}{l}\text { Alta resistência mecânica } \\
(\boldsymbol{\gamma} \simeq \mathbf{1} \mathbf{T} \mathbf{P a}, \mathbf{F} \simeq \mathbf{1 3 0} \mathbf{~ G P a})\end{array}$ & Materiais compostos, sensores de pressão. \\
\hline $\begin{array}{l}\text { Alta razão área/massa } \\
\qquad\left(\mathbf{2 6 0 0} \mathbf{m}^{2} / \mathbf{g}\right)\end{array}$ & $\begin{array}{c}\text { Armazenamento de energia (baterias, } \\
\text { supercapacitores), células de combustível. }\end{array}$ \\
\hline $\begin{array}{c}\text { Alta transparência } \\
\text { (97\%) }\end{array}$ & Eletrodos transparentes, fotônica. \\
\hline $\begin{array}{l}\text { Alta capacidade de amperagem } \\
\qquad\left(\mathbf{1 0}^{\mathbf{9}} \mathrm{A} / \mathbf{c m}^{\mathbf{2}}\right)\end{array}$ & Fiação elétrica de alta amperagem. \\
\hline Alta sensibilidade química & Sensores químicos e biológicos. \\
\hline $\begin{array}{l}\text { Alta condutividade térmica } \\
\qquad(\mathbf{3 0 0 0} \mathbf{W} / \mathbf{m K})\end{array}$ & Armazenamento e gerenciamento de calor. \\
\hline Alta impermeabilidade & Barreira química e biológica, revestimento. \\
\hline Alto grau de hidrofobicidade & Repelente de água. \\
\hline
\end{tabular}

Fonte: (Adaptado de CASTRO NETO, 2013).

\section{Aplicações}




\subsection{Nanocompósitos Poliméricos aditivados com Grafeno}

Os nanocompósitos poliméricos são constituídos de uma matriz polimérica e um reforço de dimensões nanométricas (1-100 nm). Esta matriz pode ser de origem termoplástica, termofixa ou elastomérica. A interação entre os nanoreforços e a matriz polimérica confere aos nanocompósitos propriedades superiores, comparadas aos polímeros convencionais. Essa multifuncionalidade criada pela junção de dois materiais influencia diretamente nas suas propriedades, tais como: melhora das propriedades mecânicas (rigidez, resistência mecânica e resistência ao impacto, tenacidade), assim com a manutenção das propriedades positivas da resina, processabilidade e baixa densidade, além da combinação de novas propriedades, como: aumento da condutividade elétrica, redução no coeficiente de expansão térmica e redução da permeabilidade de gases (KOO, 2006; MAI et al., 2006; NGUYEN et al, 2009; VELMURUGAN et al., 2009).

A fração volumétrica de nanomateriais utilizada no processo de incremento dos polímeros depende da força das interações entre as nanoestruturas e a matriz polimérica. Estas interações são fortemente dependentes da composição do polímero, da natureza da nanoestrutura de carbono e também da forma como o nanocompósito é preparado. A eficiência do produto final é dependente da interação entre a matriz polimérica e a nanoestrutura. Os pré-requisitos básicos para garantir uma boa interação entre o polímero e a nanoestrutura são a dispersão homogênea das nanoestruturas isoladas e o estabelecimento de uma boa afinidade química (covalente ou não) com a matriz polimérica. A aplicação de tratamentos químicos as nanoestruturas visa gerar dispersões cada vez mais estáveis, aumentando a afinidade química entre elas, gerando nanocompósitos de elevado desempenho (KUILLA et al., 2010; MATOS et al. 2012; POTHEN et al., 2013).

Não é desejável o nanocompósito apresentar aglomerados de nanopartículas, pois promove a redução na área superficial, gerando uma concentração de tensão, e posterior fragilização do material composto. Como aditivo em compósito de matriz polimérica o grafeno pode aumentar a temperatura de operação dos compósitos, reduzir a absorção de umidade, induzir comportamento antiestático, tornar resistente ao fogo e melhorar a resistência compressiva do compósito (ALEXANDRE \& DUBOIS, 2000; POTTS, 2011; ZHU, 2010; CARVALHO, 2011; NOVOSELOV, 2012). 
No processo de inibição da corrosão, a resina epóxi é o revestimento polimérico mais utilizado. Isso ocorre devido às suas excelentes propriedades, alta resistência à tração, baixa retração estrutural pós-cura, boa resistência química e à corrosão, elevada adesão e ótima estabilidade dimensional. A adição de nanopatículas de grafeno potencializa as propriedades anticorrosivas do nanocompósito polimérico, atuando como uma barreira de alta energia, impedindo a difusão do oxigênio e da água, dificultando os processos corrosivos. Outro fator importante é que, apesar do grafeno ser adicionado em pequenas quantidades, seu desempenho se iguala ou excede o desempenho de cargas tradicionais, utilizadas em maior proporção (PRASAI et al., 2012; JIANG et al., 2013; LIU et al., 2013; NAYAK et al., 2013; ZHANG et al., 2013).

$\mathrm{Na}$ indústria, os revestimentos poliméricos normalmente estão expostos a ambientes com interações mecânicas-térmicas-corrosivas. Portanto, para o desenvolvimento de propriedades anticorrosivas eficientes, faz-se necessário que o revestimento polimérico tenha boas propriedades térmicas e mecânicas. Como exemplo, se a barreira do revestimento for mecanicamente ou termicamente modificada, o eletrólito que ele está exposto, penetra por dentro do revestimento, promovendo a corrosão do metal. Por isso, as propriedades térmicas e mecânicas são essenciais para o estudo do comportamento anticorrosivo dos compósitos nanoaditivados com grafeno (VERKER et al., 2009; MIRABEDINI et al., 2013; ZHANG et al.,2015).

$\mathrm{Na}$ literatura científica, existem muitos trabalhos envolvendo o sistema epóxi/nanoaditivos de carbono. A seguir, será feita uma breve síntese dos trabalhos mais importantes envolvendo o sistema epoxídico nanoativado, com enfâse no processo de caracterização das propriedades físico-químicas do grafeno repercutindo efeitos em suas propriedades anticorrosivas.

O impacto nas propriedades anticorrosivas foi estudado por Harb, 2015, que sintetizou revestimentos anticorrosivos híbridos de siloxano-PMMA reforçados com nanotubos de carbono, óxido de grafite e óxido de grafite reduzido pelo processo sol-gel. Constatou, através da Espectroscopia de Impedância Eletroquímica (EIS), que a adição de óxido de grafite manteve a alta eficiência anticorrosiva da matriz híbrida. E amostras de óxido de grafite reduzidas com maior razão molar ácido ascórbico/GO apresentaram maior ângulo de contato (mais hidrofóbica) e maior proteção anticorrosiva. 
Zhang e colaboradores (2015) prepararam compósitos aditivados com nanofolhas de grafeno, nas proporções: $0.1 \%, 0.4 \%$ e $0.7 \%$ em massa de grafeno, pelo método de síntese in situ. Para a análise do comportamento anticorrosivo, realizaram ensaios eletroquímicos. Além de medir propriedades mecânicas, através da técnica de nanoindentação, com o intuito de maximizar as propriedades anticorrosivas do sistema. As medidas eletroquímicas e os ensaios de imersão em $\mathrm{NaCl}$, indicaram que o revestimento à base de resina epóxi aditivadas e GNS (graphene nanosheets) com propriedades térmicas e mecânicas superiores, apresentaram melhor resistência à corrosão. Tiwari e colaboradores (2017) caracterizaram eletroquimicamente os revestimentos aditivados com grafeno multicamadas e compararam com os resultados disponíveis na literatura. Concluiram que o revestimento contendo grafeno multicamadas fornecia uma resistência à corrosão significativa por longos períodos de tempo ( 400h), quando comparado com revestimentos de grafeno monocamada. Já Prasai e colaboradores (2012) estudaram folhas atomicamente finas de grafeno como revestimento protetor na inibição da corrosão do $\mathrm{Cu}$ e Ni. Através de medições de voltametria cíclica, constataram que o revestimento de grafeno inibe a corrosão do metal e a redução do oxigênio. Além disso, quantificaram as taxas de corrosão através da análise das Curvas de Tafel e concluíram que as películas de cobre revestidas com o grafeno corroem sete vezes mais lentamente numa solução de $\mathrm{Na}_{2} \mathrm{SO}_{4}$ comparado ao cobre puro. Já as películas de níquel revestidas com grafeno crescido diretamente no substrato, corroem vinte vezes mais lentamente quando comparado à superfície de níquel revestida com quatro camadas de grafeno depositadas mecanicamente. Rajabi e colaboradores (2014) investigaram as propriedades anticorrosivas dos nanocompósitos aditivados com óxido de grafeno através da técnica de Espectroscopia de Impedância Eletroquímica (EIS). Concluíram que a proteção anticorrosiva dos revestimentos foi melhorada com adição de óxido de grafeno (OG) na matriz polimérica. Além de alcançarem melhores resultados de resistência à corrosão para revestimentos aditivados entre 0 e $25 \%$ em peso de OG. 


\section{Materias e métodos}

\subsection{Materiais}

\subsubsection{Grafeno}

O grafeno utilizado neste trabalho foi produzido pelo CTNano (Centro de Tecnologia em Nanomateriais) da UFMG, sintetizado via rota química, por oxidação e posterior redução do grafite. A oxidação foi realizada pelo método de Hummers modificado, em seguida foi esfoliado e reduzido termicamente via microondas (ZHU et al., 2010). A técnica utilizada permite a esfoliação e redução simultânea do óxido de grafite através de irradiações rápidas via microondas, produzindo o óxido de grafeno reduzido. A Figura 14 mostra o aspecto macroscópico do grafeno obtido por esta metodologia.

Figura 14: Aspecto do Óxido de Grafeno Reduzido (OGR) utilizado nesta dissertação.

\subsubsection{Substrato}

O substrato utilizado foi o aço carbono AISI 1020 cuja composição química padrão está detalhada na Tabela 02. A composição química percentual 
para cada componente é estipulada e a diferença equivale à composição do elemento ferro predominante no material.

Tabela 02: Composição química em percentual do aço AISI 1020 utilizado.

\begin{tabular}{cccccc}
\hline ABNT/SAE/AISI & C & Mn & P máx & S máx & Fe \\
\hline AÇO 1020 & $0.18-0.23$ & $0.30-0.60$ & 0.04 & 0.05 & - \\
\hline
\end{tabular}

Para os ensaios de corrosão, os corpos de prova foram usinados em duas configurações como mostrado na Figura 15, onde a corresponde às dimensões de $25 \mathrm{~cm}$ de comprimento, $25 \mathrm{~cm}$ de largura e $0.6 \mathrm{~cm}$ de espessura para o ensaio de corrosão em célula atlas, e b com dimensões de $15 \mathrm{~cm}$ de comprimento, $10 \mathrm{~cm}$ de largura e $0.6 \mathrm{~cm}$ de espessura para os ensaios cíclicos de corrosão. Observa-se que para os testes de corrosão apenas uma das faces, com áreas de $625 \mathrm{~cm}^{2}$ e 150 $\mathrm{cm}^{2}$, dos corpos de prova é utilizada, correspondendo a primeira e segunda configuração dos CP's, respectivamente.

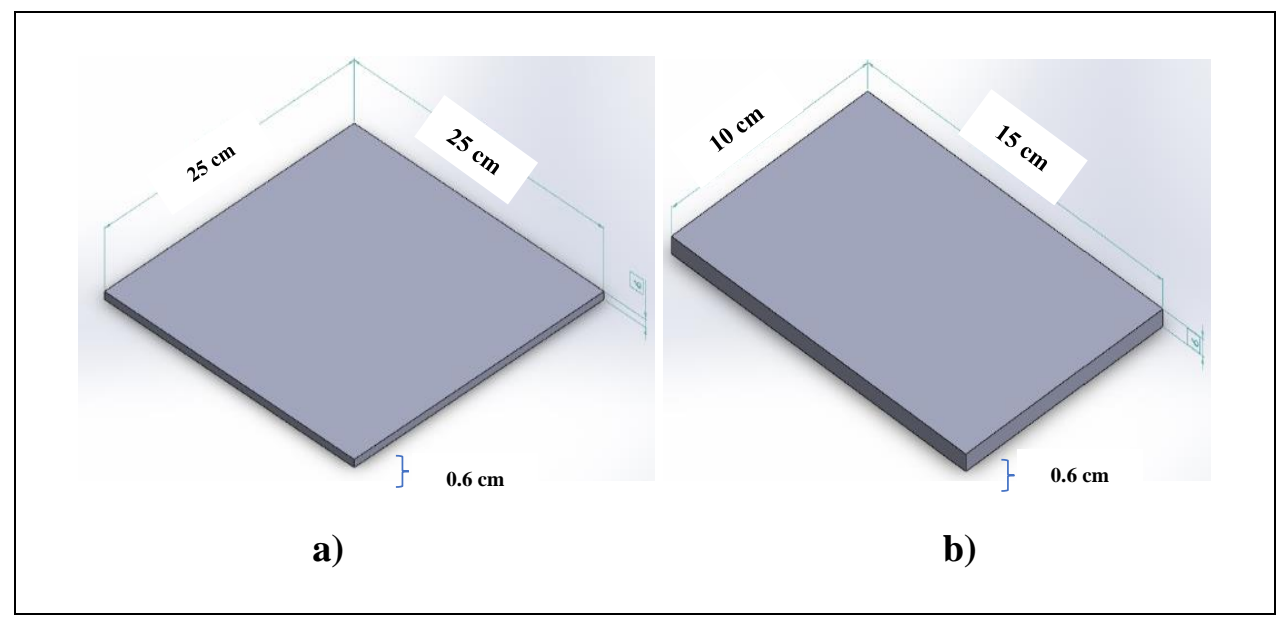

Figura 15: Dimensões dos corpos de prova para a a) primeira e b) segunda configurações.

\subsubsection{Revestimento}

O revestimento polimérico depositado no substrato metálico foi a tinta epóxi Novolac tipo II, fabricada pela empresa WEG Tintas. Considerado como um primer epóxi bi-componente com alta espessura $(400$ a $500 \mu \mathrm{m})$ e alto teor de sólidos $(96 \% \pm 1)$. A composição do componente A desta tinta é baseada no bisfenol $\mathrm{F}$ e aproximadamente $45 \%$ de cargas inorgânicas. O componente B é constituído pelo polímero com formaldeído 1,3 - benzenodimetanamina e fenol. 
Este material é conhecido por possuir excelente resistência química, boa resistência à abrasão e impacto, proteção anticorrosiva, excelente dureza superficial e impermeabilidade. A Norma Petrobras N2912 fixa as características, verificáveis em laboratório, exigíveis para a tinta epóxi Novolac bicomponente.

A aditivação do componente $\mathrm{A}$ da tinta foi realizada pelo CTNano, utilizando a técnica que consiste na produção de um masterbatch (concentrado) de grafeno em resina epóxi (DGEBA), diluiu-se $1.71 \mathrm{~g}$ da mistura DGEBA mais grafeno $(3 \% \mathrm{~m} / \mathrm{m})$ com $50 \mathrm{~g}$ da tinta, a fim de alcançar $0.1 \%$ de grafeno no componente A da tinta Wegpoxi. Para a dispersão do grafeno na tinta, foi executada uma dispersão mecânica através de moinho de rolos. A resina epóxi DGEBA foi escolhida por apresentar uma composição similar a epóxi e por misturar-se completamente ao componente da tinta trabalhada.

O masterbach foi processado em altas concentrações de grafeno em pequenas quantidades de resina DGEBA, evitando possíveis interferências no sistema. A coloração variou, gradativamente, em tons de cinza, comprovando a incorparação de grafeno em pequenas concentrações. Nesta dissertação, a tinta foi aditivada em três concentrações de grafeno (I. $0.1 \% \mathrm{~m} / \mathrm{m}$, II. $0.25 \% \mathrm{~m} / \mathrm{m}$ e III. $0.5 \% \mathrm{~m} / \mathrm{m})$. $\mathrm{O}$ aspecto visual da coloração da tinta após a aditivação pode ser observado na Figura 16.

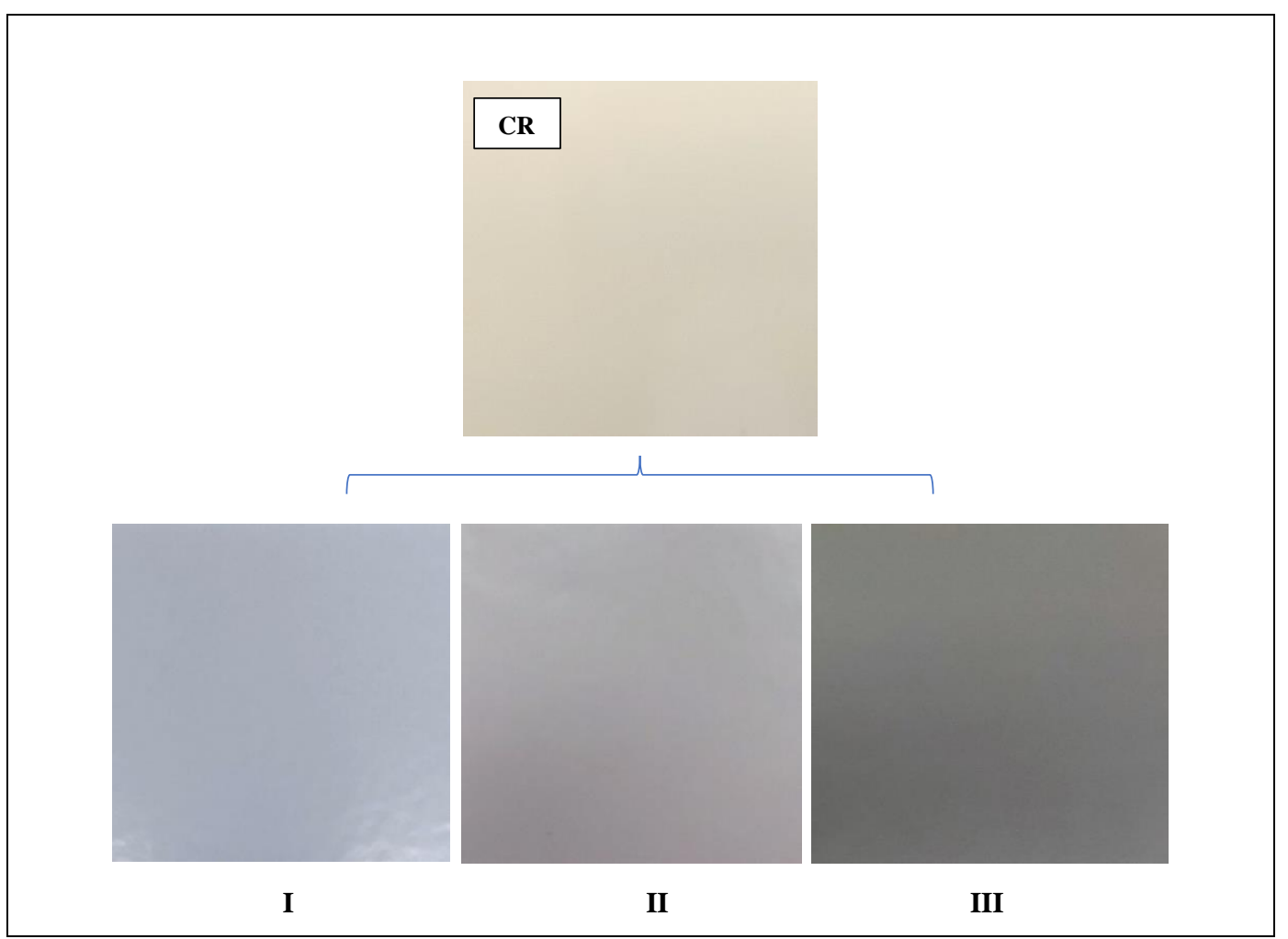

Figura 16: Aspecto visual da tinta após aditivação nas concentrações I, II e III. 


\subsection{Matriz de Ensaios}

Os ensaios realizados nesta dissertação se dividiram em dois grupos:

- Caracterização físico-química (grafeno e nanocompósito pós-cura);

- Ensaios de corrosão do sistema (substrato + revestimento).

As técnicas utilizadas na caracterização do pó de grafeno foram: Difração de Raios X (DRX), Espectroscopia Raman, Microscopia Eletrônica de Varredura com Emissão de Campo (FEG) e Microscopia de Força Atômica (AFM).

A caracterização dos nanocompósitos foi realizada em três condições (I, II e III) e as técnicas utilizadas foram: Espectrocopia Raman, FTIR e Efeito Hall. Para a realização dos ensaios foram confeccionadas pastilhas de nanocompósitos curados nas condições a seguir: I. Tinta como recebida (CR); II. e III. Tintas aditivadas com concentração de $0.1 \%$ e $0.5 \%$ em massa de grafeno.

Tabela 03: Matriz de caracterização físico-química do grafeno e nanocompósitos.

\begin{tabular}{|c|c|c|c|}
\hline & \multicolumn{3}{|c|}{ CARACTERIZAÇÃO } \\
\hline & GRAFENO & NANOCOMPÓSITO & DESCRIÇÃO \\
\hline DRX & & & Identificação Química \\
\hline RAMAN & & & $\begin{array}{l}\text { Identificação das bandas } \\
D, D^{\prime} \text { e G }\end{array}$ \\
\hline FTIR & & & $\begin{array}{l}\text { Identificação dos grupos } \\
\text { funcionais }\end{array}$ \\
\hline MEV-FEG & & & Análise morfológica \\
\hline AFM & & & $\begin{array}{l}\text { Análise } \\
\text { Estrutural e morfológica }\end{array}$ \\
\hline EFEITO HALL & & & $\begin{array}{l}\text { Determinação da } \\
\text { condutividade elétrica }\end{array}$ \\
\hline PULL OFF & SUBSTR & ATO REVESTIDO & Adesão \\
\hline
\end{tabular}


Para avaliar o comportamento anticorrosivo do revestimento, foram realizados dois tipos de ensaios de corrosão: Célula Atlas e Ensaios Cíclicos. Os parametros utilizados nos ensaios de corrosão estão descritos na Tabela 04.

Tabela 04: Parâmetros utilizados nos ensaios de corrosão.

\begin{tabular}{|c|c|c|c|}
\hline \multicolumn{4}{|c|}{ ENSAIOS DE CORROSÃO } \\
\hline ENSAIO & TEMPO & SOLUÇÃO & CONDIÇÕES \\
\hline $\begin{array}{c}\text { CÉLULA } \\
\text { ATLAS }\end{array}$ & 83 dias & $\begin{array}{l}\text { Solução salina com } 70.000 \\
\text { ppm }+21 \mathrm{~g} \text { de } \mathrm{C}_{2} \mathrm{H}_{3} \mathrm{NaO}_{2}\end{array}$ & $\begin{array}{l}\mathrm{T}_{\text {Interno }}=60^{\circ} \mathrm{C} \\
\mathrm{T}_{\text {Externo }}=20^{\circ} \mathrm{C}\end{array}$ \\
\hline $\begin{array}{l}\text { ENSAIO } \\
\text { CÍCLICO }\end{array}$ & $\begin{array}{c}175 \text { dias } \\
\text { (25 ciclos) }\end{array}$ & $\begin{array}{c}\text { Ciclo: } \\
\text { 72h Salt Spray }+24 \mathrm{~h} \text { à }-10{ }^{\circ} \mathrm{C} \\
+72 \mathrm{~h} \text { à radiação UV }\end{array}$ & $\begin{array}{c}\mathrm{T}_{\text {Salt Spray }}=40^{\circ} \mathrm{C} \\
\mathrm{T}_{\text {Freezer }}=-11^{\circ} \mathrm{C} \\
\mathrm{T}_{\text {Radiação UV }}=40^{\circ} \mathrm{C}\end{array}$ \\
\hline
\end{tabular}

\subsection{Métodos}

Neste item serão descritas as técnicas e os parâmetros utilizados no processo experimental.

\subsubsection{Caracterização do óxido de grafeno reduzido (OGR)}

\subsubsection{Difração de Raios-X (DRX)}

O objetivo das análises por DRX foi a determinação da distância interplanar do grafeno. Utilizando o fenômeno de difração é descrito pela Lei de Bragg, sabemos que:

$$
d=\frac{\lambda}{2 \operatorname{sen} \theta}
$$

Sendo $d$ a distância interplanar, $\lambda$ o comprimento de onda da radiação empregada e $\theta$ é o ângulo de Bragg no plano referente ao pico obtido. A Lei de 
Bragg correlaciona a intensidade dos raios utilizados, ângulo de difração e a distância entre os planos que a originam. Ray e Okamoto (2003) obtiveram o espaçamento $d$ entre as camadas atômicas de nanopartículas lamelares do grafeno. As análises do grafeno por difração de raios- $\mathrm{X}$ foram realizadas no Laboratório de Difração de Raios- X da PUC-Rio, em um difratômetro D8-Discover da marca Bruker utilizando tubo de cobre, com comprimento de onda $(\mathrm{Cu}-\alpha)$ 1,54 , operado a $40 \mathrm{kv}$ e $40 \mathrm{~mA}$. Nas análises das nanolâminas de grafeno foram utilizados porta amostra de safira, ângulo $2 \theta$ com varredura de $10^{\circ}$ a $60^{\circ}$, passo de 0,05 a temperatura ambiente.

\subsubsection{Espectroscopia Raman}

A Espectroscopia Raman é uma técnica de caracterização não destrutiva, fornecendo informações detalhadas sobre as bandas de energia dos materiais analisados.

Esta técnica é função da detecção de luz espalhada inelásticamente pelo material, proviniente da interação de uma radiação monocromática e está diretamente relacionada com as transições vibracionais e rotacionais das moléculas. Lobo et al., (2005) confirmaram que uma das principais aplicações da técnica é na caracterização de materiais carbonosos, identificando os tipos de ligações e o grau de desordem da rede cristalina.

As análises de Raman para o grafeno foram realizadas a temperatura ambiente em um Microscópio Confocal Raman da marca Horiba, cuja fonte de excitação foi um laser verde com comprimento de onda de $532 \mathrm{~nm}$ e o tempo de aquisição das medidas foi de $5 \mathrm{~s}$.

As análises de espectroscopia Raman da tinta epóxi Novolac e dos nanocompósitos aditivados com grafeno foram realizadas com o espectrômetro Raman Statio Perkin Elmer no Laboratório de Biocombustíveis (LABIO)Departamento de Química - PUC/Rio. O intervalo dos dados foi de $2.00 \mathrm{~cm}^{-1}$, com 10 varreduras e tempo de exposição de $1.0 \mathrm{~s}$. O comprimento de onda do laser utilizado é $532 \mathrm{~nm}$. O intuito da análise é comparar os espectros e analisar a influência do polímero no comportamento das bandas D, D’ e G do grafeno. 


\subsubsection{Microscopia de Força Atômica (AFM)}

As imagens por AFM foram obtidas, no Laboratório de Caracterização de Nanomateriais e Compósitos da PUC-Rio, num equipamento da marca Bruker, modelo Multimode 8, e software de análise das imagens Nanoscope_9 Analyses. Para analisar topografia, altura e morfologia as imagens foram capturadas no modo peak force QNM e frequência de ressonância de $79 \mathrm{KHz}$.

De modo a observar as folhas de grafeno OGR e para aumentar o grau de dispersão destas folhas às amostras foram suspensas em álcool isopropílico durante $1 \mathrm{~h}$ em banho de ultrassom. Como as folhas de óxido de grafeno reduzido têm elevada tendência à aglomeração, após o banho de ultrassom, foi realizado o Spin Coating da suspensão com dispersão em baixa concentração. A amostra suspensa foi rotacionada e depositada em substrato de silício para posterior análise por AFM.

\subsubsection{Microscopia Eletrônica de Varredura com Emissão de Campo (MEV-FEG)}

As análises de microscopia de varredura com emissão de campo foram realizadas no Laboratório de Microscopia Eletrônica (LME) da PUC-Rio, com o intuito de caracterização morfológica. O equipamento utilizado na análise foi o Field Emission Scanning Electron Microscope, marca Jeol JSM-6701F, operando a $1 \mathrm{kV}$ e $9 \mu \mathrm{A}$. Para aumentar a dispersão, o pó de grafeno foi suspenso em álcool isopropílico durante 20 minutos no banho de ultrassom e em seguida foi gotejado sobre a fita de carbono.

\subsubsection{Espectroscopia no Infravermelho por Transformada de Fourier (FTIR)}

Os espectros de absorção na região do infravermelho médio (4000 a 550 cm-1) foram obtidos em um espectrofotômetro Perkin-Elmer Spectrum 400 FT-IR 2000, no Laboratório de Biocombustíveis (LABIO)- Departamento de Química PUC/Rio. Os espectros foram obtidos com as amostras dos nanocompósitos em estado sólido, com acessório ATR, resolução de $4 \mathrm{~cm}^{-1}$ e 4 scans. 


\subsubsection{Condutividade Elétrica (Efeito Hall)}

A condutividade elétrica dos nanocompósitos foi medida pelo método 4 pontas, no equipamento Hall Effect Measurement System da marca Ecopia, modelo HMS 3000, no Laboratório de Espectroscopia Óptica e Optoeletrônica Molecular da PUC/Rio. Os corpos de prova para esse ensaio foram confeccionados em molde de silicone e cortados no equipamento Minitom, em formato de pastilha quadrada com dimensões de $1 \mathrm{x} 1 \mathrm{~cm}$ e espessura de $1 \mathrm{~mm}$. Os ensaios foram realizados em corpos de prova nas condições como recebida sem aditivação, aditivada $0,1 \%$ e aditivada $0,5 \%$.

\subsubsection{Microscopia Eletrônica de Varredura (MEV)}

Anteriormente as análises no $\mathrm{MEV}$, as amostras do corte transversal do sistema revestimento/substrato foram embutidas em resina, lixadas (lixa fina 1200) e polidas. Para as análises, as amostras foram metalizadas com ouro, depositado pelo equipamento sputter coater da marca Balzers modelo SCD 050. As micrografias de microscopia eletrônica de varredura (MEV) foram obtidas num equipamento Jeol, modelo JSM 6510LV. O objetivo da análise foi a investigação da aderência na interface entre o revestimento epóxi e o substrato metálico.

\subsubsection{Medida de Aderência (Pull Off)}

O método conhecido como pull-off é um dos testes mais utilizados para medir a aderência de revestimentos orgânicos. O método de ensaio consiste em colar um pino métálico à superfície do revestimento, em seguida aplicar uma força trativa até arrancá-lo do substrato revestido. Os resultados do teste são medidos em função da força trativa aplicada (através dos valores de tensão de ruptura em $\mathrm{MPa})$ e a respectiva falha observada, podendo ser adesiva ou coesiva. $\mathrm{O}$ esquema configuracional das possíveis falhas que ocorrem entre as camadas envolvidas no teste, se o desprendimento ocorre entre o substrato metálico e o revestimento $(\mathrm{A} / \mathrm{B})$; ou entre a primeira e a segunda demão do revestimento $(\mathrm{B} / \mathrm{C})$; ou entre a segunda demão do revestimento e a cola $(\mathrm{C} / \mathrm{Y})$ ou entre o pistão e a cola (Y/Z), 
podem ser visualizadas nas Figuras 17 e 18. A norma que regulamenta a realização do teste é a Norma ASTM D 4541-2.

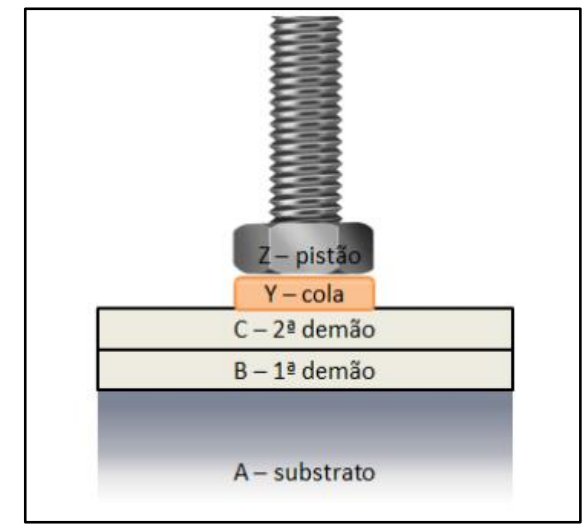

Figura 17: Esquema das camadas envolvidas no teste.

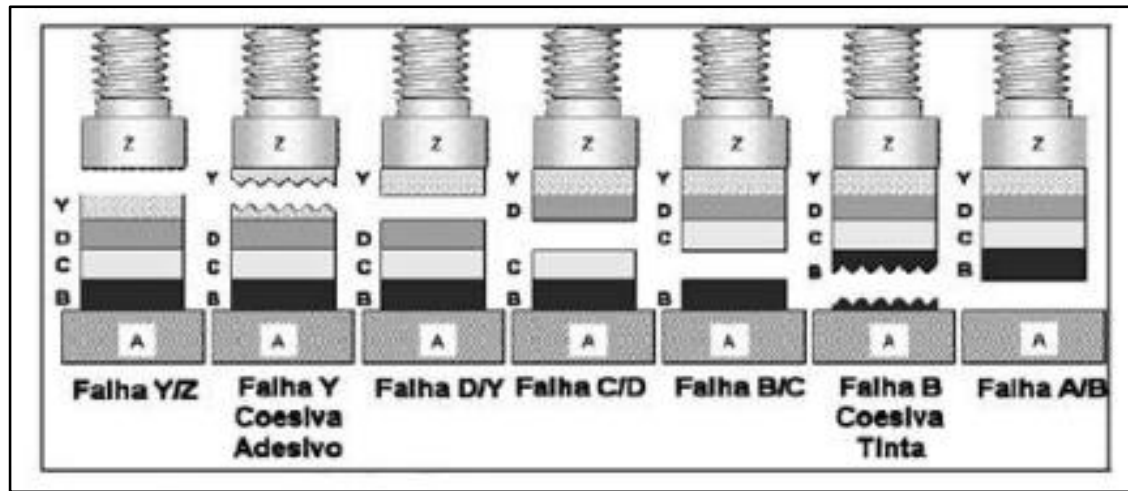

Figura 18: Esquema das camadas suscetíveis a falhas conforme norma ABNT NBR 15877

O Teste de Pull Off foi realizado no equipamento PATTI 100 (Figura 19), com gás $\mathrm{CO}_{2}$ de linha a 100 psi, pistão $\mathrm{F}-8$, à temperatura ambiente $23^{\circ} \mathrm{C} \mathrm{e}$ umidade $81 \%$, regulado numa taxa de $1 \mathrm{MPa} / \mathrm{s}$.

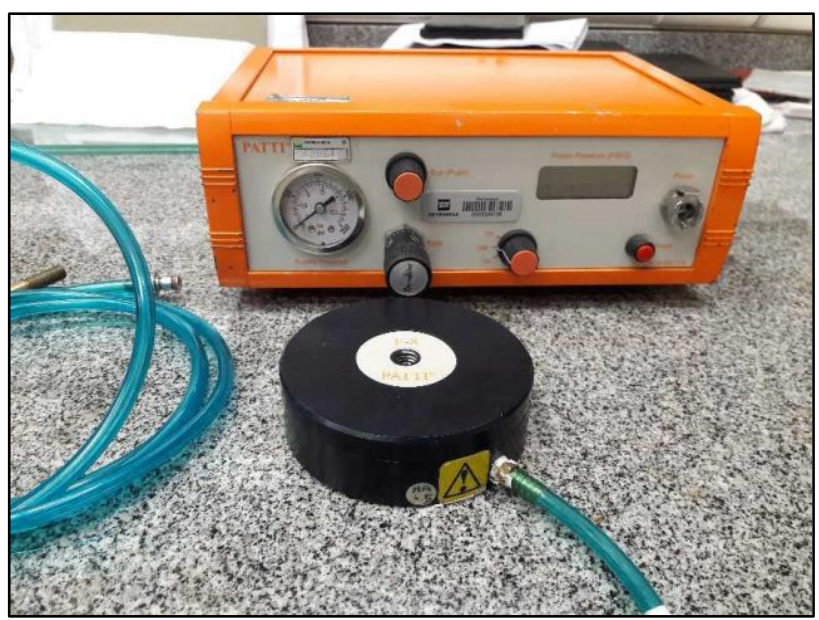

Figura 19: Instrumento portátil para medição de aderência Pull Off. 


\subsubsection{Preparação das amostras de metal revestido com tinta Epóxi}

Todo o protocolo de preparação das amostras para os ensaios de corrosão foi realizado no CENPES (Centro de Pesquisas e Desenvolvimento Leopoldo Américo Miguez de Mello) em parceria com o Laboratório de Revestimentos Anticorrosivos.

\subsubsection{Rugosidade Superficial do Substrato}

A limpeza de uma superfície através do jateamento com granalhas pode ser considerada como uma operação de bombardeamento, em que inúmeras partículas abrasivas são arremessadas em alta velocidade contra o alvo. O aumento na rugosidade superficial do substrato com o jateamento abrasivo tem como objetivo aumentar a aderência entre o revestimento (tinta) e o metal substrato.

A superfície dos corpos de prova metálicos para os ensaios de corrosão foram jateadas com granalhas de aço inox G25, na cabine jateadora da marca Polo Ar, com tratamento superficial SA $2^{1 / 2}$, que significa limpeza por jato abrasivo a fundo. Após o processo de jateamento abrasivo, foram realizadas medidas de rugosidade superficial no rugosímetro analógico da marca Elcometer. Análise por Microscopia Ótica para quantificação da rugosidade superficial do aço 1020, também foram realizadas. $\mathrm{O}$ equipamento utilizado nessa análise foi o Microscópio Óptico Motorizado Axio Imager M2M da marca Zeiss.

\subsubsection{Aplicação do Revestimento}

O processo de homogeneização das tintas bicomponentes seguiu a sequência a seguir:

I. Homogeneização o componente A da tinta;

II. Homogeneização o componente B da tinta;

III. Adicionar o comp. B no comp. A respeitando a relação de mistura;

IV. Homogeneizar a mistura com agitação mecânica intensa.

V. Após o processo, a tinta estará pronta para uso. 
A homogeneização mecânica é realizada até que a consistência e a cor da tinta resultante estejam homogêneas a olho nu, para todo volume de tinta (GNNECO et al., 2003).

Após o processo de mistura, adiciou-se um solvente GTA 220, da marca International composto basicamente por aromáticos e oxigenados. $\mathrm{Na}$ sua composição a proporção em peso predominante é de xileno e nafta, com proporções menores de Butan-1-ol, 1,2,4-Trimetilbenzeno, Etilbenzeno e 1,3,5Trimetilbenzeno.

A aplicação do revestimento orgânico (tinta) na superfície do aço estudado foi feito através da pistola de compressão por ar comprimido da marca DeVilbiss. A proporção da mistura dos componentes A e B foi, respectivamente, 100 para 5,5 em massa (g) com espessura por demão entre 400 - $500 \mu \mathrm{m}$. Para aplicação em todos os corpos de prova utilizou-se $240 \mathrm{~g}$ do componente A e $13.2 \mathrm{~g}$ do componente $\mathrm{B}$, respeitando as proporções determinadas pelo fabricante. A massa de solvente utilizado foi de $25.5 \mathrm{~g}$, respeitando a proporção de $10-15 \%$ do peso de tinta trabalhado.

Após a aplicação do revestimento, o tempo de cura do sistema (substrato + revestimento) foi $168 \mathrm{~h}$ ( 7 dias) a $25{ }^{\circ} \mathrm{C}$, respeitando o tempo de secagem para manuseio definido pelo manual do frabricante.

\subsubsection{Ensaios de corrosão}

Os ensaios de corrosão, imersão em célula atlas e ensaios cíclicos, foram realizados no CENPES (Centro de Pesquisas e Desenvolvimento Leopoldo Américo Miguez de Mello) em parceria com o Laboratório de Revestimentos Anticorrosivos.

\subsubsection{Célula Atlas}

O ensaio de corrosão em célula atlas é um teste de laboratório acelerado utilizado para avaliar o controle da corrosão de um revestimento orgânico submetido a um ambiente quimicamente agressivo. Este teste avalia a resistência de um revestimento mediante a aplicação de um gradiente de temperatura entre as superfícies interna (célula atlas) e externa (ambiente) de um corpo de prova 
revestido. Esse gradiente de temperatura promove o "efeito de parede fria" simulando condições reais de operação, como ocorre no interior de tanques não isolados ou vasos marinhos. Esse efeito gera a formação de bolhas e deslocamento na superfície dos substratos.

A geometria quadrada dos corpos de prova revestidos com tinta epóxi novolac tipo II (Figura 20 I) é determinante na montagem do sistema da célula atlas, onde o revestimento estará em contato direto com a solução salina. Baseado na Norma Petrobras N2912, a composição da solução é: 70000 ppm de íons cloreto, $21 \mathrm{~g}$ de acetato de sódio trihidratado em $1 \mathrm{~L}$ de água destilada, com pH 5, controlado com ácido clorídrico.

O aquecimento da solução é realizado por uma resistência de alta carga tipo cartucho com potência de $500 \mathrm{~W}$, ligado a um controlador que fornece a tensão necessária para realizar o aquecimento. O aquecimento é efetivado por meio de uma serpentina resistente a altas temperaturas, na qual o calor irá se dissipar gradativamente aquecendo solução até esta atingir a temperatura de 60 ${ }^{\circ} \mathrm{C}$. Para manter o sistema na temperatura de $60{ }^{\circ} \mathrm{C}$ pré- determinada, um termopar tipo J protegido por um tubo fino de vidro é mergulhado na solução salina.

A caixa controladora (1) fornece a tensão necessária para aquecer o sistema, e manter a solução na temperatura de operação e evitando qualquer oscilação no valor de temperatura de $60^{\circ} \mathrm{C}$ determinado. A evaporação da solução é controlada pelo condensador acoplado no orifício superior do sistema (2), que estará ligado diretamente a um reservatório (3), evitando qualquer perda. A numeração citada refere-se à Figura 20 II.

O revestimento em contato com a solução possui $2 / 3$ da sua área circular em contato com a solução líquida salina e o 1/3 restante, entrará em contato com o vapor da solução aquecida. O tempo mínimo para a execução completa do teste é de 2000 h (83 dias) com monitoramento diário da temperatura. A metodologia utilizada na execução do teste em célula atlas desta dissertação está em acordo com a Norma Petrobras N2912.

Foram utilizadas três células atlas, correspondendo a três pares de revestimentos com as configurações mostradas na Tabela 05, onde CR (como recebido) sem adição de grafeno e $0.1,0.25$ e $0.5 \%$ correspondendo às porcentagens de adição realizadas. 
Tabela 05: Configurações dos pares de amostras na célula atlas.

\begin{tabular}{clc}
\hline Configuração & \multicolumn{2}{l}{ Pares de amostras/condição } \\
& \multicolumn{2}{c}{$0.1 \% ;$} \\
\hline I & CR & $0.25 \%$ \\
\hline II & CR & $0.5 \%$. \\
\hline III & CR &
\end{tabular}

Todos os corpos de prova utilizados na célula atlas possuem geometria quadrada com dimensões de $25 \times 25 \times 0.6 \mathrm{~cm}$.

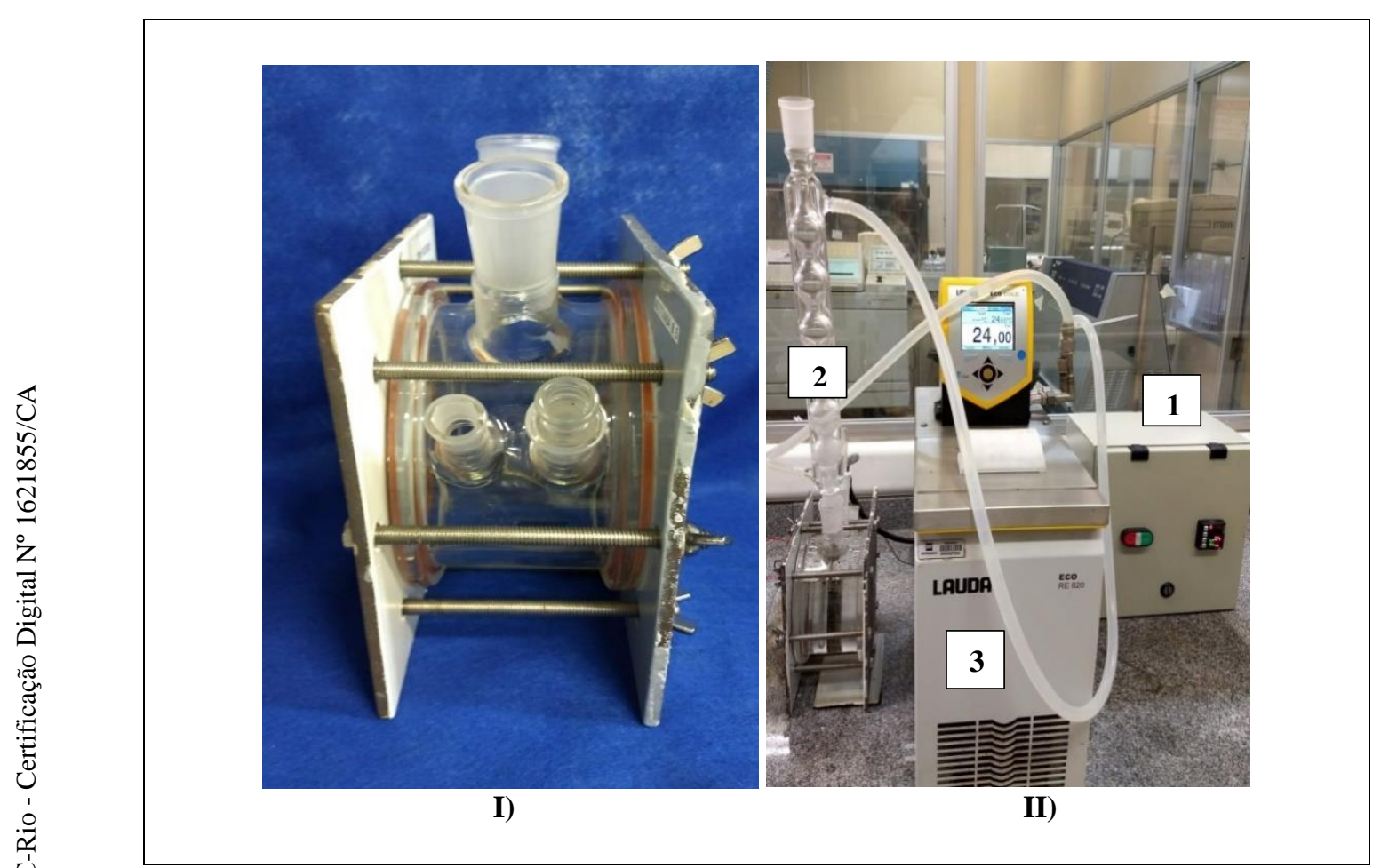

Figura 20: Configuração estrtural da Célula Atlas I) Revestimentos II) Sistema em funcionamento.

\subsubsection{Ensaios Cíclicos}

Os ensaios cíclicos objetivam garantir uma maior representatividade do ambiente em que o material está exposto. Neste teste diferentes condições ambientais são aplicadas de modo intercalado e cíclico. Onde cada ciclo é composto por diferentes etapas que representam condições específicas do meio exposto. Os ambientes de exposição mais utilizados nesta aplicação são, por exemplo, ambientes salinos, altas e baixas temperaturas asim como imersão entre outras. A definição do ciclo é feita através de uma análise prévia das condições à que o material estará exposto durante seu tempo útil. O número de repetições de 
cada ciclo não é fixo, depende do grau de discriminação das amostras que compõem o teste (ASSIS, 2000; TRIDAPALLI, 2011).

Nesta dissertação os ensaios cíclicos foram realizados respeitando a norma ISO20340, que indica que o ensaio cíclico deve ser composto de 25 ciclos de $168 \mathrm{~h}$ cada, totalizando 4200h, expondo os painéis as seguintes condições de agressividade:

I. $\quad 72 \mathrm{~h}$ (3dias) de exposição à névoa salina neutra, utilizando solução de cloreto de sódio $(\mathrm{NaCl})$ a $5 \%$ a temperatura de $40{ }^{\circ} \mathrm{C}$;

II. $\quad 24 \mathrm{~h}(1 \mathrm{dia})$ de exposição à baixa temperatura $\left(-10^{\circ} \mathrm{C}\right)$;

III. $72 \mathrm{~h}$ (3 dias) de exposição à radiação UV-A. Sendo 36h exposto à condensação e $36 \mathrm{~h}$ exposto a radiação ultravioleta, ambas à $40^{\circ} \mathrm{C}$.

Em cada painel utilizado para o ensaio cíclico, deve ser feito um entalhe paralelo à aresta de menor dimensão, com $50 \mathrm{~mm}$ de comprimento e $2 \mathrm{~mm}$ de largura, localizado a $70 \mathrm{~mm}$ da borda inferior. O entalhe deve ser feito, criando uma fresta por meio de uma incisão e removendo o revestimento até a exposição do substrato metálico.

O objetivo de posicionar um entalhe no revestimento é de possibilitar uma avaliação quantitativa de dados, tais como: formação de bolhas, propagação da corrosão e das fendas decorrentes das falhas no revestimento. Além disso, serve como parâmetro para avaliação anticorrosiva do revestimento submetido ao ensaio.

Quantitativamente, para medir o avanço da corrosão no entalhe posicionado no revestimento, devem ser realizadas leituras da largura total da região do revestimento afetado pelo processo de corrosão ou com empolamento a partir da incisão. São medidos 9 pontos ao longo do comprimento do entalhe, sendo 1 no centro e 8 (oito) medidas equidistantes $5 \mathrm{~mm}$ do centro. $\mathrm{O}$ avanço da corrosão é calculado através da equação abaixo:

$$
\mathrm{A}=\frac{\mathrm{P}-\mathrm{L}}{2}
$$

Sendo:

$\mathrm{A}=$ Avanço da corrosão/degradação, na incisão em mm; 
$\mathrm{P}=$ Valor médio da largura do revestimento afetado pela corrosão ou empolamento (média do avanço da corrosão das 9 medidas, em mm)

$\mathrm{L}=$ Largura do entalhe (2mm).

Após o ensaio cíclico, não deve ser constatada a presença de bolhas ou de pontos de corrosão superficial, nem avanço do processo corrosivo no entalhe superior a $10 \mathrm{~mm}$.

Foram fabricadas duas placas para cada condição estudada (CR, $0.1 \%$ e 0.5\%) nas dimensões de $15 \times 10 \mathrm{~cm}$ e os ciclos foram realizados respeitando a norma ISO20340. 


\section{Resultados}

\subsection{Caracterização do óxido de grafeno reduzido (OGR)}

\subsubsection{Difração de Raios-X (DRX)}

O difratograma do óxido de grafeno reduzido (OGR) está apresentado na Figura 21. Neste difratograma é possível observar a presença de um pico com intensidade elevada, $2 \theta=26.5^{\circ}$, correspondendo a um espaçamento interplanar de $0.33 \mathrm{~nm}$, seguido de três picos com baixíssima intensidade, $2 \theta=21^{\circ}, 43^{\circ}$ e $51^{\circ}$, com espaçamento interplanar de $0.42 \mathrm{~nm}, 0.21 \mathrm{~nm}$ e $0.17 \mathrm{~nm}$, respectivamente, conforme mostrado na Tabela 06. Levando em consideração que o plano referente ao grafite (002) com pico de difração em $26.5^{\circ}$ e distância interplanar de $0.33 \mathrm{~nm}$, remetendo a presença do grafite na amostra estudada. O pico de $21^{\circ}$ remete a uma tentativa de restruturação da rede cristalina reflexo do processo de redução do óxido de grafite. Este difratograma apresenta valores aproximados para picos característicos do OGR e o grafite na literatura (SALEEM et al., 2018).

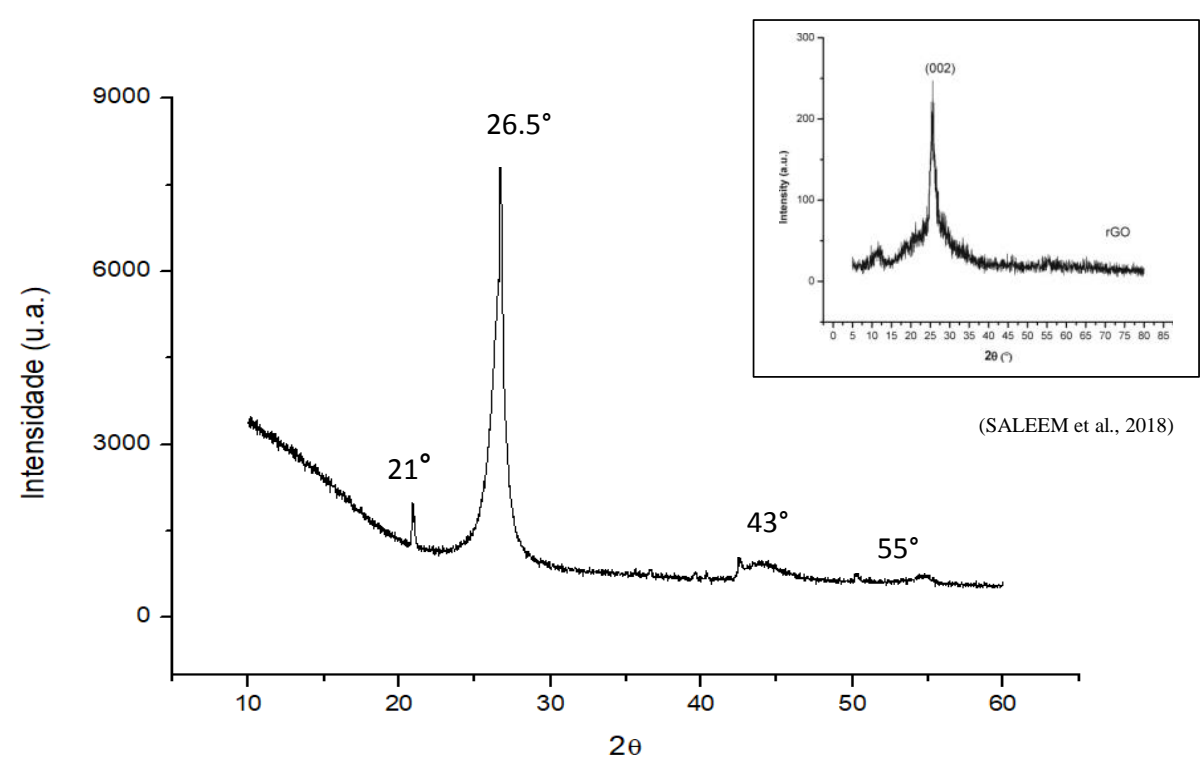

Figura 21: Difratograma da amostra de OGR. 
Tabela 06: Distâncias interplanares para picos do OGR.

\begin{tabular}{ccc}
\hline AMOSTRA & $\mathbf{2 \theta}\left(^{\circ}\right)$ & $\boldsymbol{d}_{(\mathbf{1 1 1})}$ \\
\hline \multirow{3}{*}{ OGR } & $21^{\circ}$ & $0.42 \mathrm{~nm}$ \\
\cline { 2 - 3 } & $26.5^{\circ}$ & $0.33 \mathrm{~nm}$ \\
\cline { 2 - 3 } & $43^{\circ}$ & $0.21 \mathrm{~nm}$ \\
\hline & $51^{\circ}$ & $0.17 \mathrm{~nm}$ \\
\hline
\end{tabular}

\subsubsection{Espectroscopia Raman}

A Espectroscopia Raman fornece parâmetros físico-químicos, tais como: organização estrutural, grau de pureza da amostra, defeitos, ordem de empilhamento, dentre outros. Esta análise foi realizada com base no comportamento das principais bandas características dos materiais carbonosos, que são as bandas D, G, D' e G' (MALARD et al., 2009). Na Figura 22, estão apresentados os espectros representativos, obtidos com diferentes elementos de difração (grading), para valores de 600, 1200 e 1800, os espectros apresentam diferentes intensidades, porém com tendências similares. A intensidade dos picos está diretamente relacionada com a interação entre o laser e a estrutura em camadas do OGR, sendo a intensidade dos picos característicos $1350 \mathrm{~cm}^{-1}$ (banda D), $1580 \mathrm{~cm}^{-1}$ (banda G), $1620 \mathrm{~cm}^{-1}$ (banda D') e $2700 \mathrm{~cm}^{-1}$ (banda G'). O espectro obtido está em acordo com espectros obtidos, sendo coincidente para o OGR (HACK, 2013).

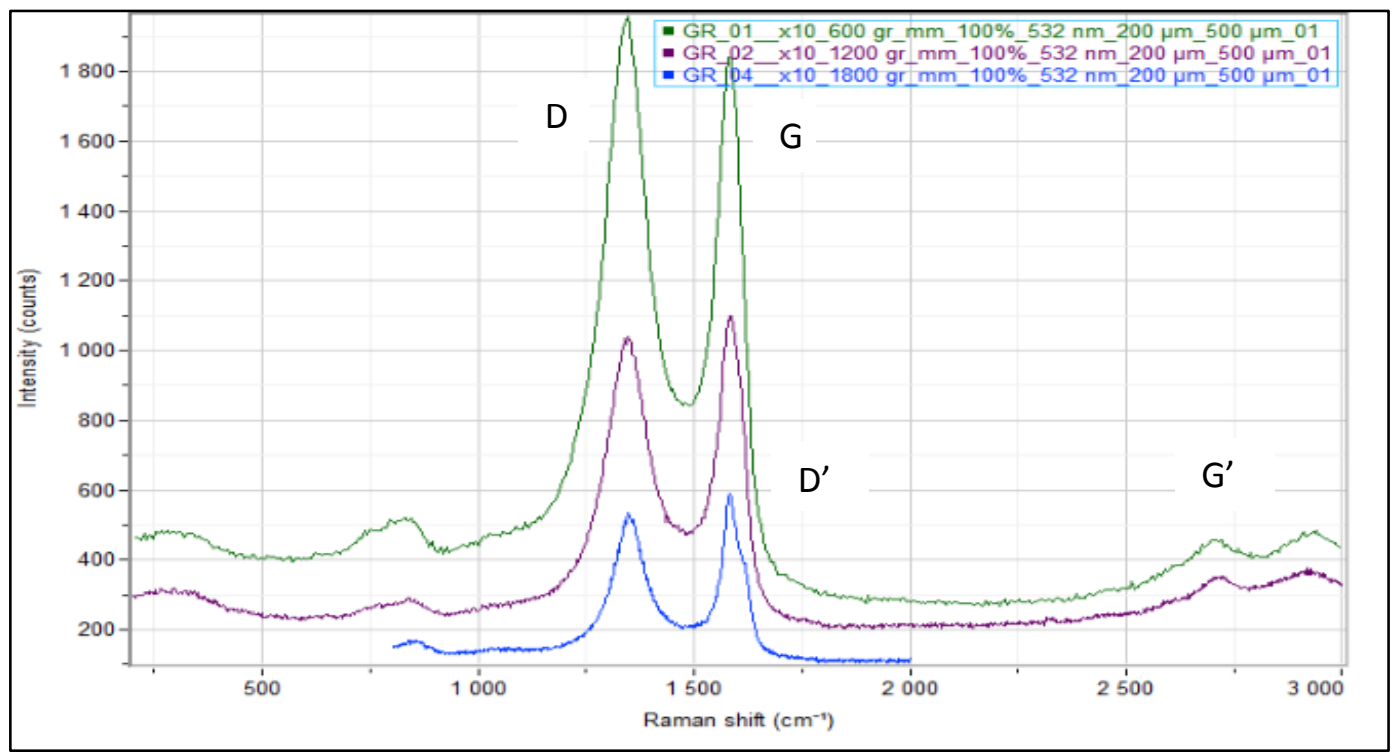

Figura 22: Espectro Raman para amostra de OGR. 


\subsubsection{Microscopia de Força Atômica (AFM)}

A estrutura e morfologia das nanofolhas de OGR foram observadas por AFM, e estão ilustradas na Figura 23. É possível visualizar, através da escala nanométrica em faixa tonal, multicamadas sobrepostas com limite geométrico bem definido. A diferença tonal sugere a existência de multifolhas de OGR espaçadas em pequenas ilhas ao longo do substrato de silício. Quantitativamente, as distâncias entre camadas foram calculadas para os dois aglomerados de folhas e podem ser vistos nas Figuras 24 e $\mathbf{2 5}$. Considerando que a primeira camada corresponde à espessura aproximada de uma folha de grafeno, a espessura média é de aproximadamente $1,53 \mathrm{~nm}$, com distâncias interplanares médias de 1,69 nm, para os dois aglomerados de OGR. Estes resultados asseguram a natureza laminar das folhas de grafeno utilizadas para aditivação. 


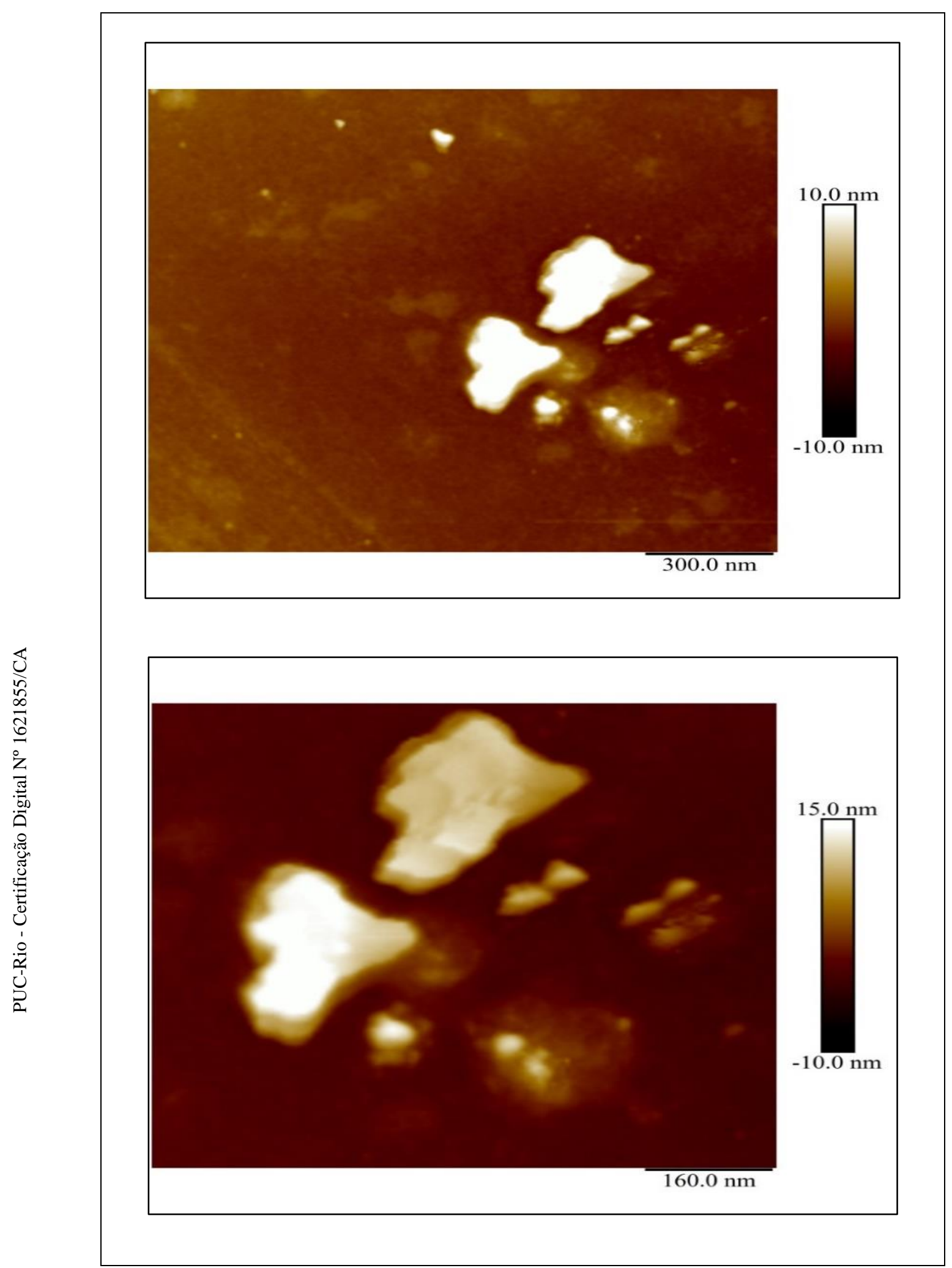

Figura 23: Micrografias de AFM para amostras de OGR. 

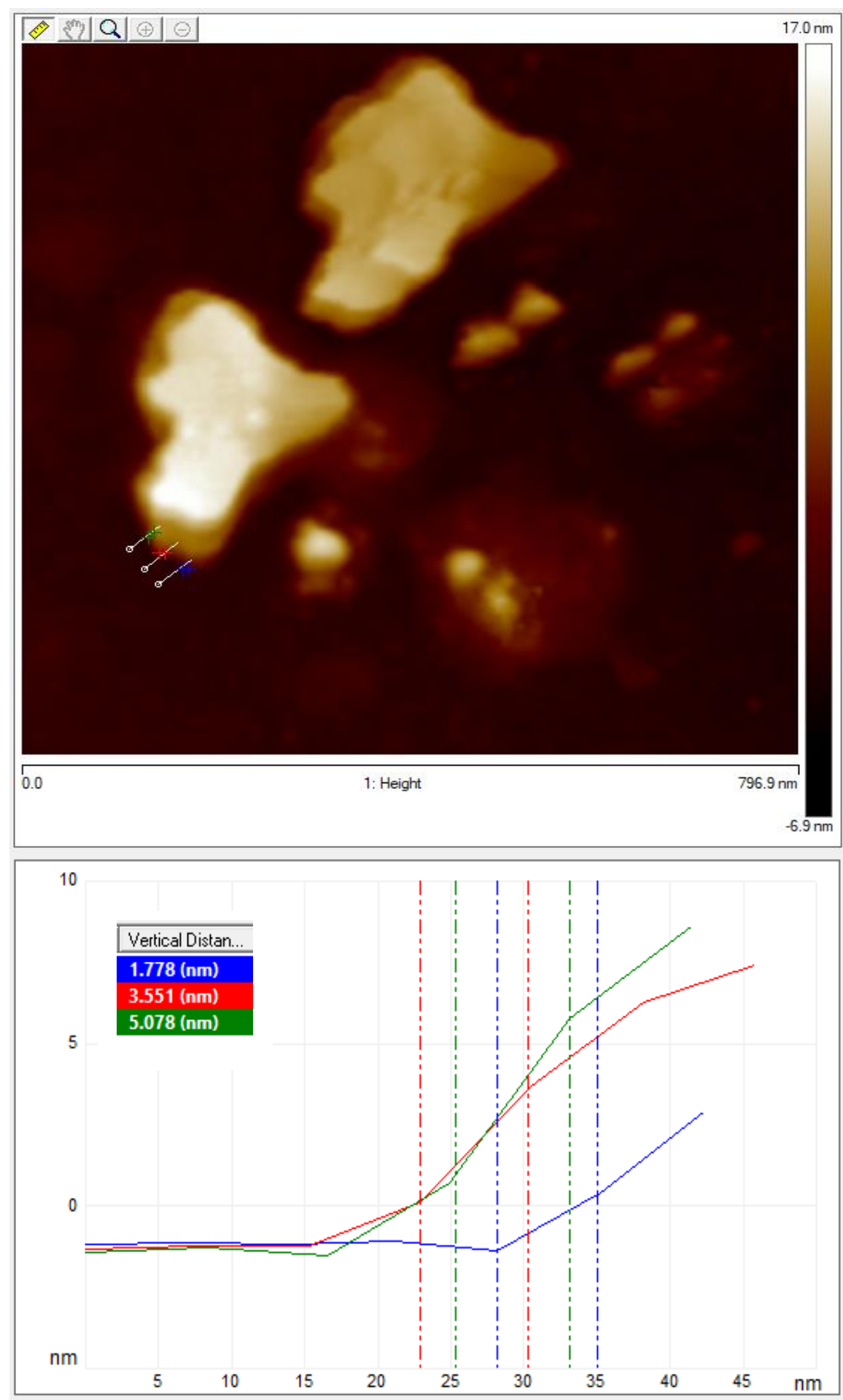

Figura 24: Distância interplanar entre folhas de grafeno. 

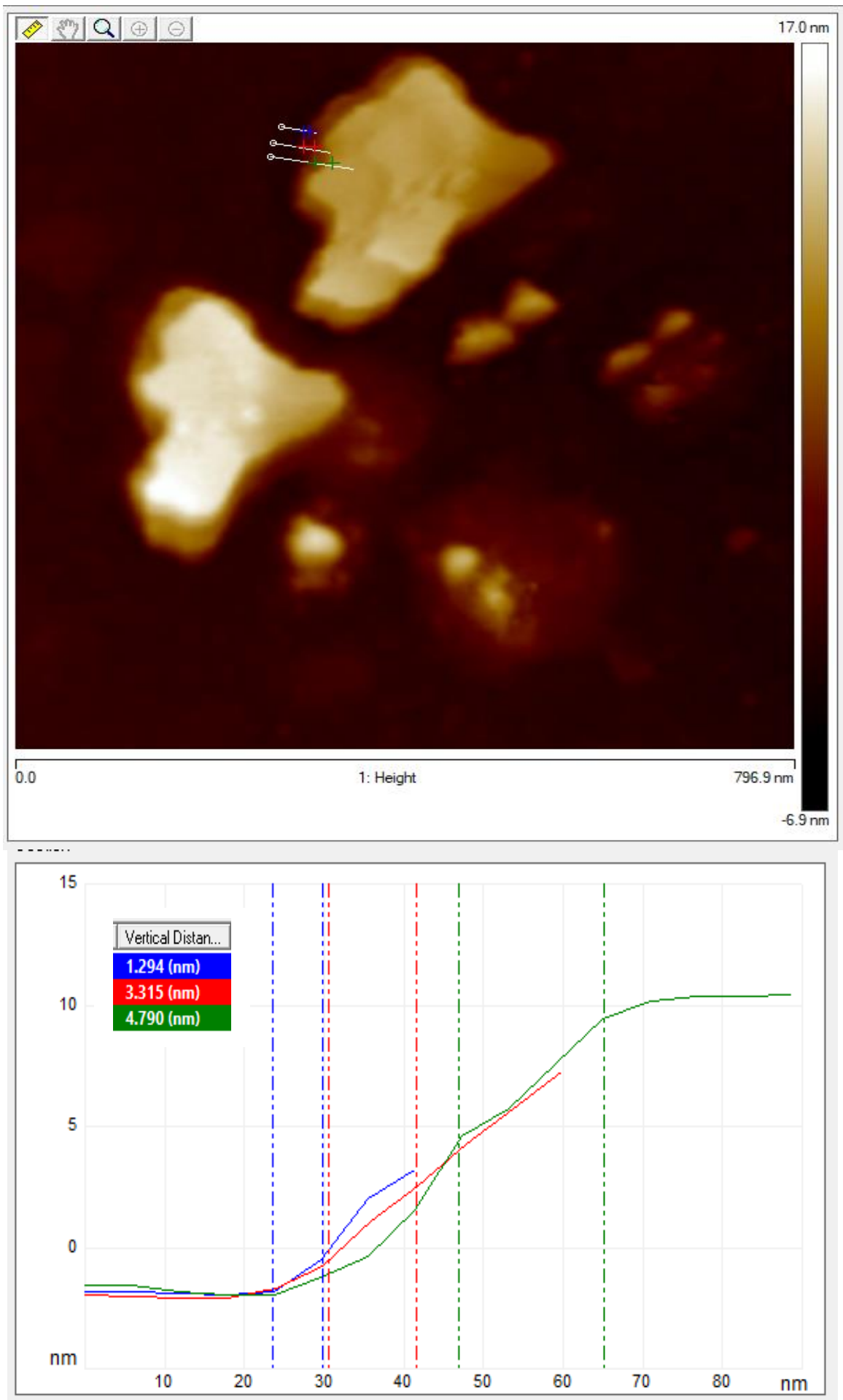

Figura 25: Distância interplanar entre folhas de grafeno. 


\subsubsection{Microscopia Eletrônica de Varredura com Emissão de Campo} (FEG)

O objetivo da análise com MEV/FEG é a caracterização morfológica das nanolâminas de OGR. As micrografias da Figura 26 mostram as folhas de OGR sobrepostas desordenadamente com espessura fina e superfície rugosa, similar a imagens obtidas na literatura. Visto que a tendência natural do grafeno, quando colocado sobre o substrato, é a superfície rugosa com a presença de vincos, uma característica intrínseca do OGR (DIZAJI et al., 2017).

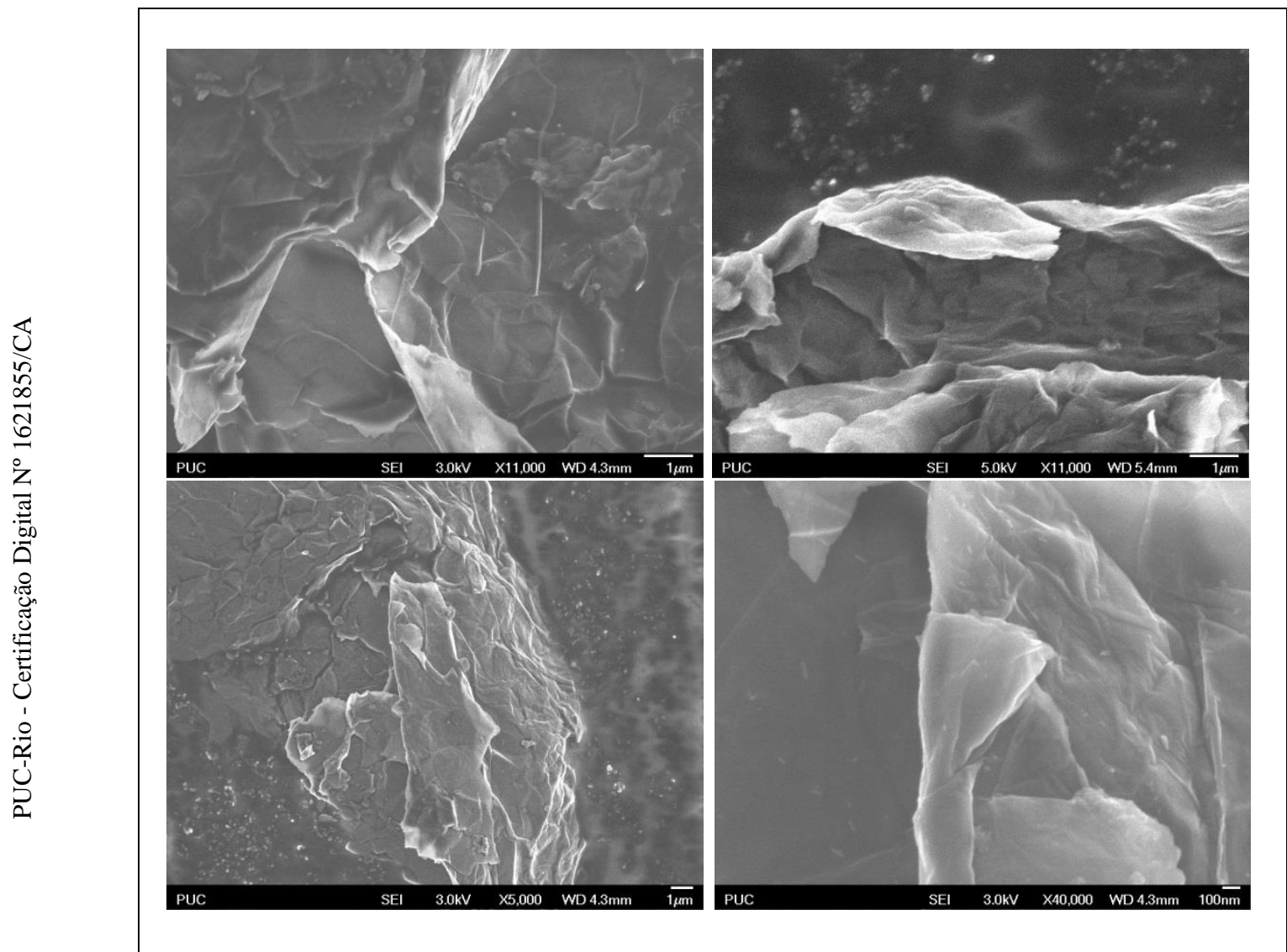

Figura 26: Micrografias de MEV/FEG do óxido de Grafeno reduzido (OGR). 


\subsection{Caracterização dos Nanocompósitos}

\subsubsection{Microscopia Eletrônica de Varredura (MEV)}

A interface do sistema substrato metálico/resina foi analisada nas condições de como recebida (sem aditivo) e aditivada. As imagens obtidas no MEV podem ser visualizadas na Figura 27. Para melhorar a visualização da interface, os cortes transversais foram embutidos em resinas, as quais não tem influência nos resultados analisados.

Em ambas as condições são possíveis analisar a espessura do revestimento, o grau de porosidade e a adesão da tinta na superfície do substrato. Como pode ser visualizada abaixo, a espessura e porosidade da condição II é inferior à condição I, considerando as mesmas condições de aplicação. Quanto à adesão da tinta no substrato, ambas as condições apresentam boa aderência na superfície rugosa do aço estudado, já que todas as imperfeições estão cobertas por revestimento.
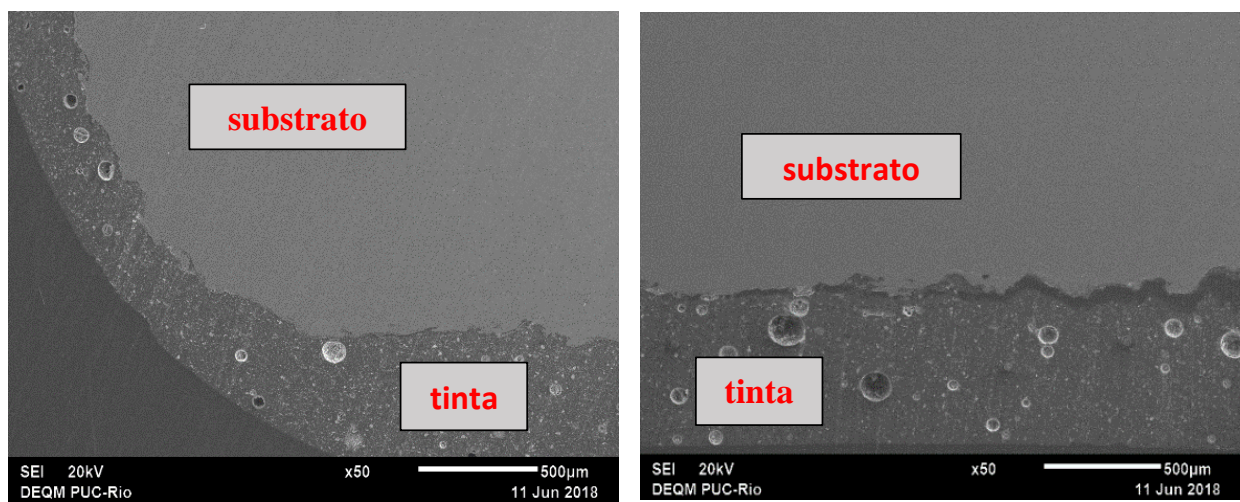

(I)

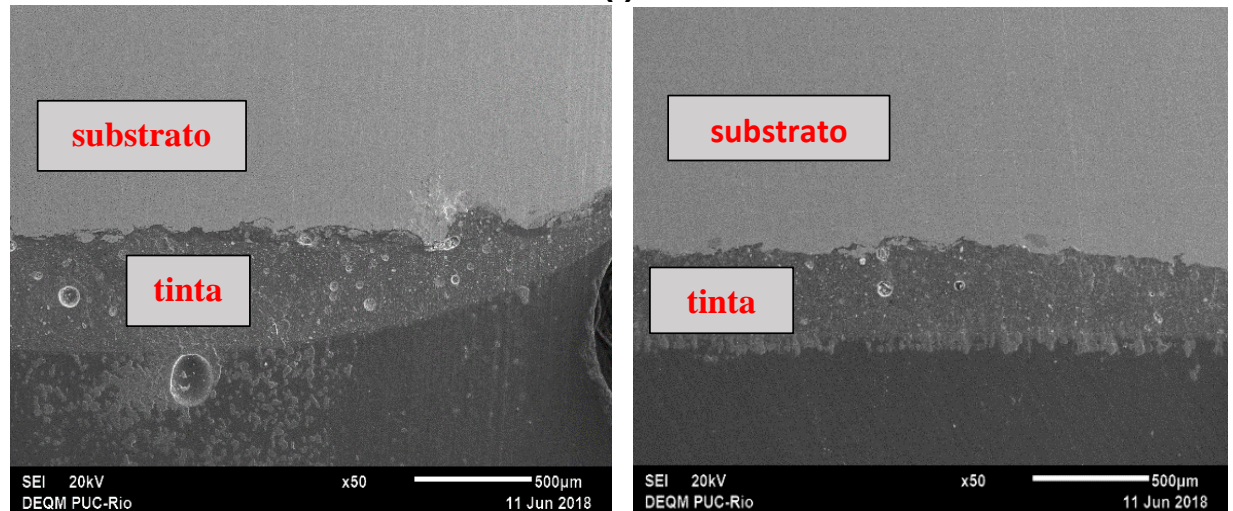

(II)

Figura 27: Micrografias de MEV da interface substrato/resina (I) CR (sem aditivo) e (II) Imagem representativa para resinas aditivadas. 


\subsubsection{Espectroscopia Raman}

Os espectros Raman individuais para cada condição estudada CR, $0.1 \%$ e $0.5 \%$ estão ilustrados na Figura 28. De modo a determinar se ocorreram mudanças foi realizada uma sobreposição dos espectros obtidos para cada condição (Figura 29), e como pode ser observado a aditivação não provocou mudanças nítidas nos espectros individuais, já que todos os picos estão igualmente sobrepostos.

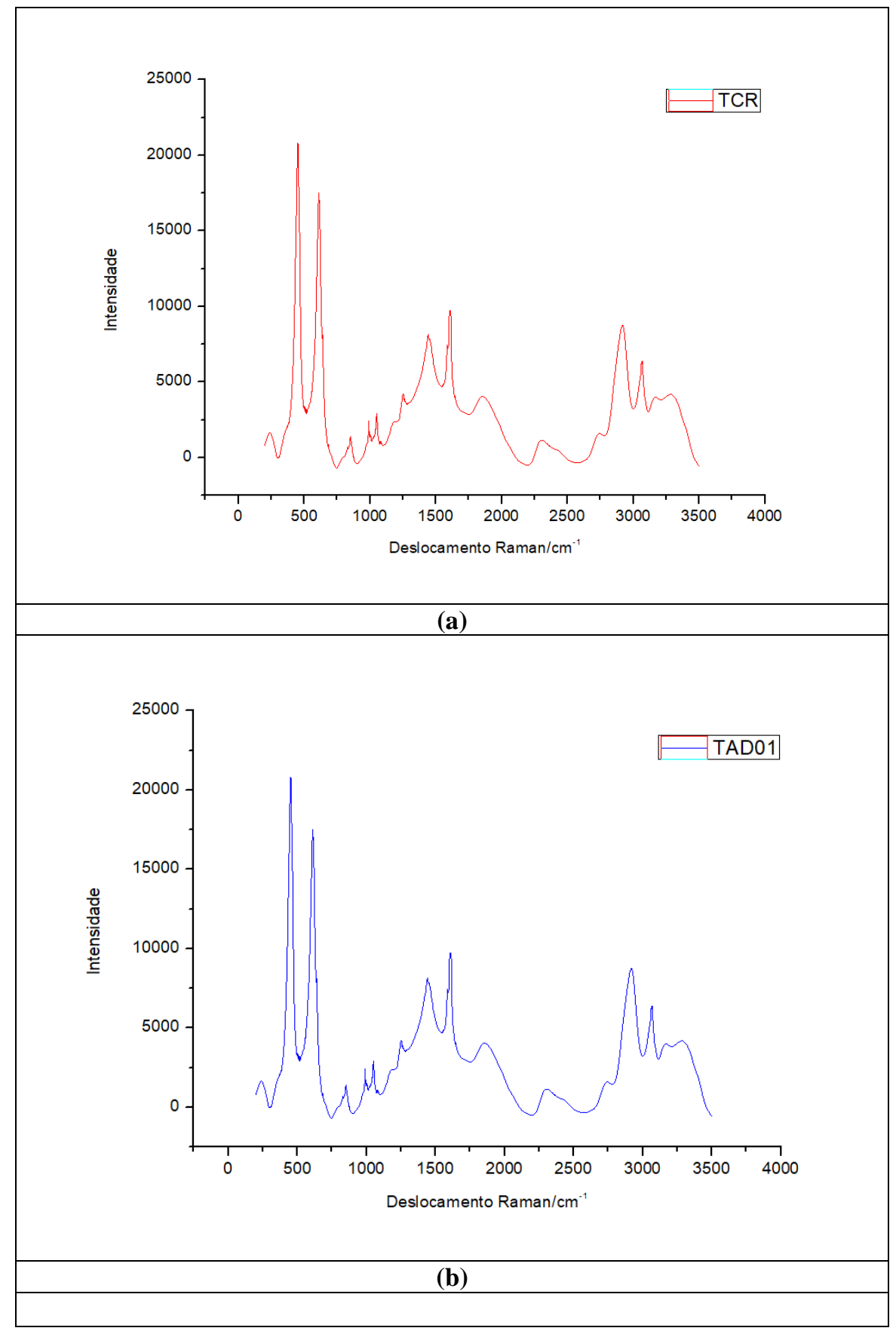




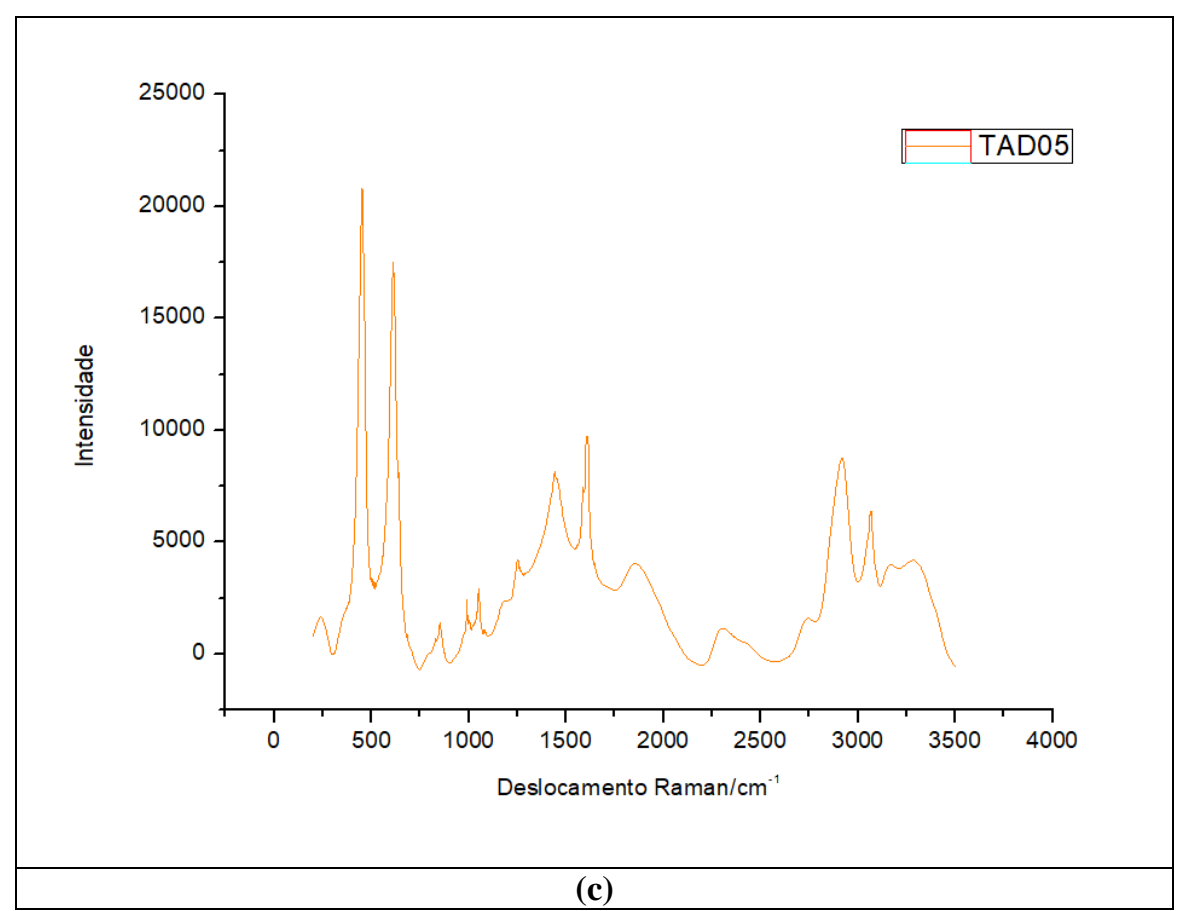

Figura 28: Espectros Raman para as condições (a)CR, (b)0.1\% e (c) $0.5 \%$.

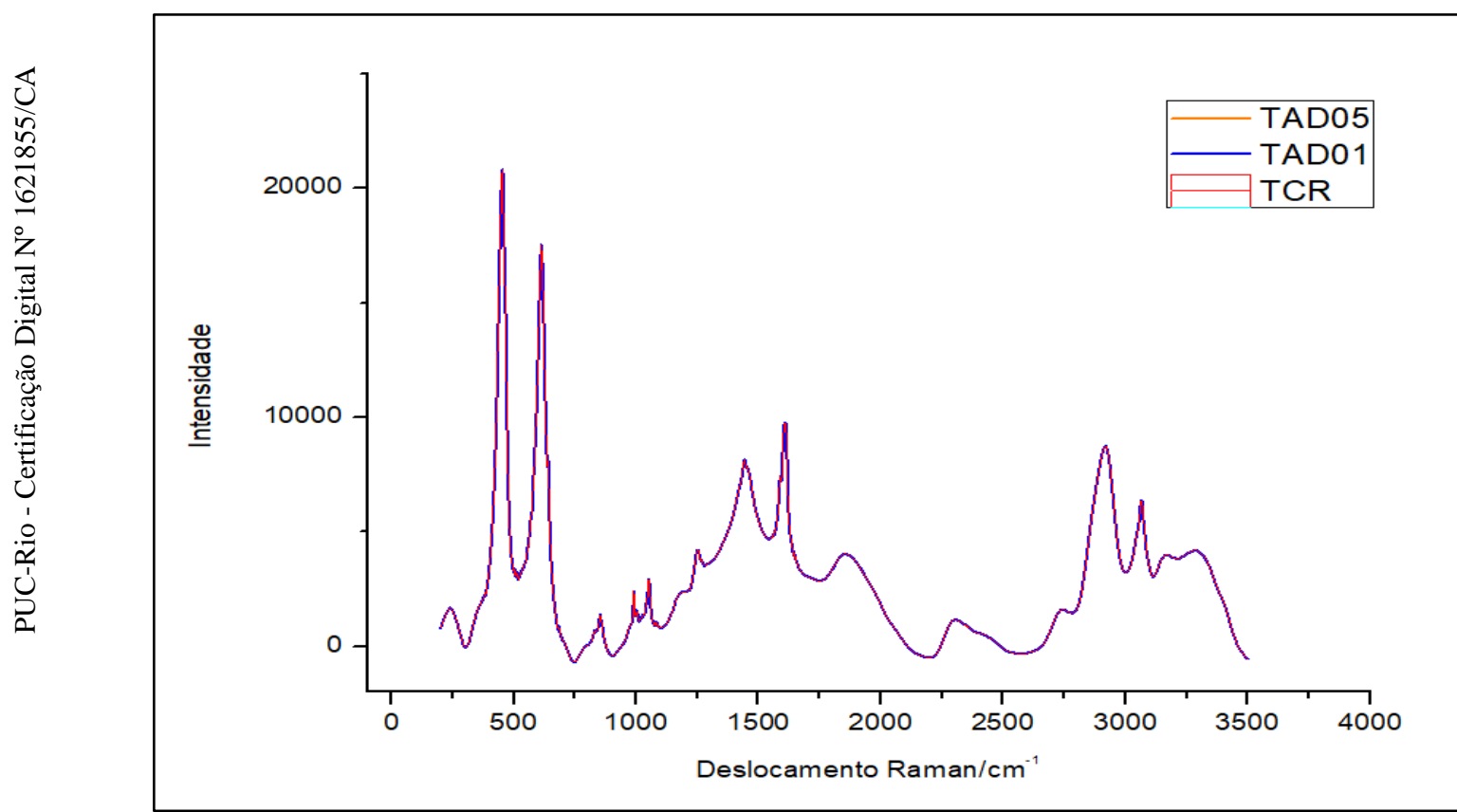

Figura 29: Espectros Raman sobrepostos para todas as condições estudadas.

Estes resultados indicam a técnica Raman em que são avaliados, os nanocompósitos aditivados ( $\mathrm{CR}, \mathrm{AD} 0.1 \%$ e $\mathrm{AD} 0.5 \%)$, não foi possível identificar a presença do grafeno na estrutura da matriz polimérica. Para efeito comparativo, não houve diferença entre os picos dos espectros encontrados para todas as condições, havendo apenas um pequeno deslocamento. 


\subsubsection{Espectroscopia no Infravermelho por Transformada de Fourier (FTIR)}

Os espectros de FTIR da tinta epóxi Novolac tipo II (CR) e daquelas aditivadas $0.1 \%$ e $0.5 \%$ (Figura 30) mostram similaridades entre as bandas, observando-se uma pequena defasagem entre os picos de maior transmitância. Uma banda larga de absorção é observada em aproximadamente a $3500 \mathrm{~cm}^{-1}$, outras bandas de absorção entre 3560 e $3585 \mathrm{~cm}^{-1}$, e uma sucessão de bandas entre 550 e $1700 \mathrm{~cm}^{-1}$. Sendo assim, constata-se que a presença de nanopartículas de grafeno não afetou significativamente a estrutura química da resina epóxi utilizada nesta dissertação. Comportamento similar observado por HACK, 2013.

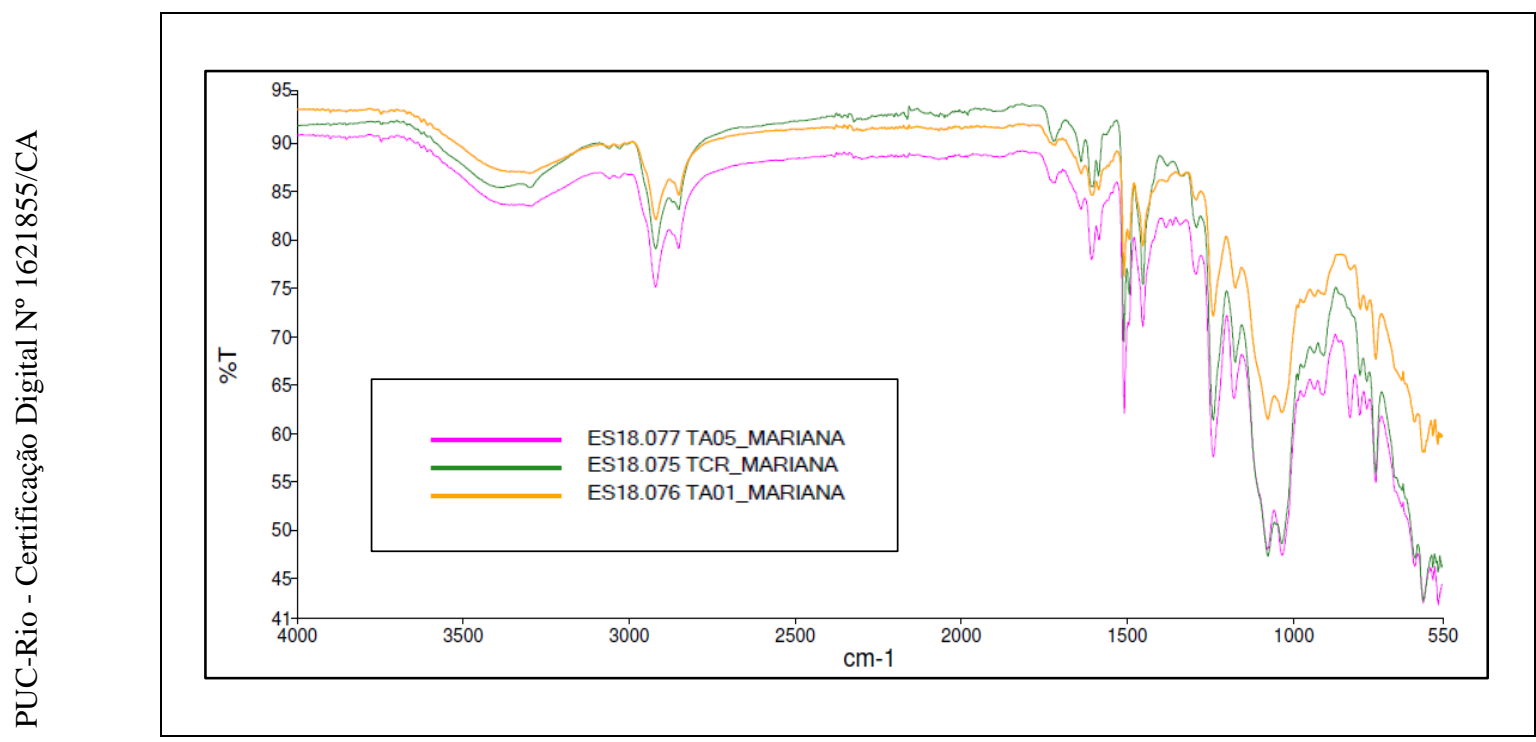

Figura 30: Espectro no FTIR para o nanocompósito nas condições CR, 0.1\% e $0.5 \%$.

\subsubsection{Condutividade Elétrica (Efeito Hall)}

O objetivo deste ensaio foi de determinar se a aditivação por grafeno promoveu mudanças na condutividade dos nanocompósitos. Durante o ensaio, de modo a estabelecer contato elétrico entre as pontas e o material utilizou-se cola de prata condutiva no limite da área delimitada pelo equipamento. A medida da condutividade só foi possível para valores mínimos de correntes (nanoampéres), correspondendo ao limite inferior do equipamento. Foram realizadas três medidas de condutividade elétrica para cada pastilha e calculada a média entre elas. Os 
resultados obtidos Tabela $\mathbf{0 7}$ traduzem um comportamento inalterado quanto à aditivação com nanopartículas de grafeno. Os valores médios de condutividade elétrica estão aproximadamente na mesma ordem de grandeza.

Tabela 07: Resultados do ensaio de condutividade elétrica.

\begin{tabular}{|c|c|c|}
\hline AMOSTRA & $\Sigma$ & $\sigma_{M E ́ D I A}$ \\
\hline \multirow{3}{*}{ CR } & $3.354 \mathrm{E}-13$ & \multirow{3}{*}{$3.33 \mathrm{E}-10$} \\
\hline & $5.499 \mathrm{E}-10$ & \\
\hline & $4.498 \mathrm{E}-10$ & \\
\hline \multirow{3}{*}{$\operatorname{AD}(0.1 \%)$} & $2.115 \mathrm{E}-10$ & \multirow{3}{*}{$9.22 \mathrm{E}-10$} \\
\hline & $1.018 \mathrm{E}-09$ & \\
\hline & $1.537 \mathrm{E}-09$ & \\
\hline \multirow{3}{*}{$\operatorname{AD}(0.5 \%)$} & $2.451 \mathrm{E}-09$ & \multirow{3}{*}{$1.12 \mathrm{E}-09$} \\
\hline & $5.372 \mathrm{E}-10$ & \\
\hline & $3.858 \mathrm{E}-10$ & \\
\hline
\end{tabular}

\subsection{Medidas de Rugosidade da Superfície}

A rugosidade da superfície do substrato foi quantificada tanto pelo rugosímetro analógico quanto por microscopia óptica, assim como o perfil topográfico. Os valores de rugosidade foram obtidos de sete pontos aleatórios da amostra. De modo a aumentar a precisão do resultado, foram eliminados dois pontos, o maior e o menor, e a média entre os valores restantes foi calculada. O valor médio de rugosidade obtido foi de $60.8 \mu \mathrm{m}$ para essa análise (Tabela $\mathbf{0 8}$ ).

Tabela08: Resultados do teste analógico de rugosidade.

\begin{tabular}{|c|c|}
\hline Rugosidade $_{A}$ & $\boldsymbol{R}_{M}$ \\
\hline 70 & \multirow{5}{*}{$60.8 \mu \mathrm{m} \stackrel{+}{-1}$} \\
\hline 54 & \\
\hline 50 & \\
\hline 76 & \\
\hline 54 & \\
\hline
\end{tabular}

A visualização da rugosidade da superfície do substrato foi obtida por microscopia óptica (MO) (Figura 31). Estas medidas consistem em delimitar os perfis topográficos em diferentes filtros, e quantificar valores médios de rugosidade superficial. Todos os perfis e valores numéricos obtidos pela MO estão na Figura 32a). Foram escolhidos cinco pontos aleatórios, em extremidades distintas da amostra com o intuito de varrer a maior parte da amostra. Os pontos estão listados em ordem crescente, com a sigla da localização na amostra. Os 
significados são: ES (Esquerda Superior); EI (Esquerda Inferior); DI (Direita Inferior); DS (Direita Superior) e CT (Centro). Na Figura 32b) cada ponto está representado pelos perfis topográficos, com diferentes filtros (a) e seus respectivos valores médios de rugosidade superficial (b).

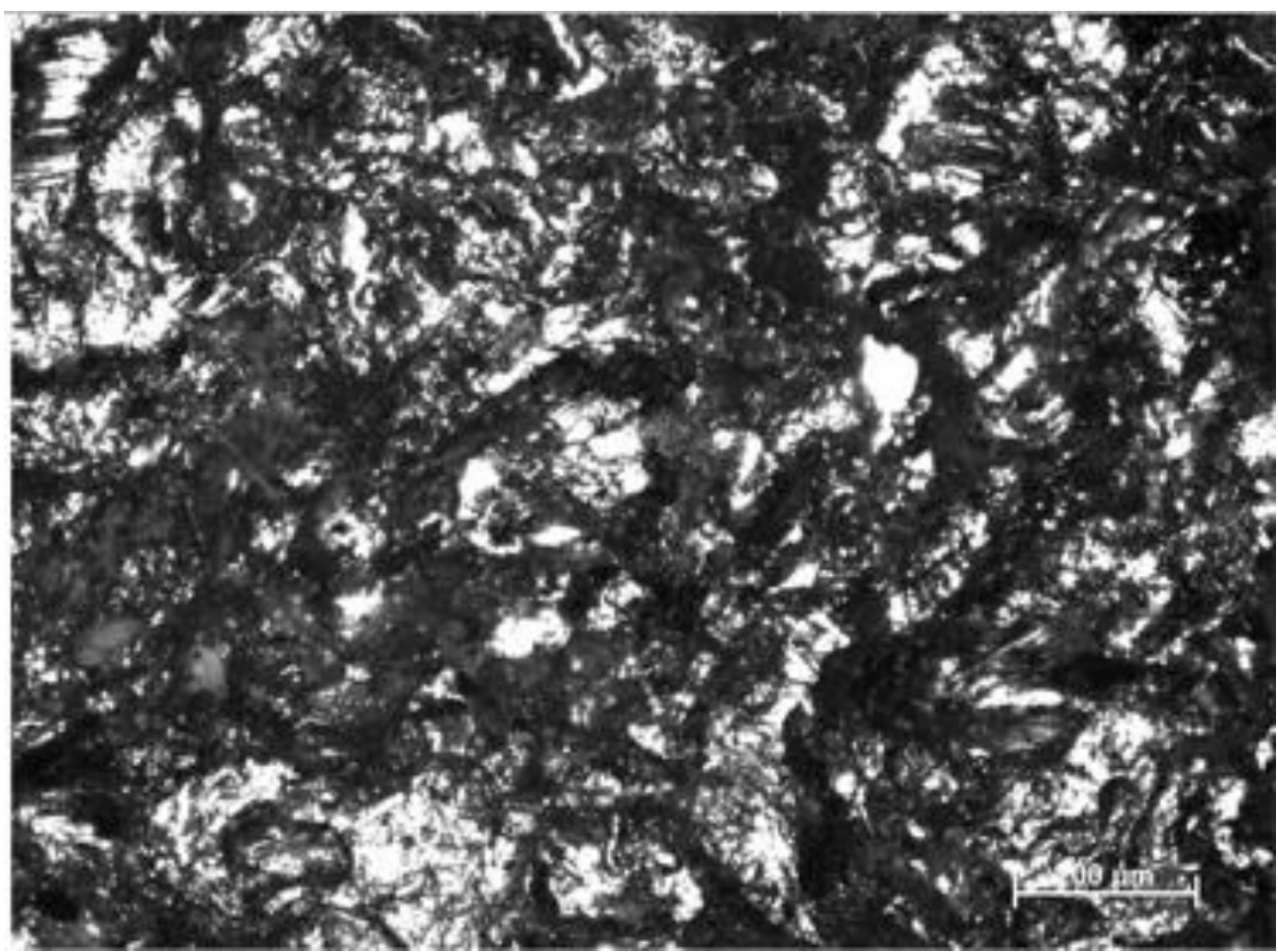

Figura 31: Aspecto da rugosidade superficial do substrato obtida por MO. 


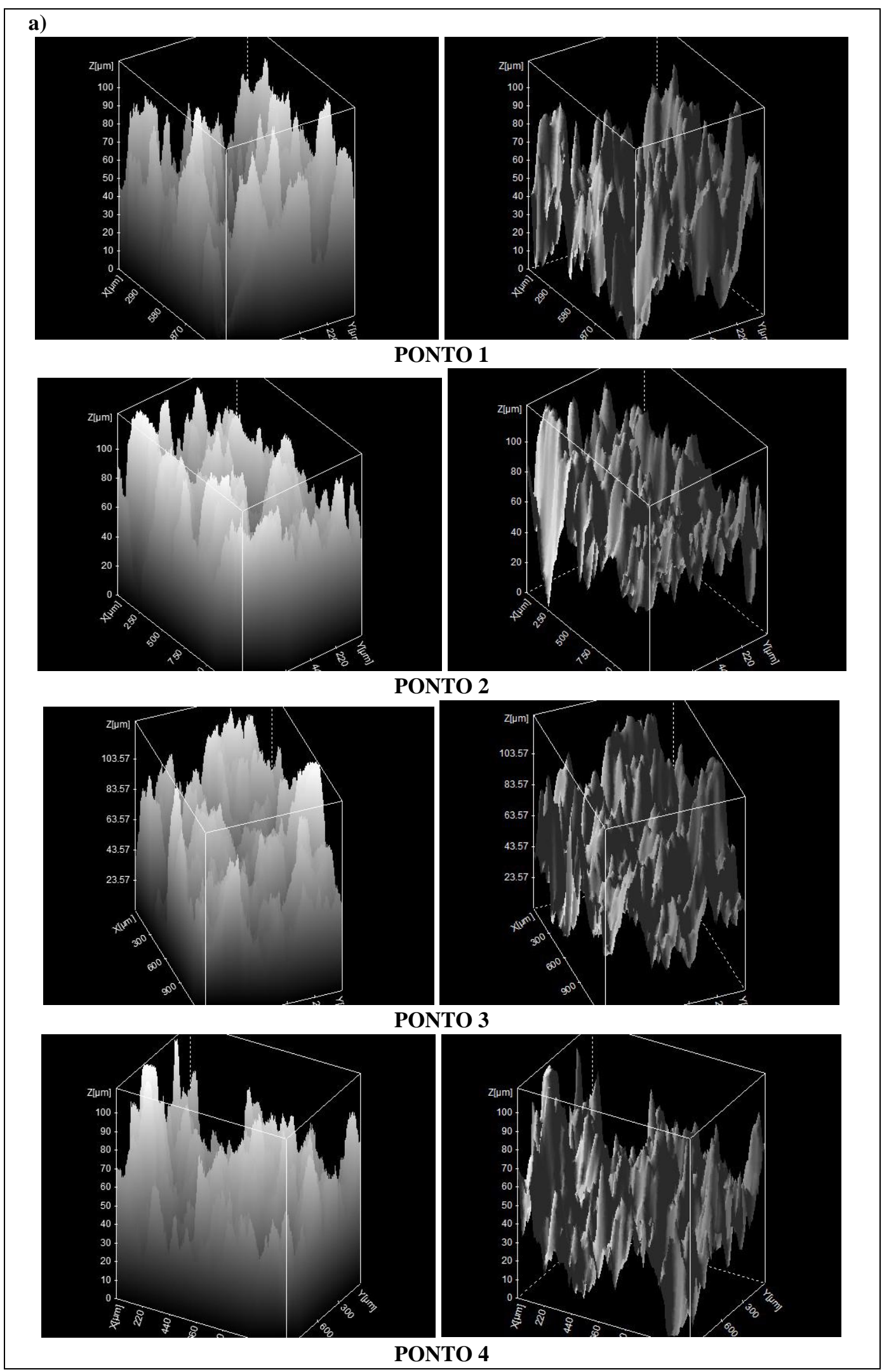




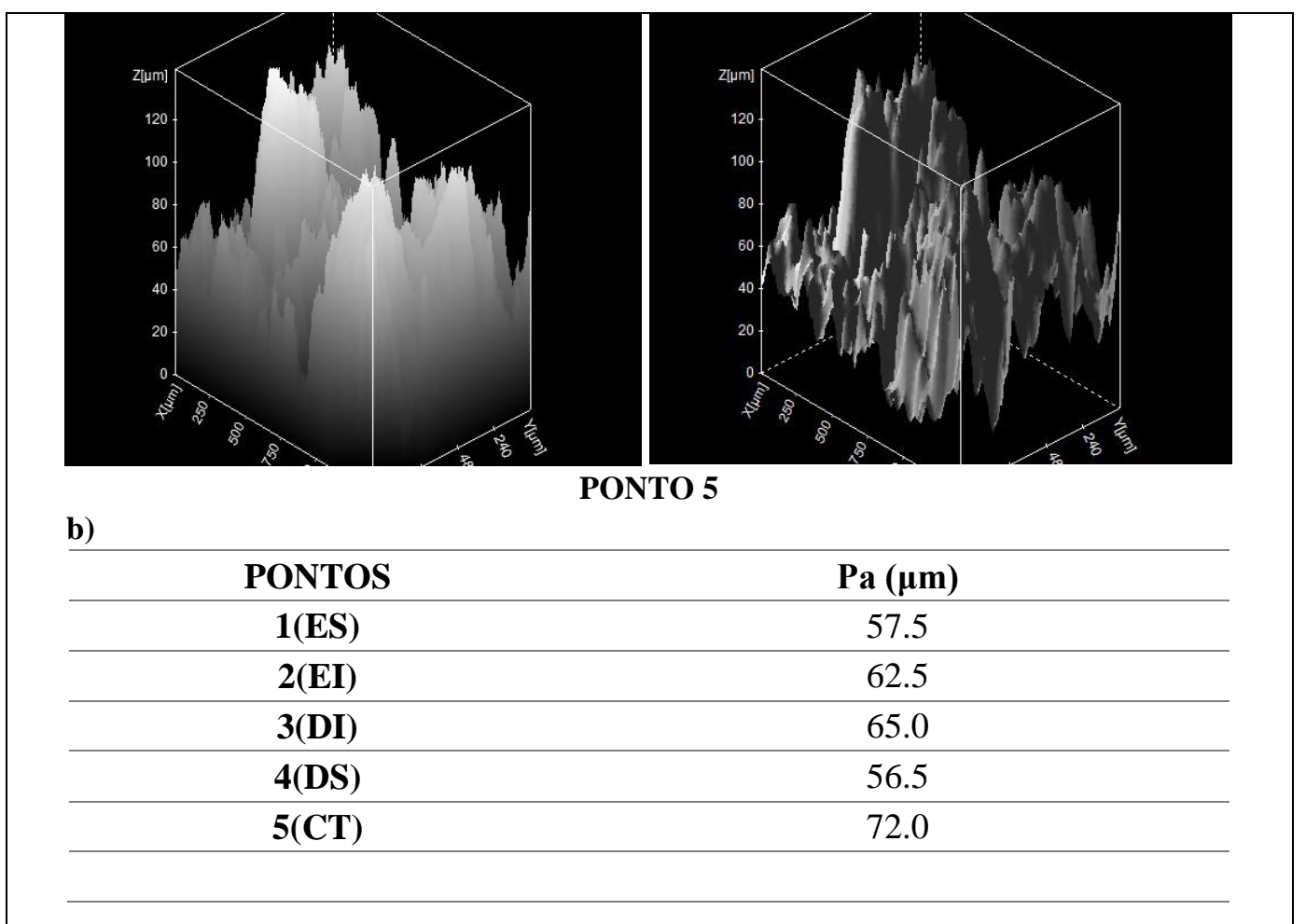

Figura 32: a) Perfis topográficos dos pontos na superfície do substrato b) Valores numéricos de rugosidade para cada ponto do substrato obtida por MO.

\subsection{Teste de Aderência (Pull off)}

O teste de pull off quantifica a resistência da aderência entre o revestimento e o substrato, identificando a região onde ocorre a falha (Figura 18). Durante a execução do teste, os parafusos (dollys) são colados equidistantes das bordas (Figura 33), com um adesivo epóxi. Para cada condição estudada, o teste foi executado em duplicata, os resultados obtidos estão na Tabela 09.

A avaliação dos tipos de falhas é feita visualmente após o descolamento do dolly, baseada no esquema de falhas da Figura 18. A tendência observada relata a ocorrência de mais de um tipo de falha e não é observado um padrão de comportamento entre os pontos da mesma amostra e entre amostras diferentes. Para esse tipo de ensaio, as falhas menos desejadas são as coesivas, que envolve o descolamento total do revestimento, expondo o substrato sem proteção. 


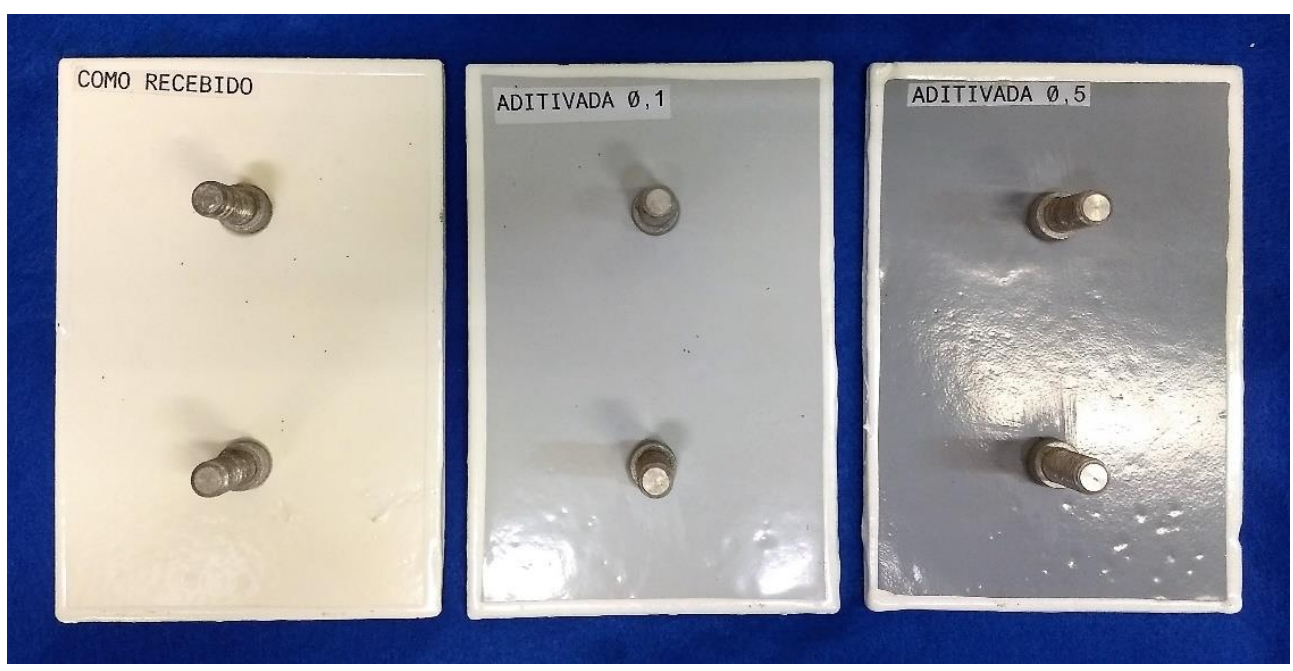

Figura 313: Posição dos parafusos (dollys) para execução do teste.

De acordo com a Norma Petrobras N2912, o valor mínimo requisitado para o ensaio de aderência à tração é de $15 \mathrm{MPa}$. Observa-se, portanto que todos os resultados obtidos (Tabela 09) são superiores ao valor limite, atendendo ao requisito mínimo exigido. Os valores de tensão de ruptura também são semelhantes e oscilam entre 24 - $26 \mathrm{MPa}$ para todas as condições estudadas.

Tabela 09: Resultados do teste de aderência pull off.

\begin{tabular}{|c|c|c|c|c|}
\hline \multirow{2}{*}{ AMOSTRAS } & \multirow{2}{*}{ REPETIÇÕES } & \multicolumn{2}{|c|}{$P_{\text {Ruptura }}$} & \multirow{2}{*}{ TIPO DE FALHAS } \\
\hline & & PSIG & MPa & \\
\hline \multirow{4}{*}{$\mathbf{C R}$} & $1^{\circ}$ & 86,3 & 24,18 & $90 \% \mathrm{D} / \mathrm{Y}+10 \% \mathrm{Y} / \mathrm{Z}$ \\
\hline & $2^{\circ}$ & 91 & 25,5 & $40 \% \mathrm{D} / \mathrm{Y}+30 \% \mathrm{Y} / \mathrm{Z}+30 \% \mathrm{D}$ \\
\hline & $3^{\circ}$ & 98.3 & 27.5 & $20 \% \mathrm{C}+30 \% \mathrm{C} / \mathrm{Y}+50 \% \mathrm{Y} / \mathrm{Z}$ \\
\hline & $4^{\circ}$ & - & - & - \\
\hline \multirow{4}{*}{$\operatorname{AD}(0,1 \%)$} & $1^{\circ}$ & 87 & 24,4 & $80 \% \mathrm{Y} / \mathrm{Z}+10 \% \mathrm{D} / \mathrm{Y}+10 \% \mathrm{D}$ \\
\hline & $2^{\circ}$ & 93 & 26,1 & $50 \% \mathrm{D} / \mathrm{Y}+50 \% \mathrm{Y} / \mathrm{Z}$ \\
\hline & $3^{\circ}$ & 53.4 & 15.7 & $50 \% \mathrm{Y} / \mathrm{Z}+20 \% \mathrm{Y} / \mathrm{Z}+30 \% \mathrm{C} / \mathrm{Y}$ \\
\hline & $4^{\circ}$ & 93.6 & 26.1 & $40 \% \mathrm{C}+30 \% \mathrm{Y} / \mathrm{Z}+30 \% \mathrm{C} / \mathrm{Y}$ \\
\hline \multirow{4}{*}{$\operatorname{AD}(0,5 \%)$} & $1^{\circ}$ & 87 & 24,4 & $60 \% \mathrm{Y} / \mathrm{Z}+30 \% \mathrm{D} / \mathrm{Y}+10 \% \mathrm{D}$ \\
\hline & $2^{\circ}$ & 87 & 24,4 & $60 \% \mathrm{Y} / \mathrm{Z}+40 \% \mathrm{D} / \mathrm{Y}$ \\
\hline & $3^{\circ}$ & 87.7 & 23.6 & $10 \% \mathrm{C}+40 \% \mathrm{C} / \mathrm{Y}+50 \% \mathrm{Y} / \mathrm{Z}$ \\
\hline & $4^{\circ}$ & 98 & 27.5 & $30 \% \mathrm{C}+70 \% \mathrm{Y} / \mathrm{Z}$ \\
\hline
\end{tabular}

Estes resultados indicam que a aditivação não interferiu na resistência a aderência do revestimento ao substrato. 


\subsection{Ensaios de Corrosão}

\subsubsection{Célula Atlas}

Os ensaios de corrosão por imersão em célula atlas foram realizados para 504h, 1000h e 2000h. Os resultados estão apresentados para cada tempo de ensaio.

A avaliação do revestimento é feita visualmente identificando os fenômenos que ocorrem no decorrer do teste. A região observada é a área circular em contato com o sistema líquido/vapor a $60{ }^{\circ} \mathrm{C}$. Atenção especial é dada para a interface entre o líquido e o vapor, zona de maior diferença de potencial, mais suscetível a maiores alterações.

\section{- Ensaio de 504h}

O acompanhamento do ensaio na célula atlas em até três semanas para a placa revestida com $0.1 \%$ de grafeno, está documentado na Figura 34. Não foi observada alteração visual significativa no revestimento, apenas uma leve mudança na coloração na $3^{\mathrm{a}}$ semana (504h). Na interface entre as fases, líquido e vapor (Figura 35), nenhuma alteração foi observada após 504 horas.

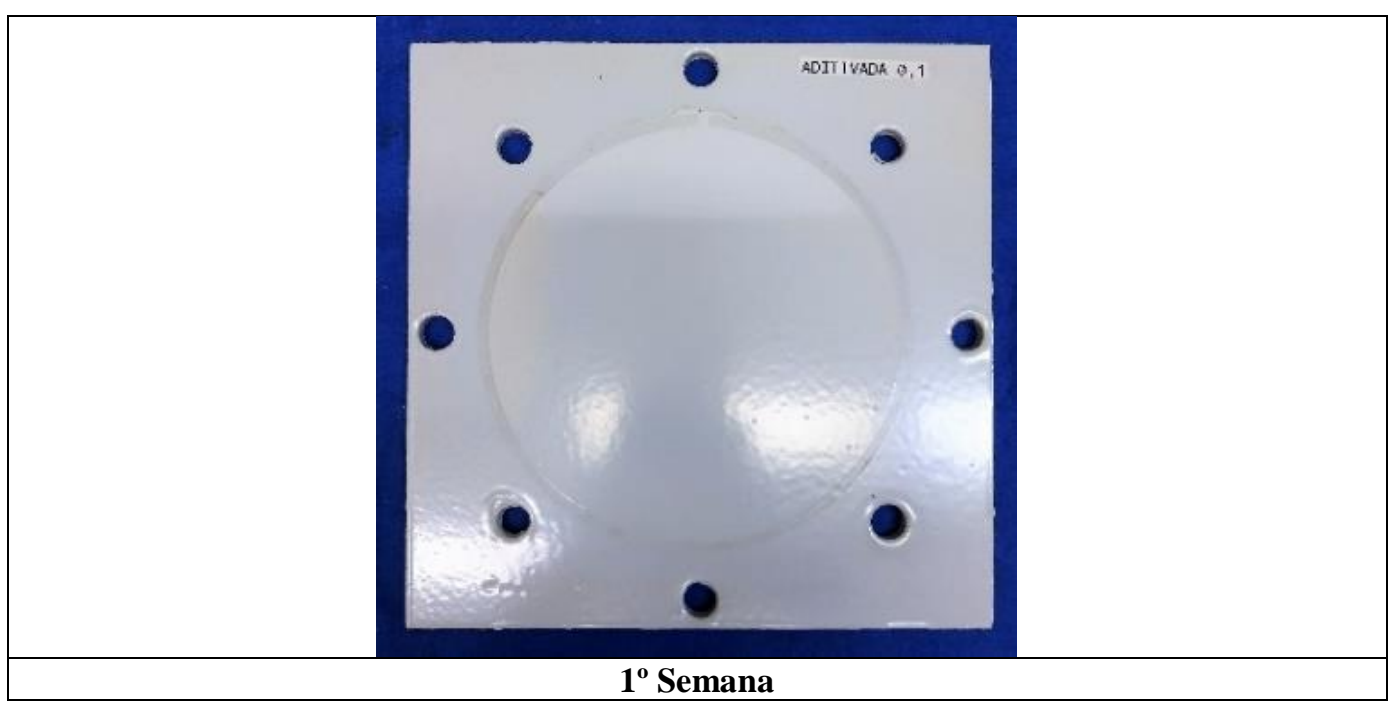




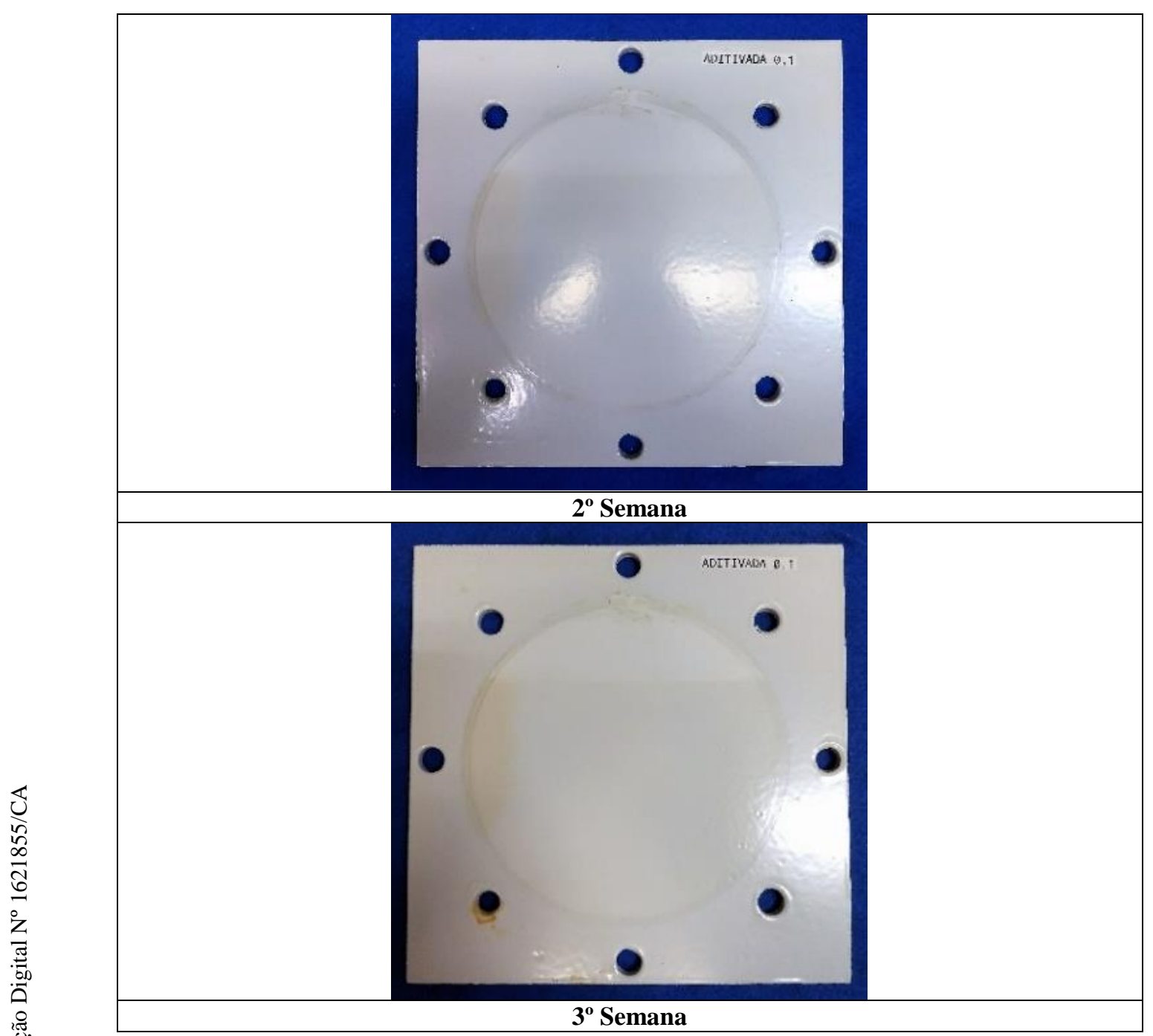

Figura 32: Placas $0.1 \%$ aditivada durante o ensaio de 504h (3 semanas).

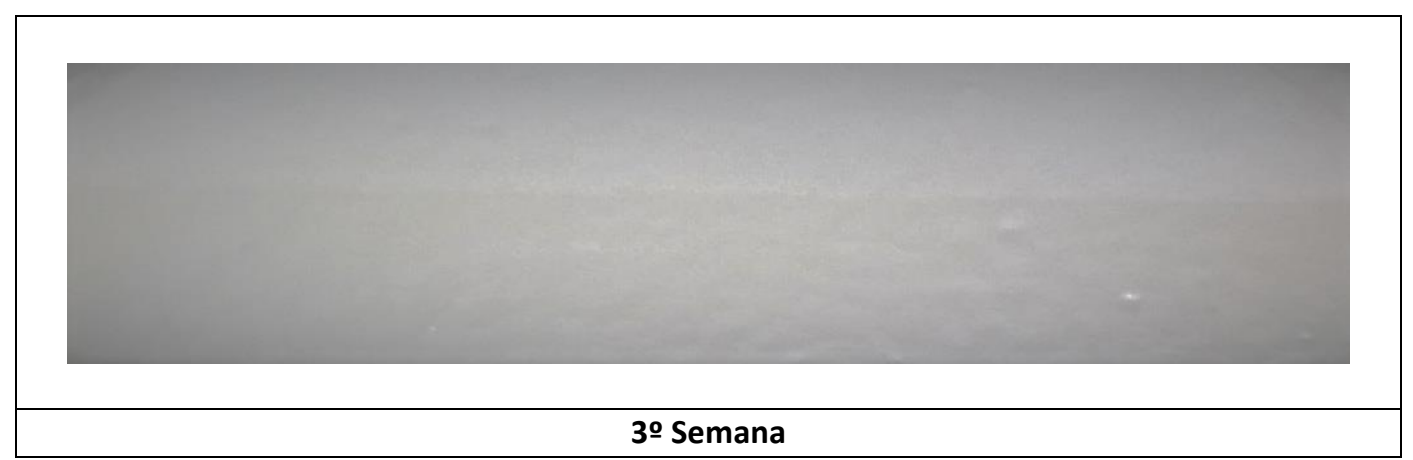

Figura 33: Interface da placa $0.1 \%$ após o ensaio de 504h. 
Para os revestimentos com adições de $0.25 \%$ e $0.5 \%$, ocorreu o aparecimento de bolhas ao longo da interface líquido-vapor. No caso do revestimento aditivado com $0.25 \%$, as bolhas começaram a surgir a partir da terceira semana Figura 36. Ou seja, o fluido penetrou no revestimento na interface líquido-vapor, como mostrado na Figura 37.

A adição de $0.5 \%$ de grafeno no revestimento acelerou o aparecimento das bolhas que neste caso começaram a surgir na primeira semana de teste. Ao longo do ensaio estas bolhas aumentaram, explodiram permitindo a corrosão na região da interface líquido-vapor. A documentação do acompanhamento semanal das placas com a aditivação de $0.5 \%$ está mostrada na Figura 38. O detalhe do acompanhamento semanal da interface líquido-vapor do revestimento com $0.5 \%$ de aditivação, Figura 39, mostra a progressão do processo corrosivo do ensaio de $504 \mathrm{~h}$.

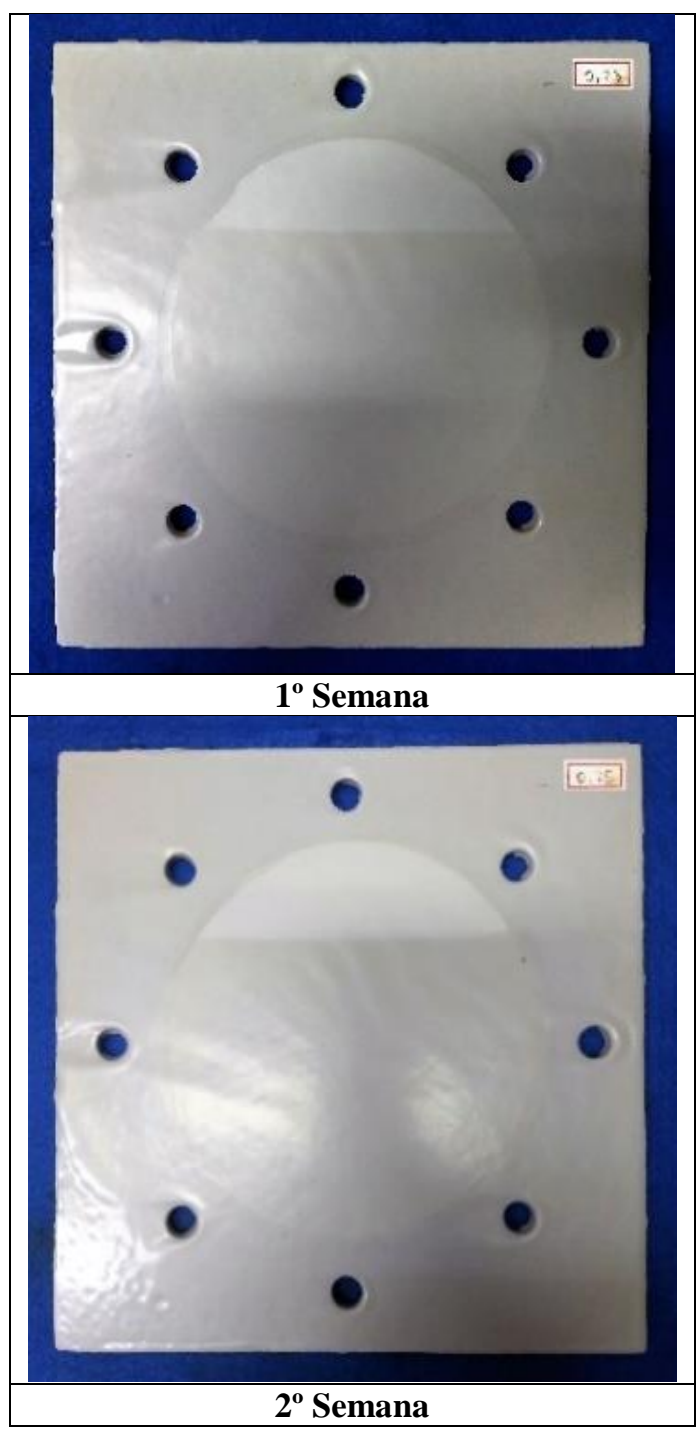




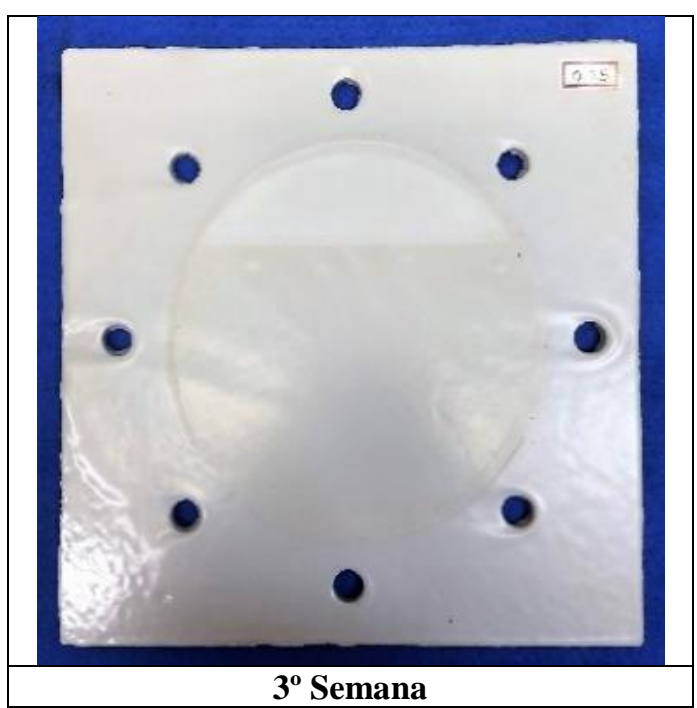

Figura 34: Aparência das Placas $0.25 \%$ aditivada durante o ensaio de 504h (3semanas).

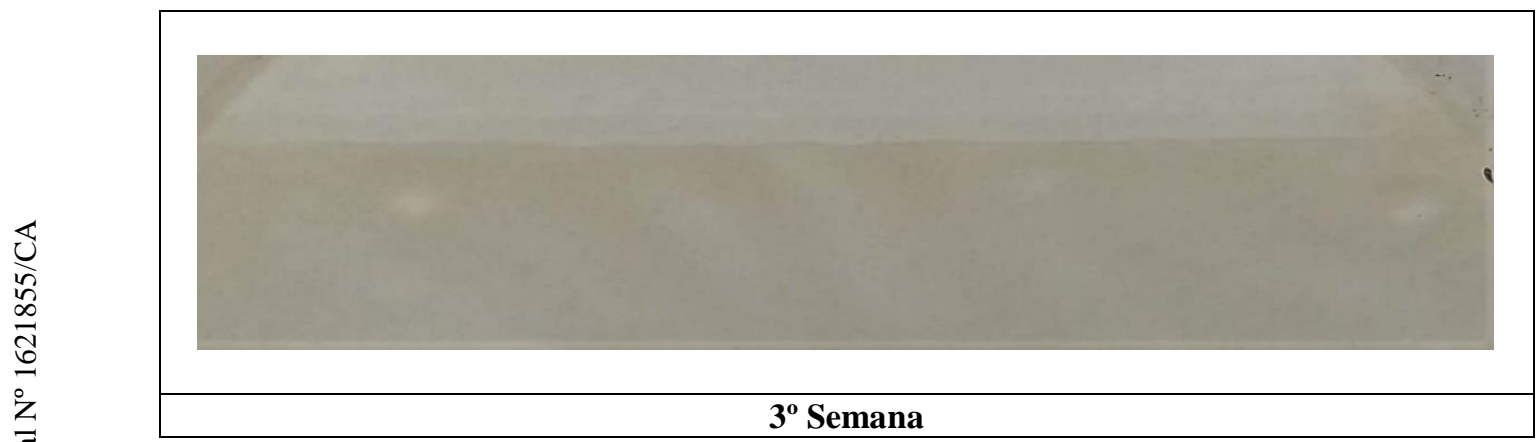

Figura 35: Detalhe da interface da placa $0.25 \%$ após o ensaio de $504 \mathrm{~h}$. 


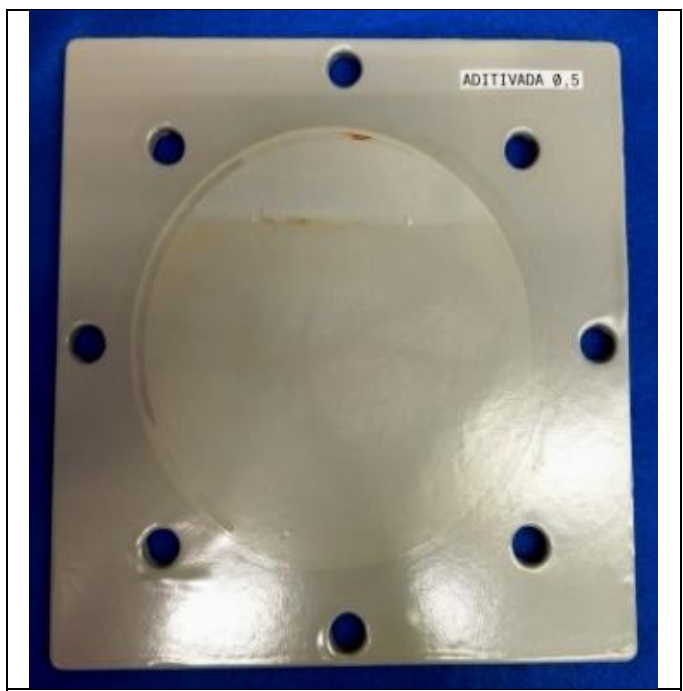

\section{$1^{\circ}$ Semana}

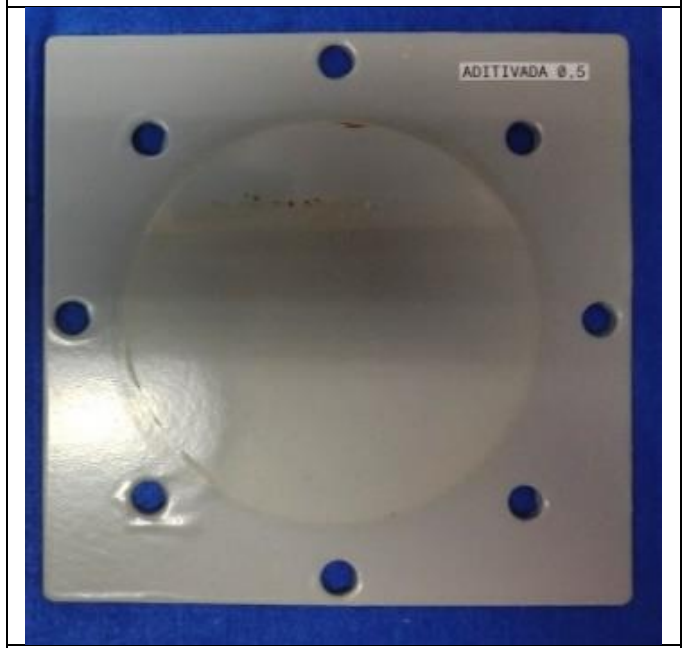

$2^{\circ}$ Semana

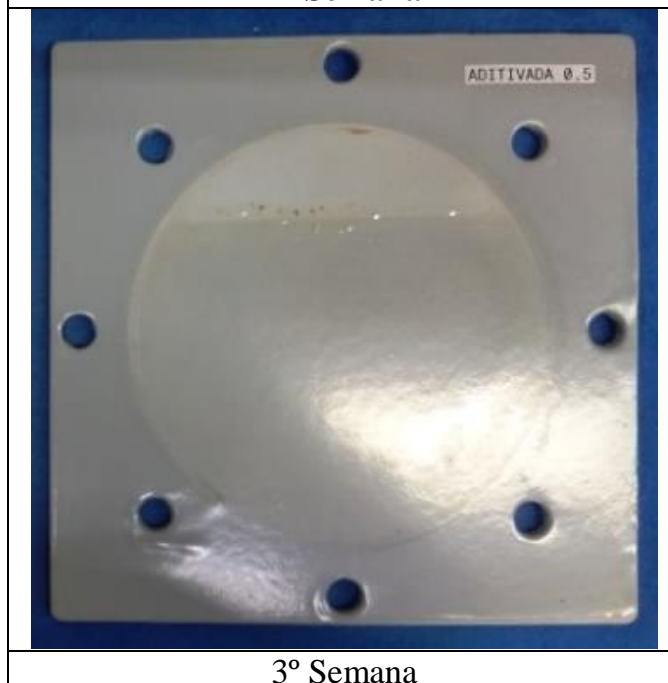

$3^{\circ}$ Semana

Figura 36: Placas $0.5 \%$ aditivada durante o ensaio de 504h (3 semanas). 


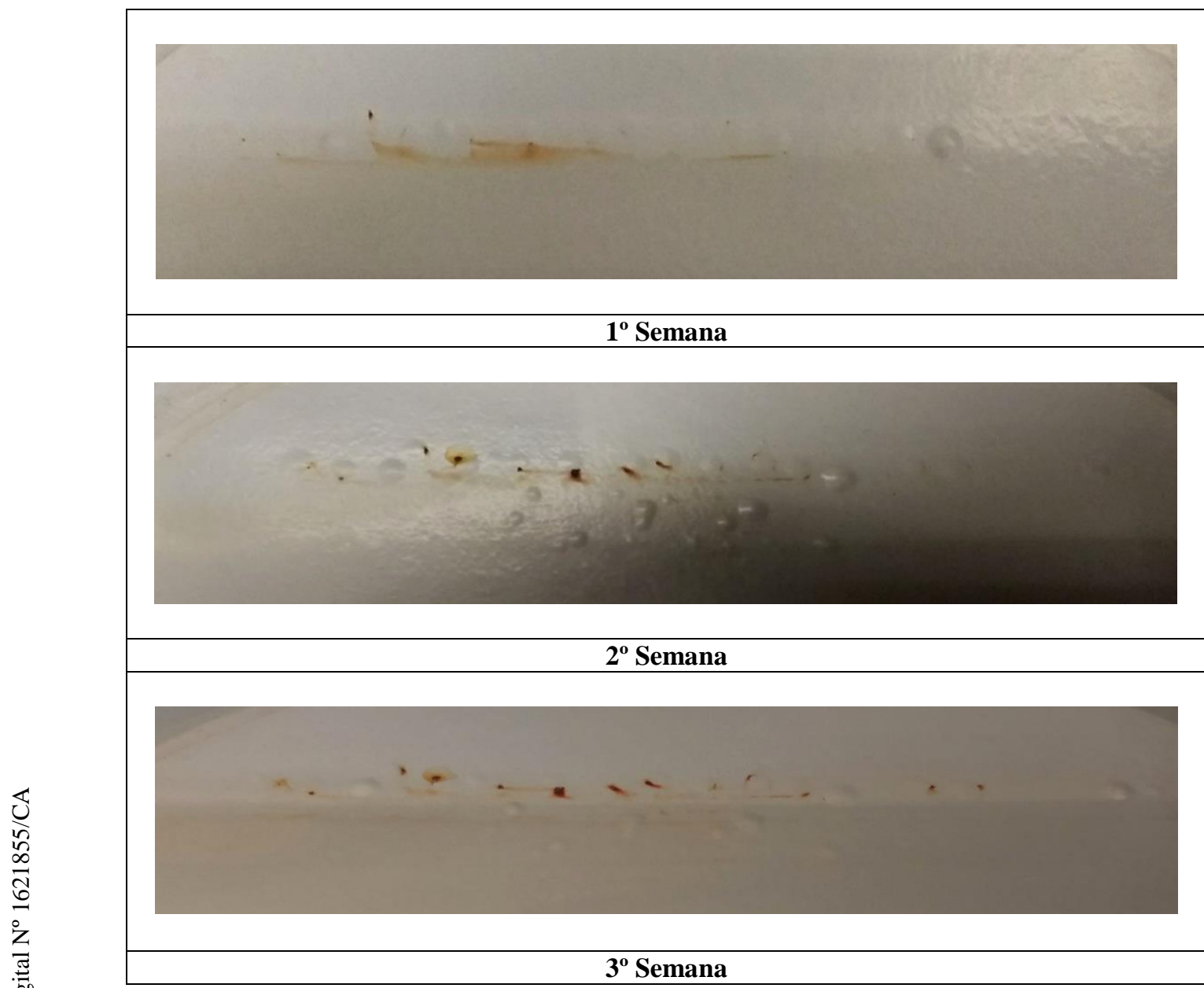

Figura 37: Progressão da interface da placa $0.5 \%$ após o ensaio de 504h.

\section{- Ensaio de 1000h}

As placas com revestimento aditivado com $0,25 \%$ e $0.5 \%$ de grafeno foram submetidas à imersão em célula atlas durante 6 semanas (1000h). Como observado as bolhas se iniciadas para concentração de $0.25 \%$ após 504 horas (Figura 37) continuaram a se espalhar ao longo da região inferior da interface liquido-vapor (Figura 40). Detalhamento do aspecto da interface mostrando na Figura 41, que as bolhas se propagaram, mas não expuseram o substrato à atmosfera. 


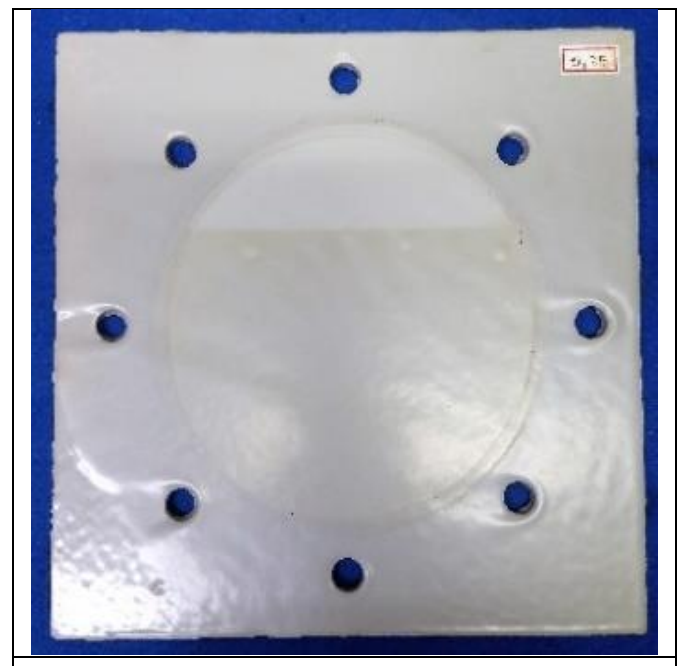

4 Semana

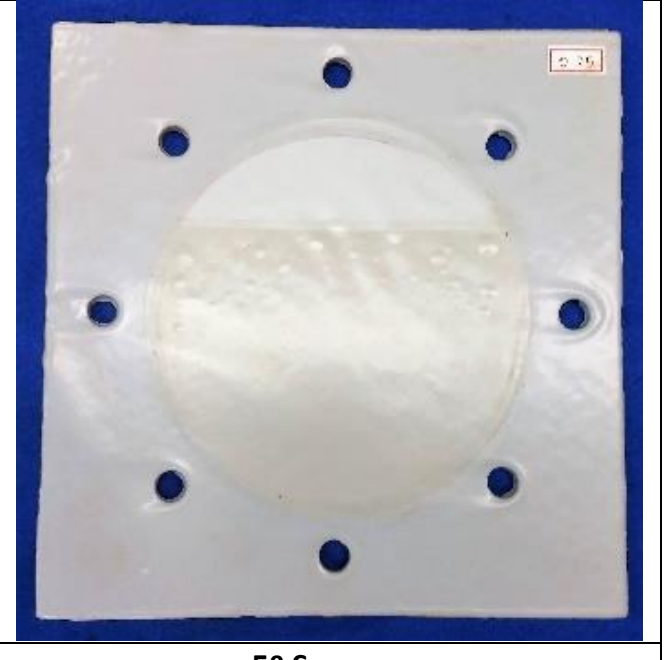

5o Semana

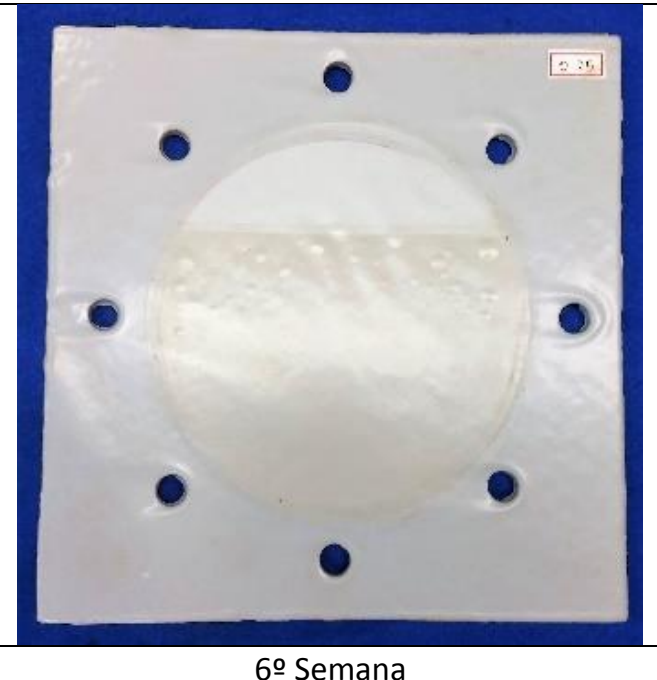

6o Semana

Figura 38: Placas $0.25 \%$ aditivada durante o ensaio de $1000 \mathrm{~h}$ (6 semanas). 


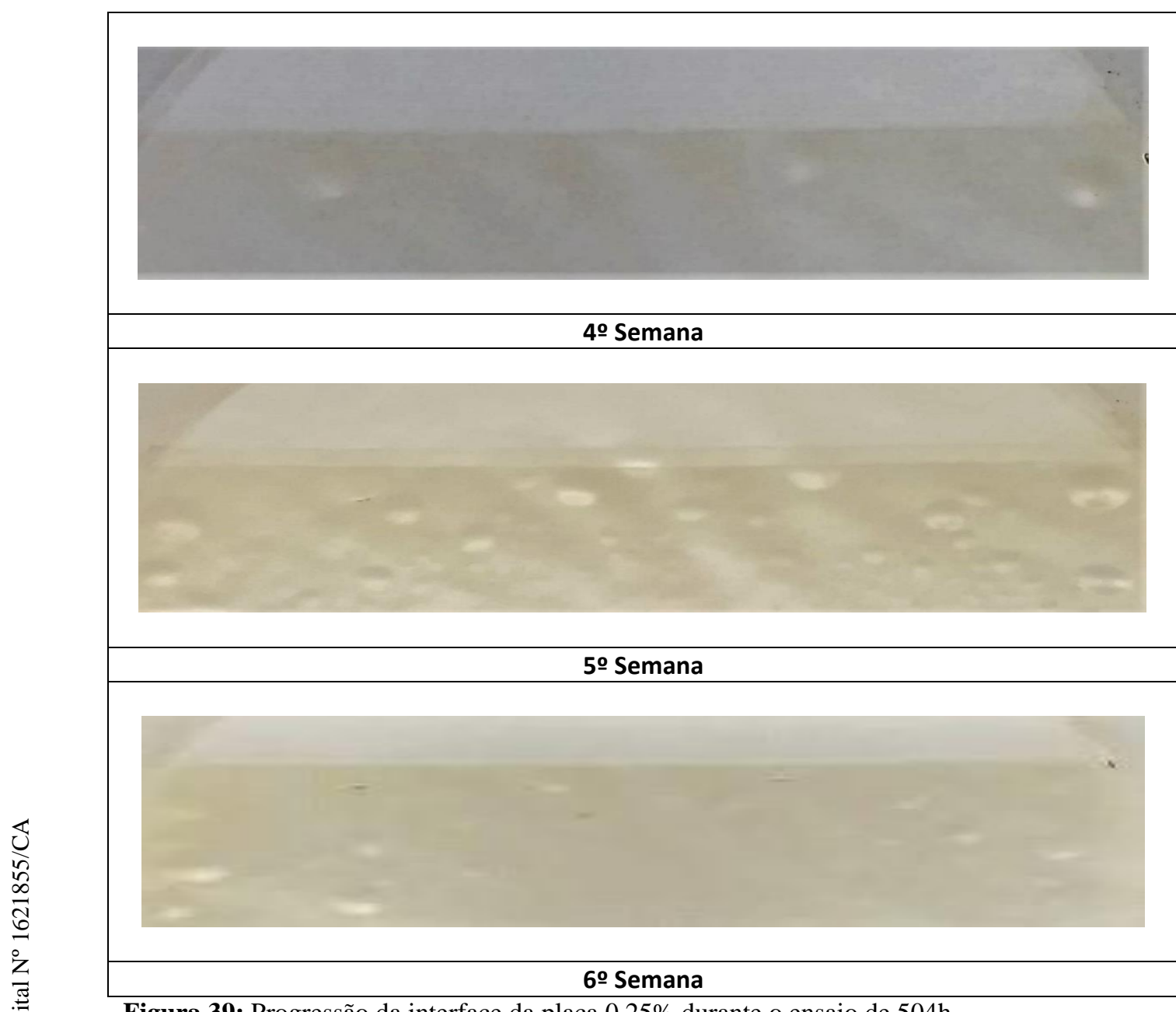

Figura 39: Progressão da interface da placa $0.25 \%$ durante o ensaio de 504h.

Para o revestimento com concentração de $0.5 \%$, o processo corrosivo se propagou ao longo da interface e comprometeu a proteção por barreira. As bolhas inicialmente formadas abriram, expondo o substrato metálico à corrosão salina e atmosférica (Figuras 42 e 43). 


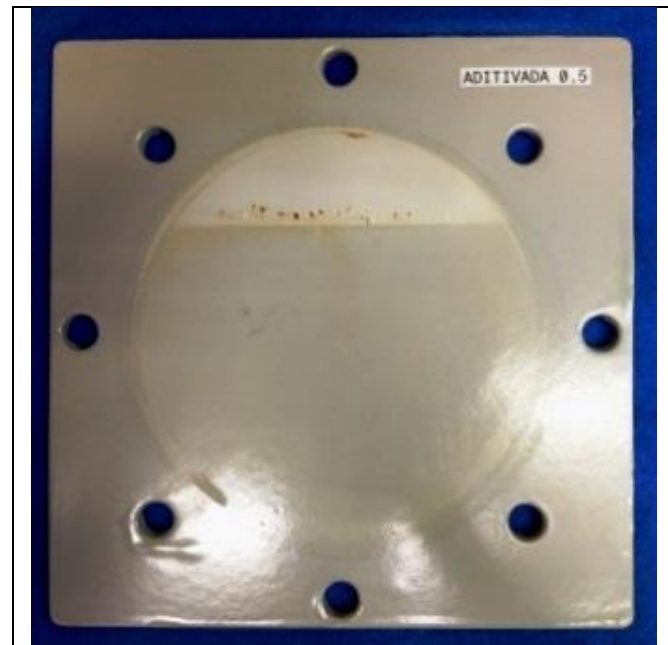

40 Semana

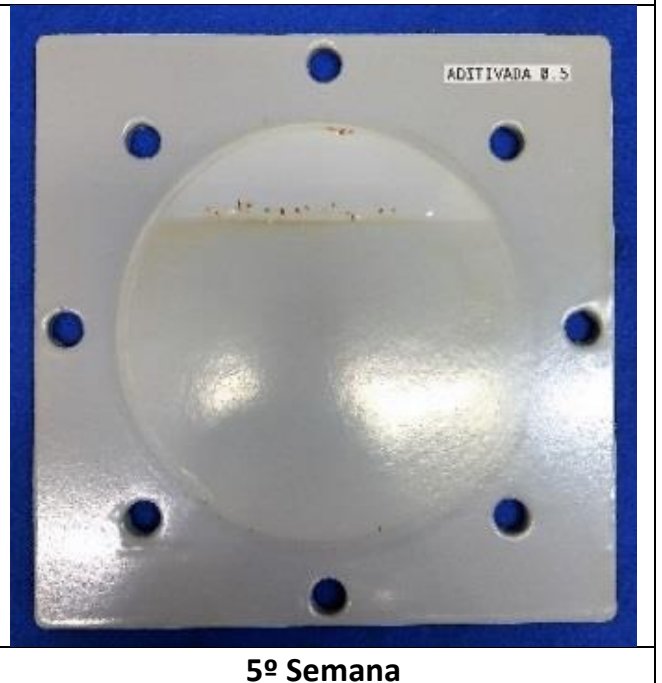

5o Semana

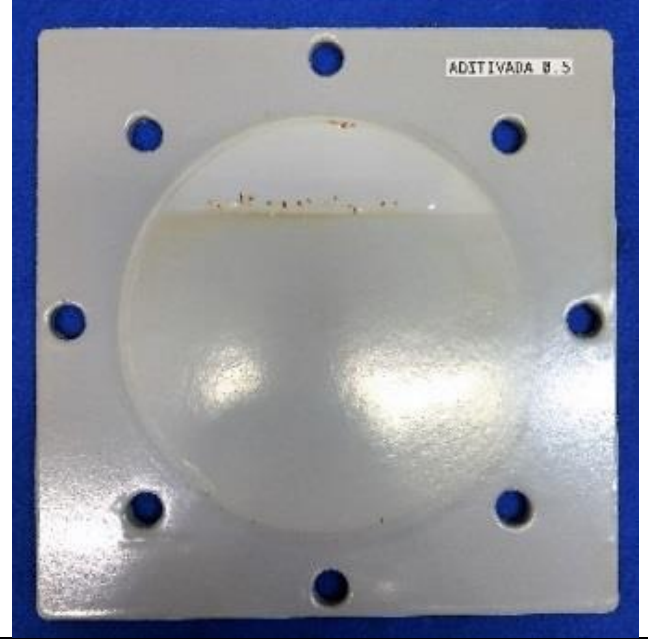

60 Semana

Figura 40: Placas $0.5 \%$ aditivada durante o ensaio de $1000 \mathrm{~h}$ (6 semanas). 


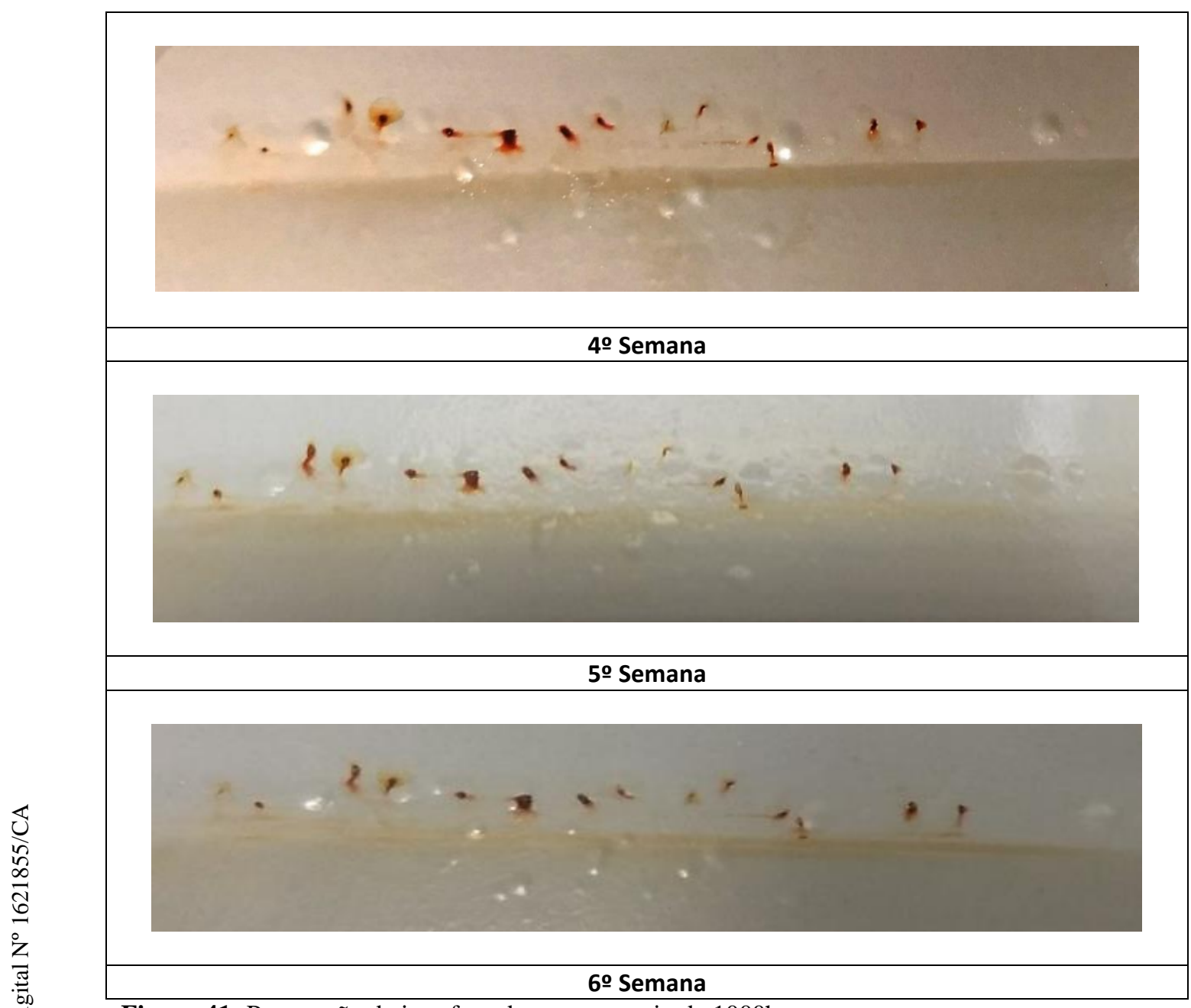

Figura 41: Progressão da interface durante o ensaio de 1000h.

A interface líquido-vapor é a única região do revestimento afetada para ambas as concentrações 0,25 e $0,5 \%$.

\section{- Ensaio de 2000h}

Nesse ensaio o revestimento na condição de como recebido foi comparado com o aditivado com $0.5 \%$ de concentração. Não foi observado nenhum sinal de corrosão no caso do revestimento na condição de como recebido (CR), sem aditivo de grafeno (Figura 44). Como já mencionado, o revestimento aditivado com $0.5 \%$ de grafeno, sofreu corrosão desde a primeira semana (168 h). O processo corrosivo ao longo de 2000h, o aumentou gradativamente comprometendo a proteção anticorrosiva do revestimento como mostrado na Figura 46. 


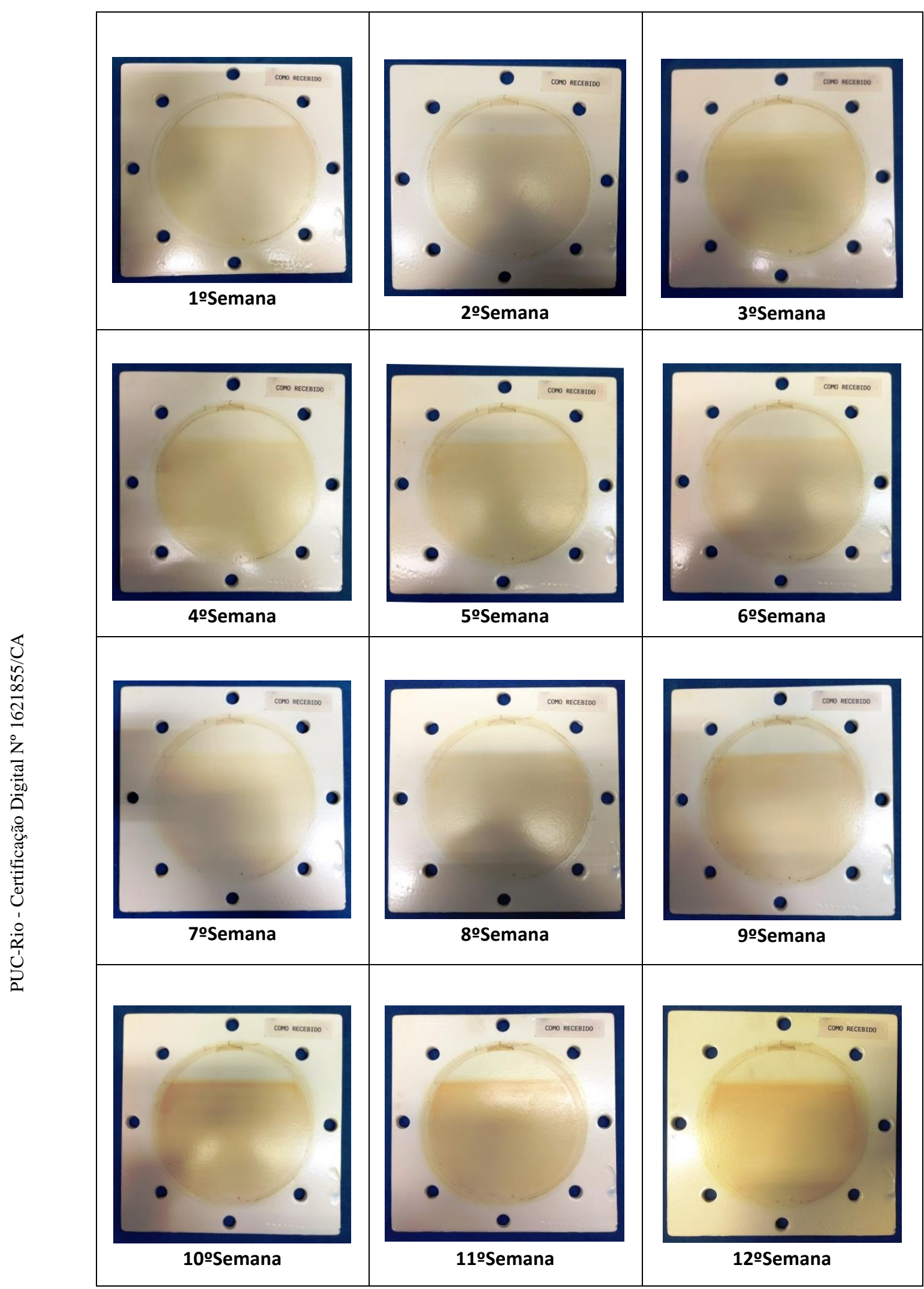

Figura 42: Placas com revestimento na condição de como recebida (sem aditivos) durante o ensaio de 2000h (12 semanas). 

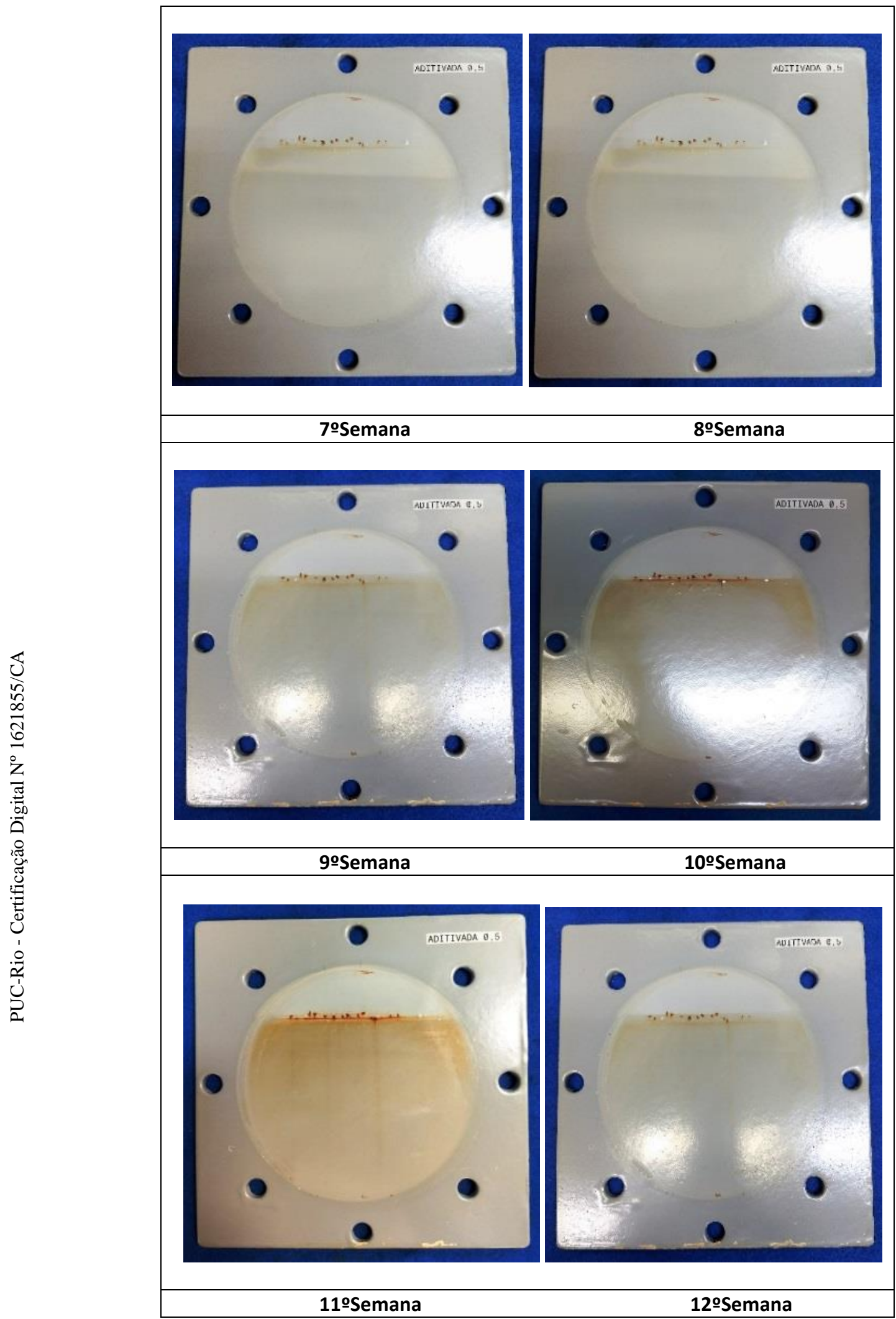

Figura 43: Placas $0.5 \%$ aditivada durante o ensaio de 2000h (12 semanas). 


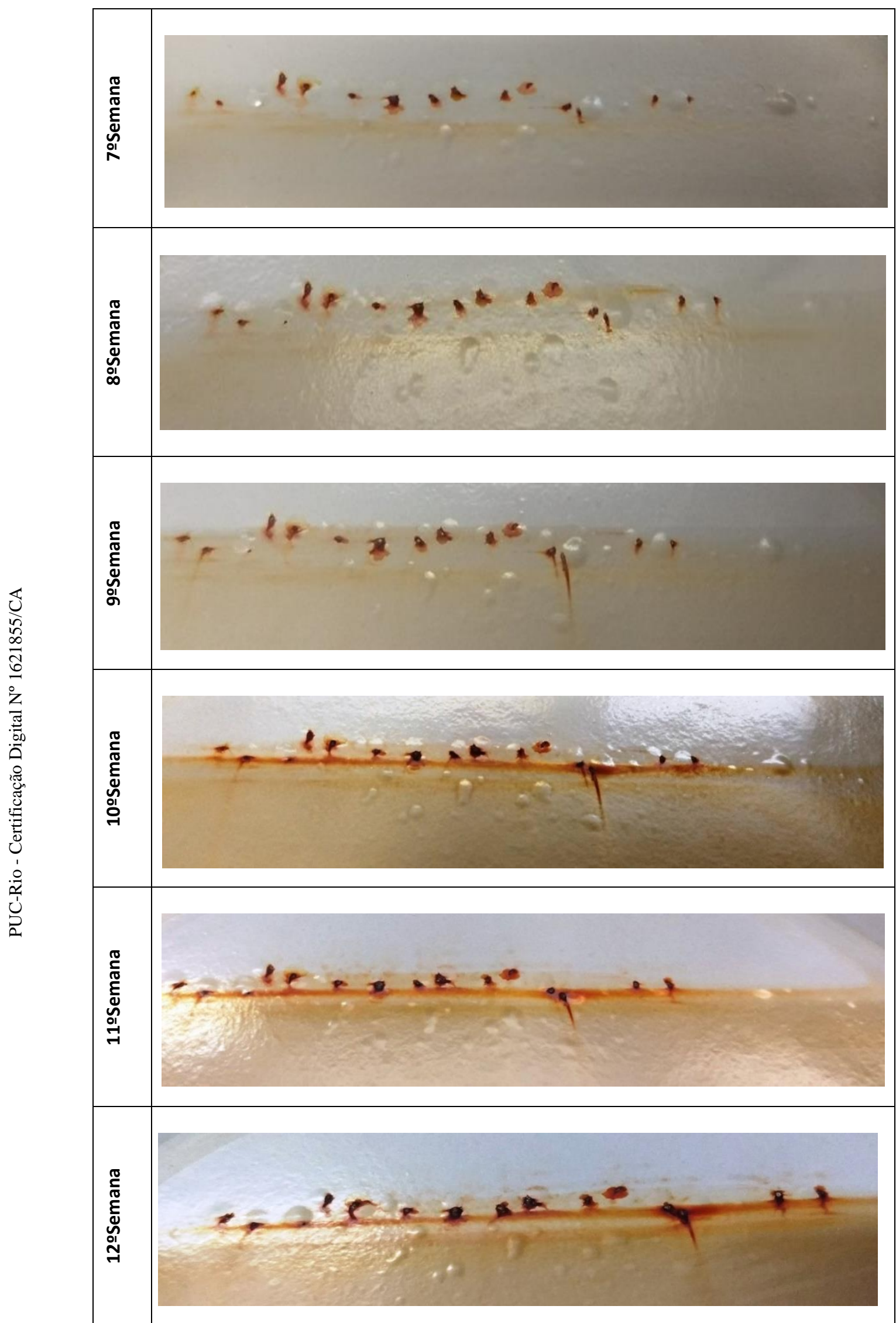

Figura 44: Progressão da corrosão interface liquido-vapor durante o ensaio de 2000h para o revestimento aditivado com $0,5 \%$ de grafeno. 


\subsubsection{Ensaios Cíclicos}

Os ensaios cíclicos foram realizados conforme descrito no Item 4.3.4.2. O aspecto visual do avanço da corrosão para 4, 15 e 22 ciclos pode ser visualizado na Figura 47.

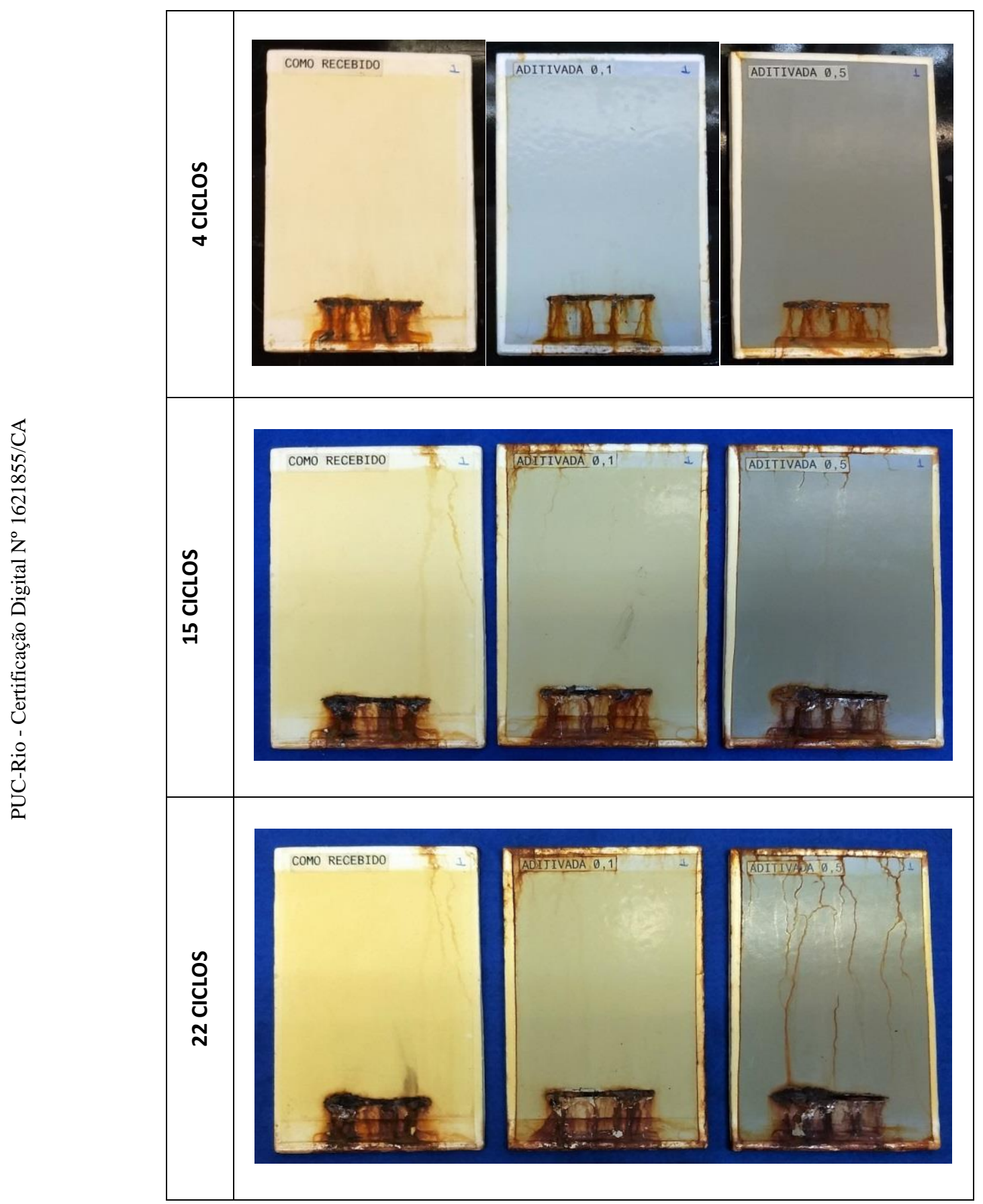

Figura 45: Aspecto Visual da superfície dos corpos de prova ao longo do ensaio cíclico. 
Ao longo dos 25 ciclos, as placas foram se degradando intensamente ao longo do entalhe. O objetivo deste ensaio é quantificar o progresso da corrosão ao longo do entalhe e consequentemente avaliar a resistência anticorrosiva dos revestimentos aplicados.

Após o término dos ciclos, foi realizada análise quantitativa (Equação 11) a fim de avaliar o revestimento quanto o seu caráter anticorrosivo.

O avanço da corrosão (A) foi obtido levando em consideração o valor médio da largura do entalhe afetado pela corrosão (P) e a largura do entalhe (L ) definida como $2 \mathrm{~mm}$.

Após o término dos 25 ciclos, para cada uma das condições estudadas, a região do entalhe afetada pela corrosão foi limpa e delimitada, como mostrado na Figura 48.

Para a realização dos cálculos foram realizadas 9 (nove) medidas da largura do entalhe afetada pela corrosão (P), 1 (uma) medida central, 4 (quatro) medidas à direita e 4 (quatro) medidas à esquerda.

Os resultados obtidos das medidas (que foram realizadas em duplicata) para os dois corpos de prova para cada condição estudada, assim como o cálculo do avanço médio da corrosão está mostrado na Tabela 10.

Os valores obtidos mostram que o avanço médio da corrosão, está correlacionado com o aumento da concentração de grafeno no revestimento, como pode ser observado na Figura 48.

Após o ensaio cíclico, as mesmas placas foram submetidas a ensaios de aderência pull off e os resultados obtidos permanecem altos para as três condições (CR, $\mathrm{AD} 0.1 \%$ e $\mathrm{AD} 0.5 \%)$ estabelecidas, havendo pontos que ultrapassaram o limite máximo do equipamento. Os resultados estão listados na Tabela 11. 

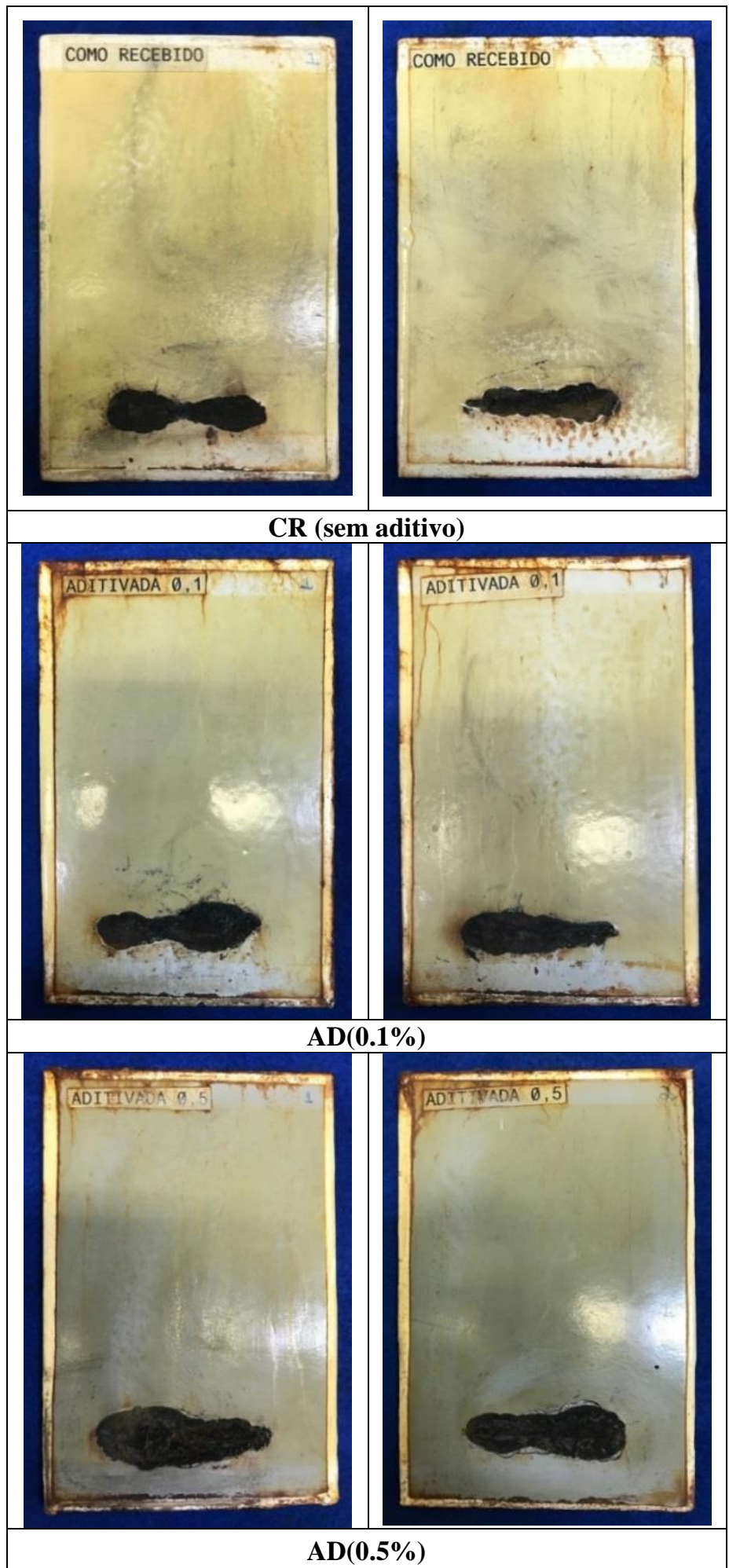

Figura 46: Aspecto do entalhe após 25 ciclos. 
Tabela08: Resultado da análise quantitativa do ensaio cíclico.

\begin{tabular}{|c|c|c|c|c|c|c|}
\hline \multirow{2}{*}{ AMOSTRAS } & \multicolumn{2}{|c|}{ CR } & \multicolumn{2}{|c|}{ AD $(0.1 \%)$} & \multicolumn{2}{|c|}{ AD $(0.5 \%)$} \\
\hline & $1^{\circ}$ & $2^{\circ}$ & $1^{\circ}$ & $2^{\circ}$ & $1^{\circ}$ & $2^{\circ}$ \\
\hline CENTRO & 5 & 8 & 8 & 12 & 20 & 12 \\
\hline \multirow{4}{*}{ DIREITA } & 8 & 9 & 18 & 19 & 19 & 18 \\
\hline & 11 & 12 & 17 & 11 & 15 & 16 \\
\hline & 12 & 13 & 18 & 8 & 16 & 19 \\
\hline & 13 & 9 & 15 & 8 & 13 & 17 \\
\hline \multirow{4}{*}{ ESQUERDA } & 12 & 9 & 10 & 15 & 22 & 19 \\
\hline & 15 & 10 & 12 & 19 & 21 & 15 \\
\hline & 14 & 8 & 12 & 13 & 18 & 14 \\
\hline & 10 & 7 & 11 & 9 & 15 & 12 \\
\hline Pmédio & 11.11 & 9.44 & 13.44 & 12.67 & 17.67 & 15.78 \\
\hline Avanço (A) & 4.56 & 3.72 & 5.72 & 5.33 & 7.83 & 6.89 \\
\hline Amédio & \multicolumn{2}{|c|}{$4.14 \mathrm{~mm}$} & \multicolumn{2}{|c|}{$5.53 \mathrm{~mm}$} & \multicolumn{2}{|c|}{$7.36 \mathrm{~mm}$} \\
\hline
\end{tabular}

Tabela 09: Resultados do teste de aderência pull off após os ensaios cíclicos.

\begin{tabular}{|c|c|c|c|c|}
\hline \multirow{2}{*}{ AMOSTRAS } & \multirow{2}{*}{ REPETIÇÕES } & \multicolumn{2}{|c|}{$P_{\text {Ruptura }}$} & \multirow{2}{*}{ TIPO DE FALHAS } \\
\hline & & PSIG & MPa & \\
\hline \multirow{4}{*}{$\mathbf{C R}$} & $1^{\mathrm{o}}$ & 85 & 23.9 & $20 \% \mathrm{C}+30 \% \mathrm{Y} / \mathrm{Z}+30 \% \mathrm{C} / \mathrm{Y}$ \\
\hline & & 100 & 28.12 & $60 \% \mathrm{C}+20 \% \mathrm{Y} / \mathrm{Z}+20 \% \mathrm{C} / \mathrm{Y}$ \\
\hline & $2^{\circ}$ & 90 & 25.3 & $10 \% \mathrm{C}+90 \% \mathrm{~B} / \mathrm{Y}$ \\
\hline & & 73.5 & 20.8 & $50 \% \mathrm{~B} / \mathrm{C}+50 \% \mathrm{C} / \mathrm{Y}$ \\
\hline \multirow{4}{*}{$\operatorname{AD}(0,1 \%)$} & $1^{\circ}$ & - & - & - \\
\hline & & 73.3 & 20.5 & $90 \% \mathrm{Y} / \mathrm{C}+10 \% \mathrm{C} / \mathrm{Y}$ \\
\hline & $2^{\circ}$ & - & - & - \\
\hline & & 99 & 27.8 & $10 \% \mathrm{C}+60 \% \mathrm{Y} / \mathrm{Z}+30 \% \mathrm{~B} / \mathrm{Y}$ \\
\hline \multirow{4}{*}{$\operatorname{AD}(0,5 \%)$} & $1^{\circ}$ & - & - & - \\
\hline & & 100 & 28.1 & $60 \% \mathrm{C} / \mathrm{Y}+40 \% \mathrm{Y} / \mathrm{Z}$ \\
\hline & $2^{\circ}$ & - & - & - \\
\hline & & 92 & 25.8 & $40 \% \mathrm{C}+30 \% \mathrm{C} / \mathrm{Y}+30 \% \mathrm{Y} / \mathrm{Z}$ \\
\hline
\end{tabular}




\section{Discussão}

\subsection{Caracterização do OGR}

O difratograma do OGR utilizado nesta dissertação, Figura 21, apresenta quatro picos com $2 \theta \mathrm{em} 26.5^{\circ}, 21^{\circ}, 43^{\circ}$ e $51^{\circ}$, onde o primeiro pico possui alta intensidade e os três picos restantes, menor intensidade. Na literatura é reportado que o grafite apresenta difratograma com picos característicos em $2 \theta=26,5^{\circ}$ e $55^{\circ}$ e espaçamento interplanar de 0,335 nm (MARASCHIN, 2016).

Durante o processo de oxidação do grafite, as ligações são quebradas na tentativa de separar as folhas de grafeno e, após o processo oxidativo, através da intercalação de grupos funcionais, o pico característico de reflexão se desloca para um ângulo menor, $2 \theta=11,2^{\circ}$, devido o aumento no espaçamento entre os planos grafíticos para aproximadamente $0,79 \mathrm{~nm}$ (KUILA et al., 2012). Como consequência, o pico $2 \theta=55^{\circ}$ desaparece, traduzindo uma mudança visível na estrutura cristalina do grafite. Após a esfoliação e redução da amostra, forma-se o OGR e o pico em $11,2^{\circ}$ é deslocado para a direita $\left(\sim 24^{\circ}\right)$, devido à tentativa de separar e eliminar parcialmente os grupos funcionais presentes nos planos da amostra (MARASCHIN, 2016).

No presente estudo, os picos gerados no difratograma evidenciam a presença do grafite, com o pico característico em $2 \theta=26,5^{\circ}$, enquanto que o pico em $2 \theta=21^{\circ}$, pode estar relacionado a uma tentativa de restruturação da rede cristalina do grafite, com distância interplanar de $0.42 \mathrm{~nm}$. Os picos observados à direita do difratograma $\left(2 \theta=43^{\circ}\right.$ e $\left.51^{\circ}\right)$, correspondem a distâncias interplanares menores de 0,21 $\mathrm{nm}$ e 0,7 $\mathrm{nm}$. Esta característica pode ser reflexo da elevada tendência à aglomeração das folhas de OGR.

Fidalgo, 2017 obteve o difratograma para o mesmo óxido de grafeno reduzido utilizado nesta dissertação. Para ângulos menores que $20^{\circ}$, não foram observados picos característicos (Figura 49). 


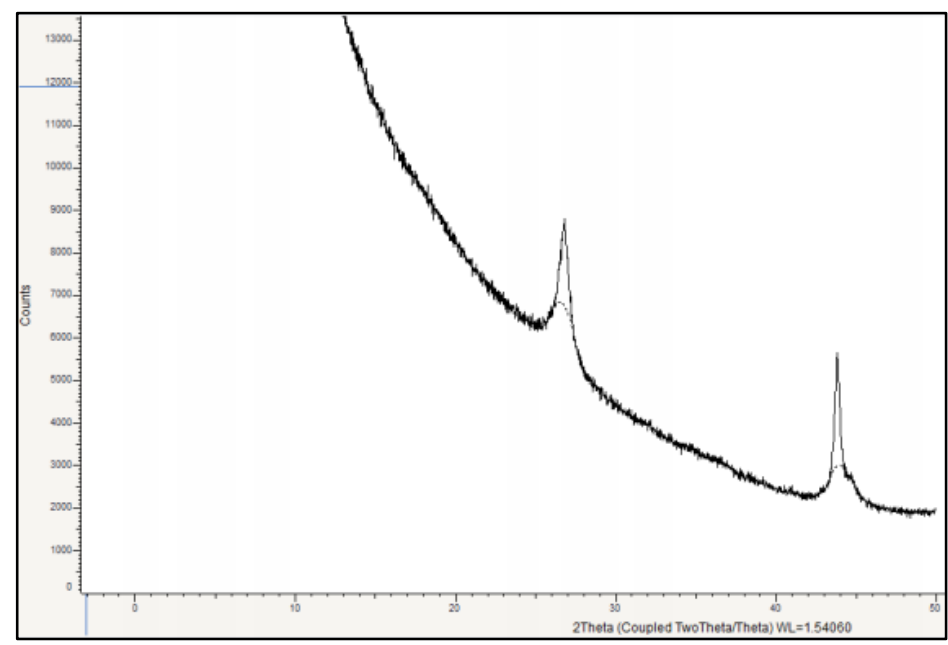

Figura 47: Difratograma do OGR para ângulos entre $10^{\circ}$ e $50^{\circ}$ (FIDALGO, 2017).

Estes resultados mostram a presença de grafite $\left(2 \theta=26,5^{\circ}\right)$ e do OGR , o qual foi confirmado pelo espectro Raman (Figura 22) apresentando picos das bandas características em $1350 \mathrm{~cm}^{-1}$, referende a banda D, $1580 \mathrm{~cm}^{-1}$, referente a banda $\mathrm{G}, 1620 \mathrm{~cm}^{-1}$, referente a banda D' e $2700 \mathrm{~cm}^{-1}$, referende a banda G'.

A banda $\mathrm{G}$ representa os modos vibracionais tangenciais do grafite, referente às ligações do tipo $s p^{2}$ entre carbonos com geometria planar, as bandas D e D' estão diretamente relacionadas aos modos vibracionais gerados por defeitos e funcionalizações, podendo representar ligações do tipo $s p^{3}$ com geometria tetragonal, e a banda $\mathrm{G}^{\prime}$, também associada à desordem e defeitos na estrutura, relacionada ao aspecto vibracional de segunda ordem da banda $\mathrm{D}$, além de ser fundamental na distinção de grafenos com diferentes números de camadas.

Para quantificar a qualidade do processo de reestruturação da rede cristalina, utiliza-se a razão entre as intensidades dos picos $\mathrm{D}$ e $\mathrm{G}\left({ }^{\mathrm{I}} / \mathrm{I}_{\mathrm{G}}\right)$. Considerando que o grafite de boa qualidade apresenta uma estrutura cristalina bem definida e organizada e não possui defeitos, no seu espectro Raman a banda D é inexistente, ou seja, o grafite não possui razão entre as bandas D e G. Baseado no parâmetro definido na literatura, a razão $\mathrm{I}_{\mathrm{D}} / \mathrm{I}_{\mathrm{G}}$ para o óxido de grafeno quimicamente ou termicamente reduzido está entre 1.2 e 1.5, associada a uma presença acentuada de defeitos na rede cristalina do grafeno. Neste estudo, considerando o espectro com o menor grading (600) e com maior intensidade, a razão é de 1.021. Sendo assim é possível concluir que o grafeno reduzido apresenta um elevado grau de defeitos e a estrtura grafítica na foi totalmente 
recuperada (MALARD et al., 2009; DRESSELHAUS et al., 2010; FERREIRA, 2011; SHIN, 2013).

A presença da banda G' é um parâmetro importante na comprovação da eficácia do processo de redução, já que sua presença traduz uma tentativa de restruturação da rede grafítica (ECKMANN et al., 2013;MARASCHIN, 2016).

$\mathrm{Na}$ caracterização estrutural e morfológica do OGR, as micrografias de AFM (Figura 23) ilustram nanometricamente, folhas de grafeno sobrepostas em multicamadas com alturas médias interplanares de aproximadamente 1,69 nm, podendo ser consideradas como nanolâminas de grafeno, com aproximadamente 1-4 camadas, devido à variação tonal da escala adotada. A espessura das multicamadas de OGR variam 4,8 a 5,2 nm, entre o substrato de silício e a última folha sobreposta, também observado por PEREIRA et al., (2018). Cujas folhas de OGR possuíam uma espessura de aproximadamente 5,2 $\mathrm{nm}$ entre o substrato de silício e as nanofolhas de grafeno.

O processo de redução do óxido de grafeno é uma tentativa de eliminação dos grupos funcionais oxigenados, causando a agregação das nanofolhas, causada devido ao restabelecimento parcial das ligações conjugadas do grafeno (SINGH et al., 2011). Nas Figuras 24 e 25 é possível visualizar a superfície da amostra em camadas com diferentes dimensões. Os resultados obtidos neste estudo estão em convergência com a análise feita por espectroscopia Raman.

As micrografias obtidas por MEV/FEG (Figura 26) confirmam essa tendência morfológica do grafeno com aspecto superficial de folhas muito finas, enrugadas, com dobras sobrepostas entre elas. A redução térmica não restaura completamente a estrutura grafítica das amostras, não eliminando, totalmente, os defeitos gerados pelo processo de oxidação do material. Por isso, o aspecto enrugado ainda é perceptível. Hack (2013) e Silva (2011) obtiveram resultados semelhantes aos encontrados nesta dissertação.

Estes resultados confirmam que o grafeno utilizado para aditivar a tinta epóxi Novolac tipo II, foi o óxido de grafeno reduzido (OGR), cujas dimensões são nanométricas. 


\subsection{Caracterização dos Nanocompósitos}

A dispersão/distribuição do aditivo na matriz (Figura 50) é a responsável pelas excelentes propriedades do sistema aditivado. A ocorrência de uma boa dispersão/distribuição do aditivo na matriz polímérica (Figura 50 (d)) ou uma má distribuição (Figura 50 (b)) da nanocarga na matriz polimérica pode influenciar diretamente nas propriedades, atuando como concentradores de tensão, comprometendo o contato superficial entre o nanoreforço e a matriz. Se a distribuição não for apropriada para a aplicação, as nanocargas atuam como defeitos no material, comprometendo suas propriedades. A dispersão está relacionada ao estado de aglomeração e a distribuição é atribuída à homogeneidade da amostra (WANG et al., 2004; LI et al., 2008; DU et al.,2004; WENG et al., 2003).

Os espectros de FTIR (Figura 30) para o revestimento epóxi (CR) e para os nanocompósitos mostraram as bandas características da estrutura epóxi curada. É possível visualizar que os espectros obtidos não apresentam diferenças significativas entre eles, apenas pequenos deslocamentos das bandas de absorção. Segundo Silverstein \& Webster (2000), a região de absorção próxima à banda $915 \mathrm{~cm}^{-1}$ está atribuída à presença de anéis epoxídicos, indicando o grau de cura da resina, ou seja, quanto maior a quantidade de anéis que reagirem menor a intensidade da banda e maior o grau de cura da resina. Analisando o espectro da Figura 51, nota-se que a intensidade dessa banda é aproximadamente nula, indicando um elevado grau de cura da resina nas condições estudadas.

$\mathrm{Na}$ banda de absorção $870 \mathrm{~cm}^{-1}$ é possível visualizar um pico mais acentuado para a condição $\mathrm{AD} 0.5 \%$ em relaçao as demais. Tal banda está relacionado a deformação axial assimétrica do anel epoxídico, conforme Tabela 12. 


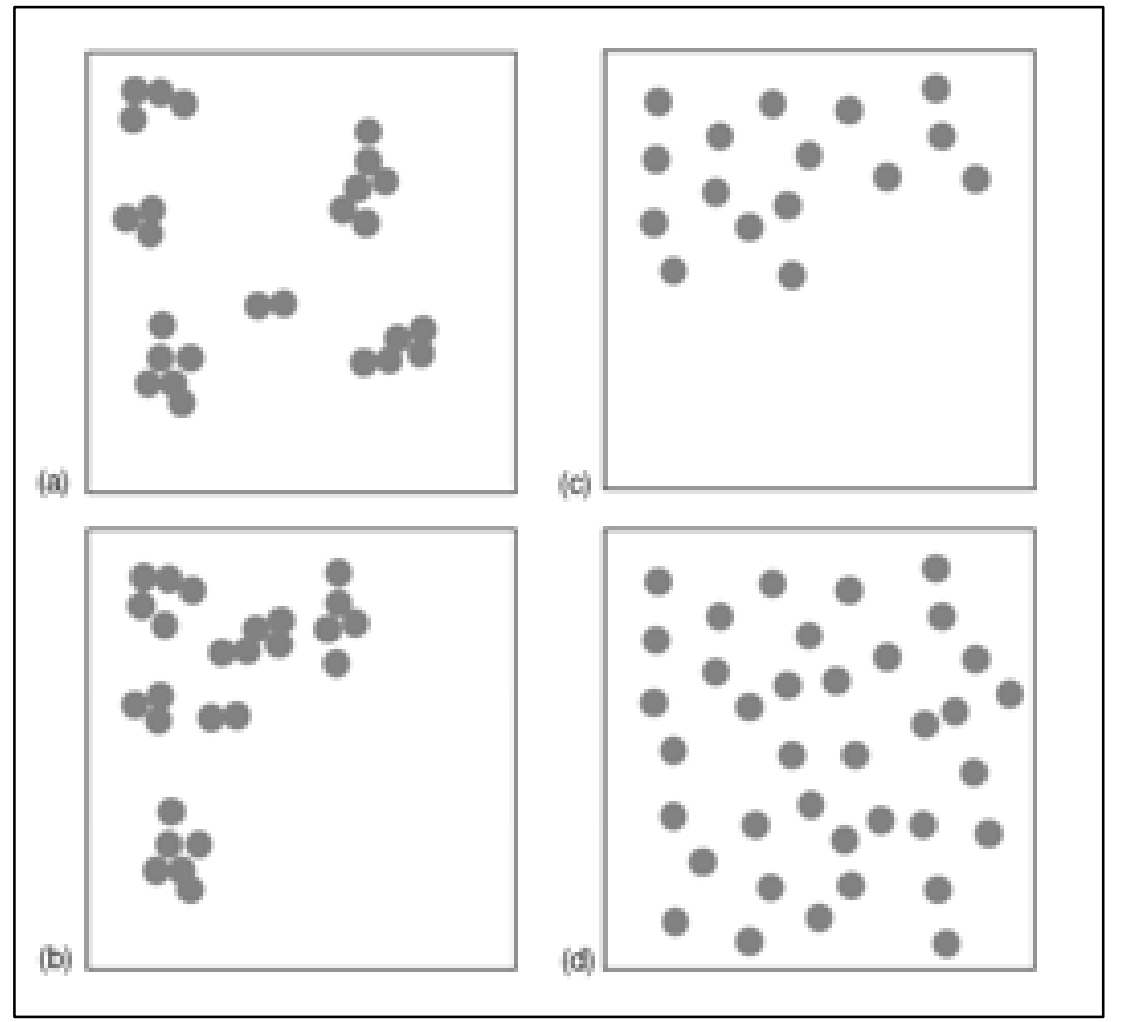

Figura 48: Ilustração esquemática de dispersão/distribuição a) má dispersão e boa distribuição b) má distribuição e dispersão c) má distribuição e boa dispersão d) boa distribuição e dispersão (Adaptado de AJAYAN et al., 2003).

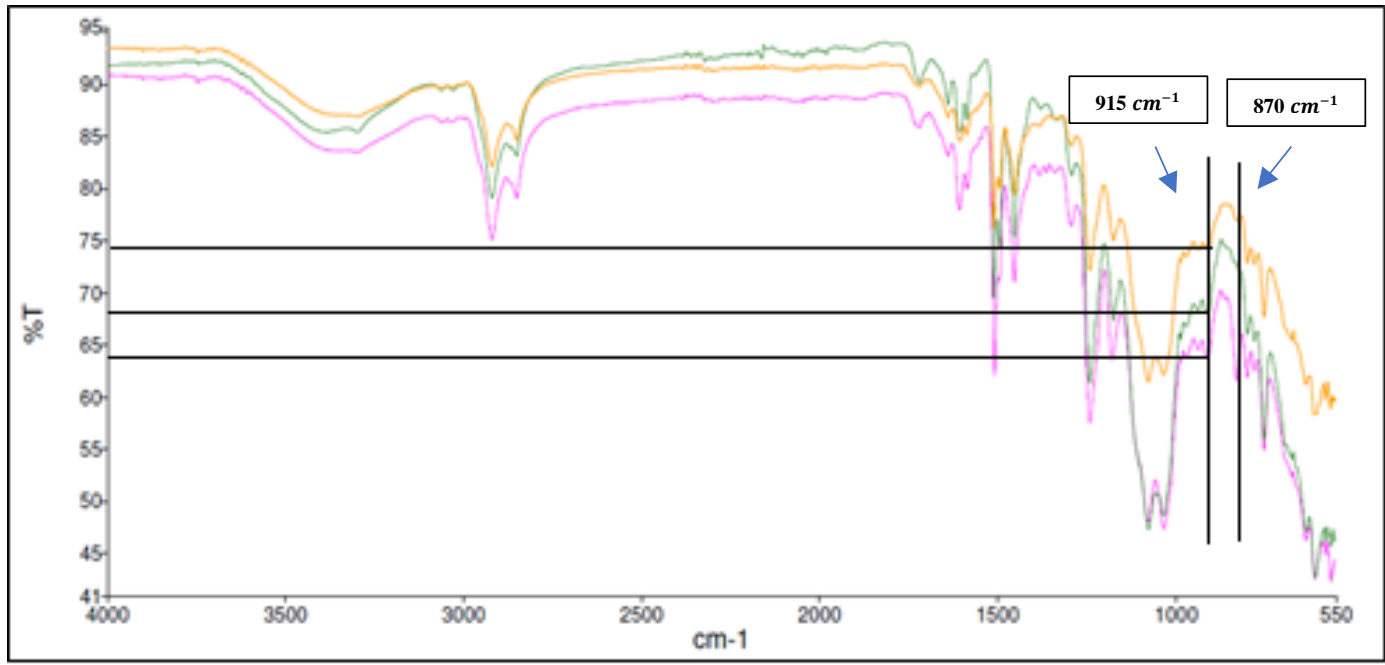

Figura 49: Espectro de FTIR para os nanocompósitos nas condições CR (Verde), AD0.1\% (Amarelo) e AD0.5\%(Rosa).

A Tabela 12 relata as atribuições das principais bandas de absorção observadas no espectro FTIR referente à resina epoxídica curada e não curada. Outras bandas importantes na interpretação de espectros da resina epoxídica estão em $1242 \mathrm{~cm}^{-1}$, relacionada à deformação axial simétrica em fase das ligações C$\mathrm{C}$ e $\mathrm{C}-\mathrm{O}$ de anéis epoxídicos em $864 \mathrm{~cm}^{-1}$, atribuída à deformação axial 
assimétrica do anel epoxídicos, na qual as ligações $\mathrm{C}-\mathrm{C}$ não se alteram, enquanto uma ligação $\mathrm{C}-\mathrm{O}$ estira e a outra contrai.

A sobreposição dos espectros (Figura 30) indica que a presença do grafeno na matriz polimérica não introduz nenhum pico adicional ao espectro base do revestimento epóxi, porém pode ter provocado pequenos deslocamentos de picos característicos (HACK, 2013). Ou seja, a adição de grafeno não interferiu significativamente na estrutura química da resina epoxídica utilizada nesta dissertação. Comportamento semelhante foi observado por Silva (2011), concluindo que não foi evidenciada a formação de ligações entre a matriz e o nanoreforço.

Tabela 10: Principais bandas de absorção da resina epoxídica curada e não curada.

\begin{tabular}{ll}
\hline BANDAS & ATRIBUIÇÕES \\
\hline 3384 & Deformação axial da ligação O-H \\
\hline 3038 & Deformação axial da ligação C-H de anéis aromáticos \\
\hline $\begin{array}{l}\text { e } 287,2925 \\
1607,1581\end{array}$ & Deformação axial da ligação C-H de grupos CH2 e CH3 \\
e 1507 & Deformação axial da ligação C-C de anéis aromáticos \\
\hline 1457 & Deformação angular assimétrica da ligação C-H de grupos CH3 \\
\hline 1362 & Deformação angular simétrica da ligação C-H de grupos CH3 \\
\hline 1295 & Deformação angular das ligações C-H de anéis aromáticos \\
\hline 1242 & $\begin{array}{l}\text { Deformação axial simétrica em fase das ligações C-C e C-O de anéis } \\
\text { epoxídicos, na qual essas fases se extiram e se contraem em fase }\end{array}$ \\
\hline 1181 e 1033 & $\begin{array}{l}\text { Deformação axial da ligação C-O acoplada à deformação axial da ligação } \\
\text { C-C adjascente }\end{array}$ \\
\hline 915 & $\begin{array}{l}\text { Deformação axial assimétrica do anel epoxídico, na qual as ligações C-C } \\
\text { estiram, enquanto as ligações C-O se contraem }\end{array}$ \\
\hline 864 & $\begin{array}{l}\text { Deformação axial assimétrica do anel epoxídico, na qual as ligações C-C } \\
\text { não se alteram, enquanto uma ligação C-O estira e contrae }\end{array}$ \\
\hline 826 & Deformação angular simétrica fora do plano do grupo OH- \\
\hline 767 e 736 & Deformação angular fora do plano da ligação C-H de anéis aromáticos \\
\hline
\end{tabular}

Fonte: Silverstein \& Webster (2000).

De modo a verificar a condutividade elétrica do nanocompósito em função da concentração de grafeno foi realizado o teste quatro pontas (Efeito Hall). O teste foi executado com correntes muito pequenas, em função da natureza polimérica da matriz obtendo-se valores de condutividade elétrica muito pequenos (Tabela 07) e muito similares.

Como o óxido de grafeno reduzido foi esfoliado via mecanismo de ultrassom, a tendência é que ele esteja disperso na matriz polimérica. Já que o 
mecanismo de esfoliação promove uma boa dispersão e distribuição das nanocargas, pois está relacionado à afinidade física ou química entre os componentes do sistema (WANG et al., 2004).

A maximização das propriedades elétricas está associada ao fenômeno de percolação elétrica. Nos compósitos de polímeros isolantes, como a resina epóxi, as nanopartículas formam caminhos condutores preferenciais, dependendo da natureza da carga utilizada. Em baixa concentração de nanopartículas, a condutividade elétrica do sistema é essencialmente a do meio polimérico. Com a adição progressiva de nanopartículas, a concentração crítica é atingida, promovendo uma variação significativa nas propriedades elétricas do compósito (Figura 52). A partir desse limiar de percolação, o nanocompósito passa a conduzir corrente elétrica, devido à formação de um caminho condutor na matriz isolante (KARÁSEK et al., 1996; SOARES et al., 1998; SOARES, 2018).

O sistema (epóxi Novolac tipo II + OGR) estudado não apresentou mudança significativa para o incremento das propriedades elétricas no material, podendo sugerir que a concentração de nanopartículas de OGR é inferior à concentração crítica, não permitindo um aumento nas propriedades elétricas do sistema polimérico estudado. Além disso, a natureza isolante das partículas sólidas cerâmicas presentes na composição da tinta pode ter influenciado nas propriedades elétricas do nanocompósito.

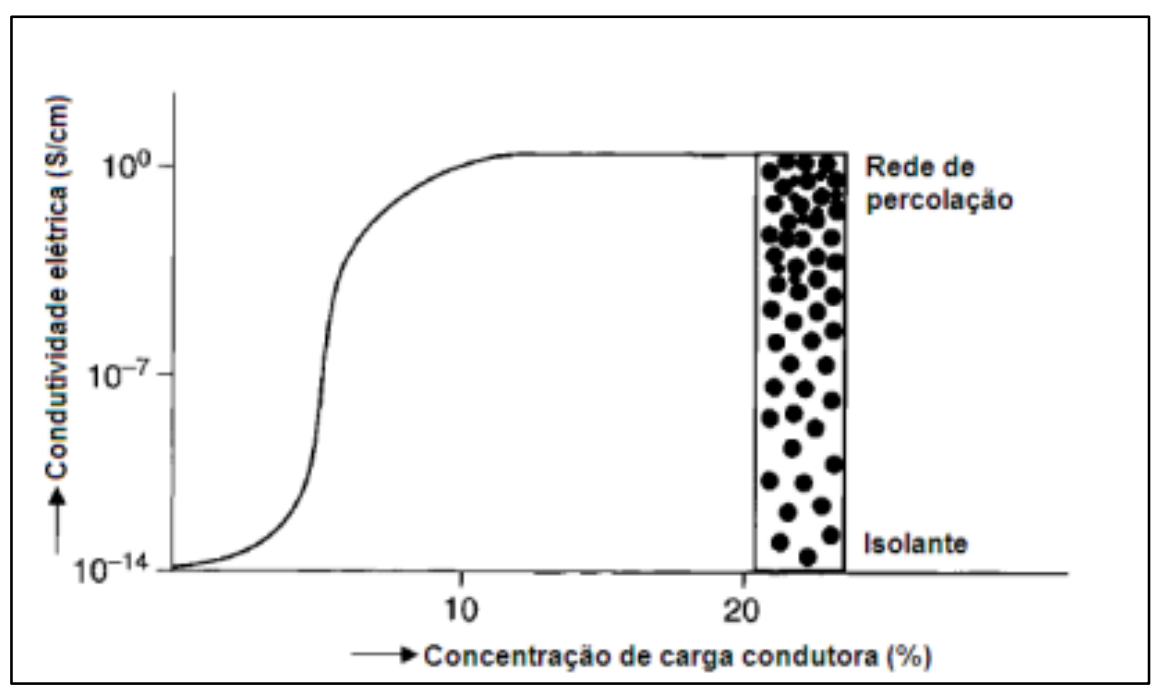

Figura 50: Representação da dependência da condutividade elétrica de um polímero condutor em função da concentração de carga condutora (CIVIERO, 2010). 


\subsection{Aderência do Sistema (Nanocompósito + Substrato)}

A rugosidade é considerada um parâmetro indispensável, pois atua diretamente na propriedade de aderência entre o revestimento e o substrato. Independente da finalidade do revestimento, o ideal é que o sistema (revestimento/substrato) mantenha a sua integridade adesiva durante a sua vida útil. Uma das formas de maximizar a aderência do sistema é através da preparação adequada do substrato (FERREIRA et al., 2002).

As tintas aderem ao substrato metálico por ligações físicas, químicas ou mecânicas. As interações químicas e físicas ocorrem através da interação entre moléculas existentes nas resinas com os grupos presentes nos metais. Já a ligação mecânica está associada às outras duas, com necessidade de uma rugosidade na superfície (GNECCO et al., 2003). A preparação da superfície engloba operações que garantam limpeza e rugosidade da superfície tratada. O jateamento abrasivo é o método mais eficiente para a remoção da camada de óxidos e outros contaminantes, através de abrasivos projetados sob altíssimas pressões, na faixa de $7 \mathrm{~kg} / \mathrm{cm}^{2}$.

Segundo o Manual de Preparação de Superfície (WEG), é considerado o método mais eficiente na obtenção de excelentes perfis de rugosidade, garantindo uma boa ancoragem da tinta na superfície metálica. Portanto, a eficiência na qualidade da limpeza e um elevado perfil de rugosidade estão associados a uma melhor aderência do sistema (revestimento/substrato).

A superfície do substrato estudado foi submetida a um processo de jateamento abrasivo padrão, com tratamento superficial SA2 $1 / 2$ e a rugosidade média obtida pelo rugosímetro analógico (Tabela 09), foi de $60.8 \mu \mathrm{m}$. Segundo o Boletim Técnico da tinta WEG Novolac tipo II baseado na norma Petrobras N2912, o valor recomendado para a rugosidade média de superfícies submetidas ao jateamento abrasivo é entre 50 - 100 micrômetros. Sendo assim, o valor obtido no ensaio de rugosidade está dentro do limite estimado pela norma seguida.

Segundo Gnecco et al., 2003, idealmente, o perfil de rugosidade deve situar -se entre 1/4 a 1/3 da espessura total do esquema de pintura, somado todas as demãos. Um perfil de rugosidade baixo produz uma base metálica insuficiente para a boa aderência do revestimento, já um perfil de rugosidade muito elevado, promove a cobertura desigual dos picos altos, gerando possíveis pontos 
localizados de corrosão, consumo desproporcional de tinta e falha prematura do sistema. A geometria esférica da granalha de aço utilizada no tratamento abrasivo das placas de aço possui tamanho de partículas de $1 \mathrm{~mm}$, confirmando um valor de altura máxima de perfil em $75 \mu \mathrm{m}$ (Tabela 13). O valor de rugosidade média obtida $(60.8 \mu \mathrm{m})$ está dentro do limite para ambas os métodos.

Tabela 11: Perfil de Rugosidade baseado na geometria da granalha de aço.

$\begin{array}{cccc}\begin{array}{c}\text { Granalha } \\ \text { de aço }\end{array} & \text { Tamanho da } & \text { Peneira ABNT (NBR } & \text { Altura máxima do } \\ \text { partícula }(\mathrm{mm}) & 5734) & \text { perfil }(\mu \mathrm{m})\end{array}$

\begin{tabular}{|c|c|c|c|}
\hline Angular & 1.7 & 12 & 70 \\
\hline Angular & 0.4 & 40 & $30-75$ \\
\hline Angular & 0.7 & 25 & 85 \\
\hline Angular & 1.0 & 18 & 90 \\
\hline Angular & 1.2 & 16 & 100 \\
\hline Angular & 1.7 & 12 & 200 \\
\hline Esférica & 0.85 & 20 & $45-70$ \\
\hline Esférica & 1.0 & 18 & 75 \\
\hline Esférica & 1.2 & 16 & 85 \\
\hline Esférica & 1.4 & 14 & 90 \\
\hline
\end{tabular}

Fonte: Adaptado de GNECCO et al., 2003.

Os perfis topográficos foram traçados em cinco pontos da amostra, para aumentar a precisão dos dados. Na Figura 32a) é possível visualizar os perfis dos cinco pontos com diferentes filtros. Numéricamente estimou-se valores de rugosidade média em cada ponto a partir da média das profundidades entre picos e vales. Os valores obtidos no ensaio de Microscopia Óptica, na Figura 32b), são similares aos valores obtidos analogicamente, variando entre 62,5 $-72 \mu \mathrm{m}$. Observa-se que mesmo utilizando metodologias diferentes, a média desses valores $(62,7 \mu \mathrm{m})$ se enquadra dentro dos valores recomendados, indicando que as rugosidades obtidas estão dentro do padrão exigido.

A análise adesão interfacial avaliada qualitativamente, através de micrografias obtidas por MEV (Figura 27) e quantitativamente através do ensaio de aderência Pull Off, (Tabela 08), mostrou que a tinta depositada na superfície metálica apresentou boa molhabilidade preenchendo todas as imperfeições da superfície. A presença de bolhas em ambas as condições (CR e AD0.5\%) está 
relacionada a intensa tixotropia e viscosidade da tinta, como apontado no manual do fabricante. A rugosidade de $60,8 \mu \mathrm{m}$, permitiu uma boa aderência ao substrato, como mostrado pelos resultados obtidos no teste pull off ultrapassando o valor mínimo requisitado de $15 \mathrm{MPa}$, e deste modo é considerado satisfatório em acordo com a Norma Petrobras N2912. De acordo com os resultados obtidos, a aditivação com grafeno não interferiu na propriedade de aderência ao substrato, apresentando tensões de ruptura elevadas para todas as condições estudadas. Os modos de falhas (Figura 18) foram semelhantes, oscilando entre falhas adesivas e coesivas, para todos os pontos ensaiados. Estes resultados indicam que a aditivação não interferiu nos mecanismos de adesão do sistema.

\subsection{Ensaios de Corrosão}

Os resultados obtidos no ensaio de imersão em célula atlas traduzem um comportamento inverso à presença do grafeno (OGR) na matriz polimérica da tinta estudada. As primeiras $504 \mathrm{~h}$ do ensaio mostram que, quanto maior a concentração de grafeno na tinta, menor o seu potencial anticorrosivo. Neste tipo de ensaio, as primeiras semanas são determinantes para traçar o perfil comportamental ao longo do ensaio completo. É possível visualizar que após as três semanas iniciais, as placas com maior concentração de grafeno na sua composição $(0,25 \%$ e $0,5 \%)$ possuíam bolhas na interface entre fases líquida e vapor da solução salina (Figura 53).

A interação entre os átomos da interface com seus vizinhos difere daquela dos átomos no interior do líquido. Os átomos da interface ligam-se apenas com seus átomos vizinhos da parte interior do líquido, uma vez que na fase vapor os átomos estão muito dispersos. Esta característica torna as interfaces regiões de maior energia, exibindo comportamento distinto daquele do interior do líquido. A coesão é mais acentuada na superfície do líquido promove o surgimento de uma fina película revestindo toda sua extensão. A tensão superficial é influenciada diretamente pela temperatura, quanto maior o seu valor, mais fraca é a interação atômica e menor será a sua tensão superficial. Na medida em que a temperatura se eleva, a massa específica do vapor aumenta e a do líquido diminui, até um determinado ponto (temperatura crítica) no qual as massas específicas, do líquido e vapor se igualam e a interface entre as fases desaparece (ATKINS, 2008). 
Devido essa instabilidade termodinâmica, a região afetada do sistema foi a interface, onde ocorreu o surgimento de bolhas em toda sua extensão. Comportamento similar foi observado por Stoot et al., 2015, onde a região da interface líquido-vapor foi a mais afetada no ensaio em célula atlas para placas inoxidáveis com uma camada de níquel revestida com uma película de grafeno. Esse comportamento foi atribuído à concentração de oxigênio ser maior na fase vapor que no líquido, quando submetidos a altas temperaturas.

Nesta dissertação, a temperatura do sistema célula atlas (eletrólito/revestimento) foi mantida constante na temperatura de $60{ }^{\circ} \mathrm{C}$, ao longo de todo o teste. Neste sistema as fases (líquido e vapor) coexistiram em equilíbrio durante todo o ensaio, não havendo, portanto, incremento de temperatura suficiente para atingir a temperatura crítica. Observa-se que no sistema utilizado o vapor não era dissipado, devido à presença de um condensador.

Para a placa com revestimento contendo $0.1 \%$ de grafeno, a área exposta suportou as 504h iniciais sem sofrer nenhuma alteração física. A continuidade do teste de $2000 \mathrm{~h}$ para a condição $\mathrm{AD} 0.1 \%$ não foi possível devido problemas operacionais durante o ensaio.

Comparativamente, é possível sugerir que a concentração de $0,1 \%$ de grafeno não foi suficiente para modificar a propriedade anticorrosiva da tinta epóxi Novolac tipo II durante as primeiras 504h de ensaio.

Observa-se que placas revestidas com a Novolac tipo II nas condições de como recebida (sem aditivação) não sofreram nenhum tipo de alteração ao longo de $2000 \mathrm{~h}$ de ensaio.

Com o aumento da concentração de grafeno para $0,25 \%$ foi possível observar que para esta aditivação (Figuras 37 e 41) as bolhas surgem na terceira semana e se propagaram lentamente ao longo do ensaio, porém não ocorre exposição do substrato à atmosfera.

No caso da aditivação contendo $0,5 \%$ de grafeno (Figuras 39, 43 e 46), as bolhas surgem desde a primeira semana, e expõe o substrato nas primeiras 504h, e consequentemente levando a degradação do mesmo.

Algumas questões experimentais complementres precisam ser levadas em conta na discussão destes resultados. No processo de aditivação com grafeno, para permitir a dispersão do OGR, foi adicionado o DGEBA no componente A da tinta. Isto pode ter gerado resquícios de DGEBA não reagido no interior o 
revestimento, o que levaria a potenciais pontos de susceptibilidade ao ataque corrosivo. Igualmente pode ser considerado que o solvente utilizado para a aplicação do revestimento pode ter intergido com as plaquetas de OGR, mantendo-se dentro do revestimento gerando defeitos microscópicos. A interferência desses fatores, inexistentes no revestimento sem aditivo, são mais significativos á medida que a concentração de OGR aumenta, pois com ele aumenta a presença de DGEBA ou solvente residual. A possível influência destas dificuldades experimentais deverá ser avaliada em estudos futuros.

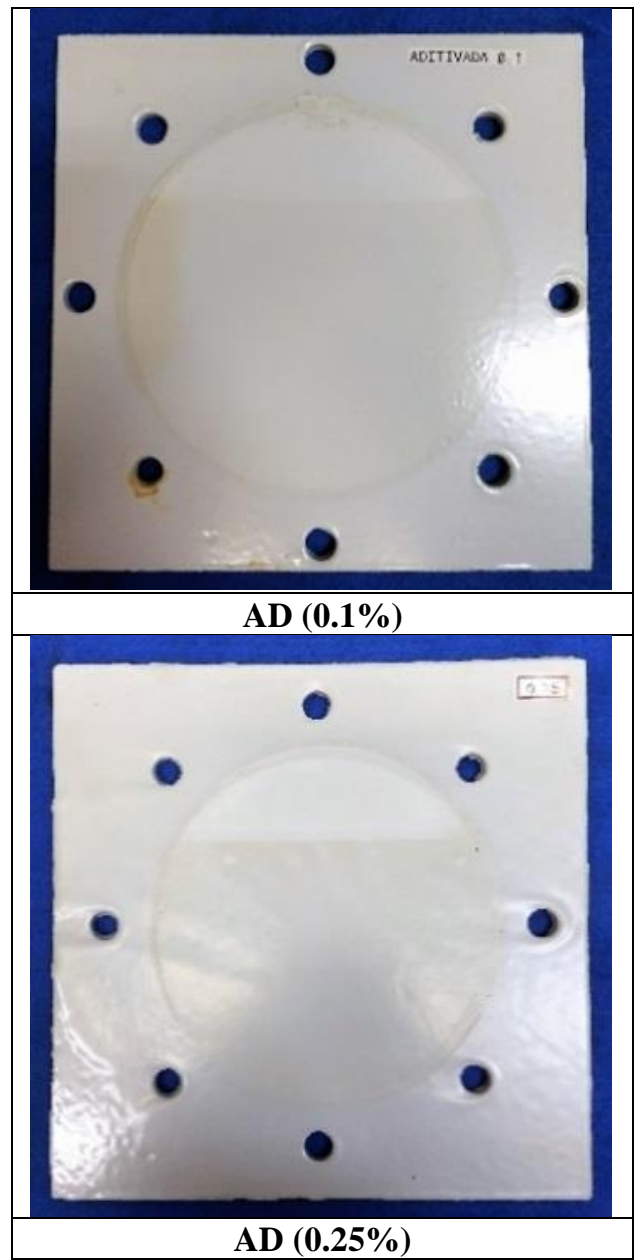




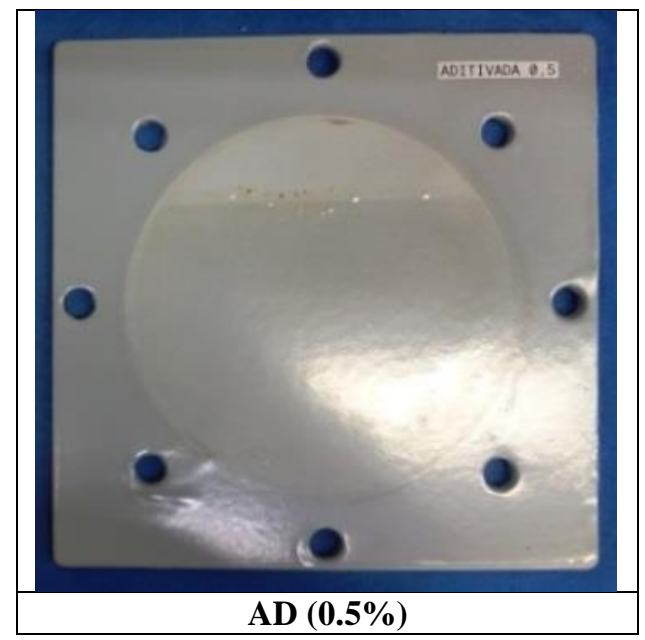

Figura 51: Superfície das placas após o ensaio de 504h.

O revestimento estudado (Novolac tipo II) possui um teor de sólidos em sua composição de $96 \pm 1 \%$, (norma ISO3233-1198), considerada excelente por possuir elevado poder anticorrosivo em acordo com a Norma Petrobras N2912 (Tipo II). A aditivação deste revestimento com nanopartículas de grafeno em concentrações $C_{g} \geq 0.25 \%$ pode ter provocado a supersaturação da concentração máxima de sólidos permitida, gerando pontos de fragilização ao longo da interface, e comprometendo a capacidade anticorrosiva do revestimento.

$\mathrm{Na}$ Figura 54 é possível visualizar a proliferação das bolhas ao longo da interface em função da concentração de grafeno no revestimento. Nitidamente a interface com maior concentração de grafeno possui um maior número de bolhas. Ao longo do ensaio completo (2000h) nas placas aditivadas, as bolhas foram se proliferando ao longo da interface, com taxas proporcionais às suas concentrações de grafeno. As placas com revestimento sem aditivação (Figura 44) apresentaram comportamento anticorrosivo ao longo do ensaio, sem apresentar qualquer alteração na superfície exposta ao ensaio de imersão em célula atlas.

Estudos eletroquímicos realizados por Rajabi et al., 2014 mostraram que o nanocompósito com $0.25 \%$ em massa de óxido de grafeno disperso na matriz polimérica epóxi obteve a melhor proteção anticorrosiva para diferentes tempos de imersão, comparado as condições como recebida (sem aditivação) e aditivadas com proporções em massa de $0.125 \%$ e $0.5 \%$ de OG. A literatura sugere que o aumento da resistência à corrosão só ocorre em revestimentos aditivados com uma pequena quantidade de nanopartículas de GO. Todavia, para os nanocompósitos aditivados com $0.5 \%$ em massa de $\mathrm{OG}$ a resistência à corrosão foi regredindo à 
medida que o tempo de exposição ao eletrólito aumentava. Os autores associam esse comportamento a uma maior concentração de carga (OG) e a elevada área superficial das folhas. Devido à alta energia superficial das folhas, possuem elevada tendência à aglomeração.

O potencial anticorrosivo de nanocompósitos com matriz epóxi aditivados com diferentes concentrações em peso $(0.05 \%, 0.1 \%, 0.3 \%$ e $0.5 \%)$ de grafeno policristalino (PG) foi estudado por Pourhashem et al., 2018. Os resultados obtidos por ensaios eletroquímicos mostraram que os nanocompósitos proporcionaram maior resistência à corrosão, comparado ao epóxi puro. Entretanto, os nanocompósitos contendo $0.05 \%$ em massa de PG apresentaram resistência à corrosão superior e menor molhabilidade. Para concentrações maiores que $0.05 \%$, foi sugerido que as folhas de PG aglomeram-se na matriz polimérica, aumentando a carga aditivada de PG. A consequência desse aumento ocasiona o aumento da hidrofilicidade e a diminuição da resistência à corrosão. Sendo assim o autor concluiu que a concentração em peso de PG tem influência direta nas propriedades anticorrosivas dos nanocompósitos finais. Pois, quanto maior a porcentagem em peso de PG, menores o ângulo de contato com a água e a resistência à corrosão.

Portanto, existem múltiplos fatores que podem influenciar diretamente no comportamento anticorrosivo dos nanocompósitos estudados. Desde a natureza defeituosa do grafeno e sua interação com a matriz polimérica até a influência direta da presença crescente de DGEBA e solvente no sistema à medida que a concentração do OGR aumentou.

Além disso, os ensaios realizados buscaram avaliar a capacidade de proteção do revestimento para testes de longos períodos de exposição e confome mencionado por Tiwari et al., 2017 existe uma tendência a falha para testes de longa duração. Todavia esta discussão necessitará de resultados complementares para ser elucidada. 


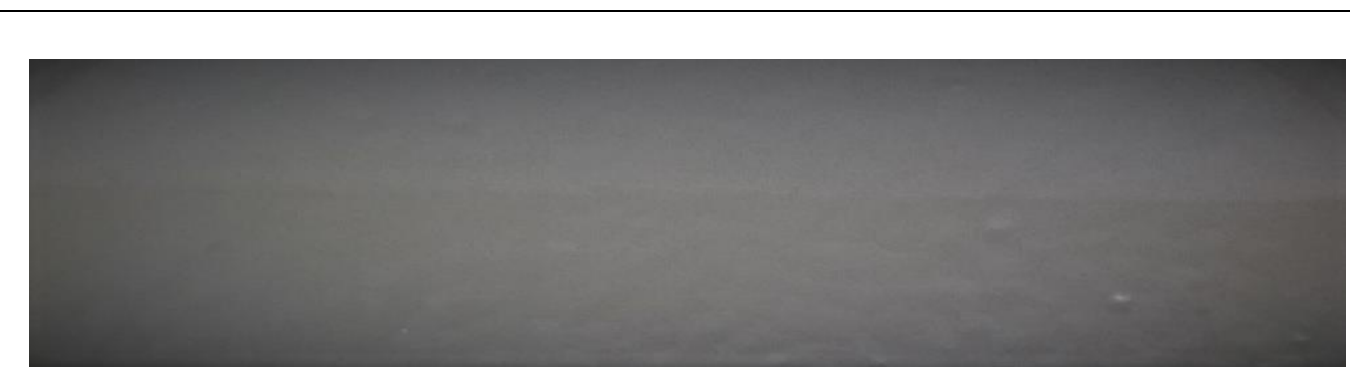

\section{AD $(0.1 \%)$}

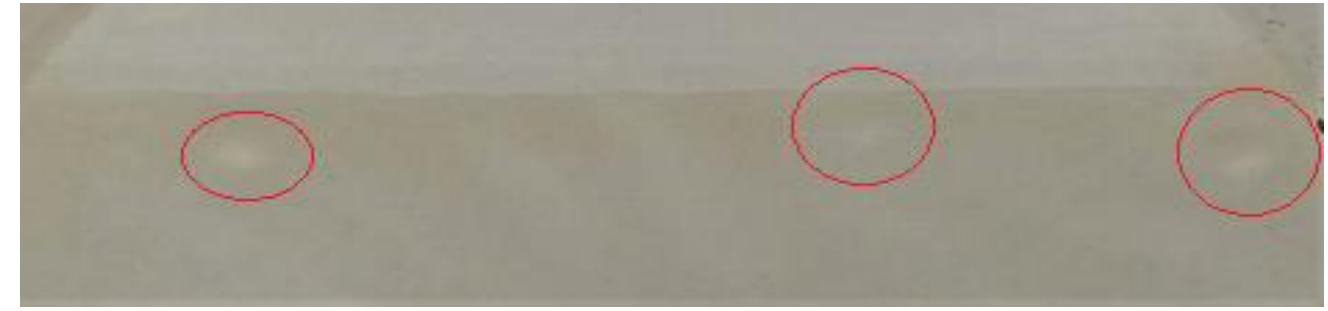

AD (0.25\%)

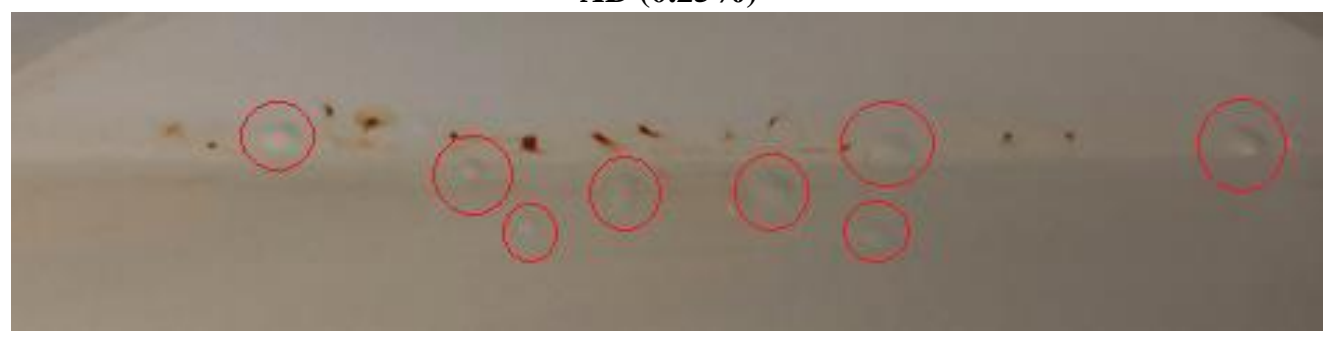

$\operatorname{AD}(0.5 \%)$

Figura 52: Interfaces após o ensaio de 504h.

Os ensaios cíclicos apresentaram comportamento semelhante, as placas revestidas com $0,1 \%$ e $0,5 \%$ obtiveram os maiores valores de avanço da corrosão, comparadas a condição como recebida. Visualmente (Figura 55) é possível perceber essa diferença, uma vez que a área comprometida pelo avanço da corrosão é maior para maiores concentrações de grafeno. O teste realizado em duplicata mostrou convergência no resultado. E como previsto pela Norma ISO20340, após o ensaio cíclico as placas não apresentaram bolhas e pontos de corrosão superficial, nem o avanço da corrosão foi superior a $10 \mathrm{~mm}$. $\mathrm{O}$ avanço oscilou entre valores 4 e $7.5 \mathrm{~mm}$, mas não ultrapassou o limite previsto pela Norma.

Os valores calculados na Tabela $\mathbf{1 0}$ confirmam a mesma tendência observada visualmente para revestimentos com maior concentração de grafeno. 


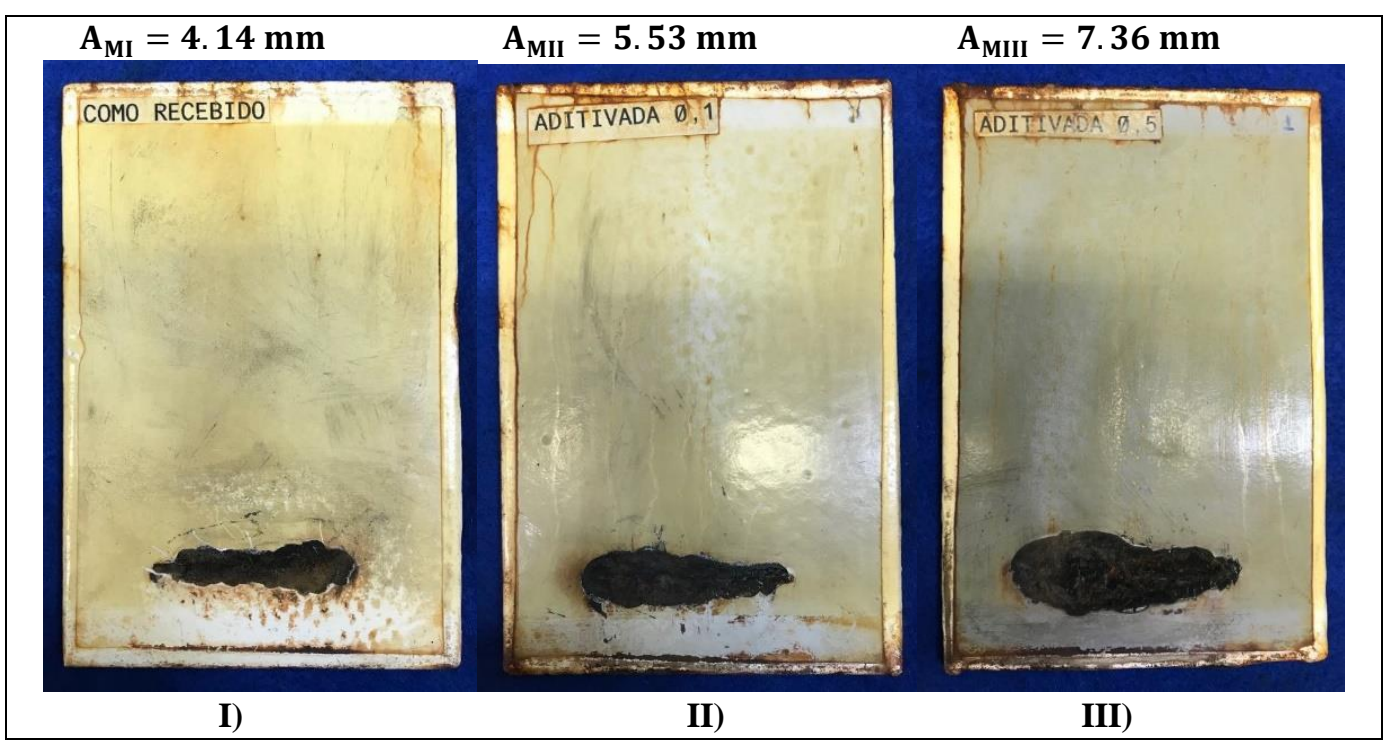

Figura 53: Avanço da corrosão pós-ensaio cíclico nas condições CR, AD0.1\% e AD0.5\%.

Além disso, os resultados obtidos no teste de aderência pull off confirmam a independência do comportamento adesivo do revestimento com a concentração de grafeno e acrescenta que a deterioração causada pelo efeito da corrosão não comprometeu pontos distintos fora do entalhe, traduzindo que o efeito do ensaio cíclico não fragilizou completamente o revestimento.

Os resultados dos testes de corrosão realizados para as condições de aditivação estudadas indicam que a adição de grafeno acima de $0.1 \%$ neste revestimento (Novolac II) leva a falha de proteção anticorrosiva. 


\section{Conclusões}

Os resultados obtidos nessa dissertação permitiram estabelecer as seguintes conclusões:

- Através das técnicas de caracterização do OGR foi possível confirmar a origem oxidada e reduzida do grafeno, bem como se constatou a presença do grafite no material estudado;

- A natureza condutiva do OGR pode ter sido comprometida pela alta dispersão das nanopartículas de grafeno ou pela natureza cerâmica isolante das partículas presentes na composição da tinta, atrapalhando o efeito de percolação elétrica no material. Além disso, como o grafeno é multicamada, as possíveis configurações presentes podem influenciar no comportamento condutor ou semicondutor dos nanocompósitos;

- Os valores de rugosidade do substrato metálico obtidos por diferentes métodos (Rugosímetro analógico e Microscopia Óptica) foram similares. A rugosidade obtida ratifica as excelentes propriedades de aderência do sistema, através do ensaio pull off;

- A deterioração do revestimento como resultado da difusão do eletrólito no revestimento foi superior para o revestimento Novolac tipo II com concentração de óxido de grafeno reduzido (OGR) $C_{g}>0.1 \%$, ocasionando falha de proteção anticorrosiva;

- Através dos ensaios cíclicos, constatou-se que o avanço da corrosão progrediu com o aumento da concentração de grafeno, porém não ultrapassou o limite de $10 \mathrm{~mm}$, estabelecido pela Norma ISO20340;

- As tensões de ruptura obtidas pelo teste de aderência pós-ensaio cíclico continuaram elevadas e constatou-se que a deterioração causada pelo efeito da corrosão não comprometeu pontos distintos fora do entalhe e não influenciou na adesão do sistema. 


\section{Sugestões para trabalhos futuros}

Considerando as conclusões obtidas nesta dissertação de mestrado, trabalhos futuros devem considerar:

- Utilização de matriz polimérica de resina epoxídica pura, sem a adição de partículas sólidas em sua composição.

- Obtenção dos dados eletroquímicos referente ao comportamento dos revestimentos em solução contendo cloreto;

- Caracterização de cada um dos componentes da tinta (componente A), antes da aditivação, a fim de obter propriedades estruturais e ligações químicas na condição pré-cura.

- Caracterização da cura dos nanocompósitos por técnicas mais aprofundadas (Termogravimetria - TG, Calorimetria Exploratória DiferencialDSC, dentre outras);

- Análise mais aprofundada dos resultados obtidos, com o intuito de verificar se a presença de DGEBA e de solvente residual (oriundo da aplicação do revestimento) não são determinantes na resposta corrosiva deficiente quando da aditivação de $C_{g}>0.1 \%$;

- Utilizar nanoaditivos funcionalizados na matriz epoxídica. 


\section{Referências bibliográficas}

ABOUIMRANE, Ali et al. Non-annealed graphene paper as a binderfree anode for lithium-ion batteries. The Journal of Physical Chemistry C, v. 114, n. 29, p. 12800-12804, 2010.

AJAYAN P. M., SCHADLER L. S., BRAUN P. V. Nanocomposites Science and Technology. Wiley VCH: Weinheim, 2003.

ALEXANDRE, M.; DUBOIS, P. Polymer-layered silicate nanocomposites: preparation, properties and uses of a new class of materials. Materials Science and Engineering R. 28 (2000) 1-63.

ALLEN M.J, TUNG V.C, KANER R.B. Honeycomb carbon: a review of graphene. Chemical Reviews. (2010) 132-45.

ALVARENGA, E. A.; Carneiro, R. A.; Miranda, F. J. F.; Ensaios de Corrosão para a Indústria Automobilística, Society of Automotive Engineers, Inc., 2001.

ANGHINETTI, Izabel Cristina Barbosa. Tintas, suas propriedades e aplicações imobiliárias. Monografia apresentada ao Curso de Especialização em Construção Civil da Escola de Engenharia da UFMG. Belo Horizonte, 2012.

ASSIS, S. L., Estudo Comparativo de Ensaios Acelerados para Simulação da Corrosão Atmosférica. Dissertação (Mestrado em Ciência na Área de Reatores Nucleares de Potência e Tecnologia do Combustível Nuclear) IPEN, Autarquia Associada à Universidade de São Paulo, São Paulo, 2000.

ATKINS, P. W. (2008), Físico-Química.2, 8. Ed. 427p.

BADHULIKA, S. et al. Graphene hybrids: synthesis strategies and applications in sensors and sensitized solar cells. Frontiers in Chemistry, v. 3, n. 38, p. 38, 2015.

$\mathrm{BAE}, \mathrm{S}$. et al. Roll-to-roll production of 30 -inch graphene films for transparent electrodes. Nature nanotechnology, v. 5, n. 8, p. 574, 2010.

BALUCH AS, Wilson B, Miller JC. Patenting graphene opportunities and challenges. Nanotechnology. Law \& Business, 2008.

BARBOSA, Dispositivos de microondas utilizando nanotubos de carbono e grafeno. Tese de Doutorado/PUC-RIO 2014. 
BATZILL M., Surf. Sci. Rep., 2012, 67, 83-115.

BAYER, R. F.; Critérios para especificação de revestimento anticorrosivos. ALCOOLbrás - 2001, 41.

BOTAS, C. et al. Graphene materials with different structures prepared from the same graphite by the Hummers and Brodie methods. Carbon, v. 65, p. 156-164, 2013.

BRITNELL, L. et al. Field-effect tunneling transistor based on vertical graphene heterostructures. Science, v. 335, n. 6071, p. 947-950, 2012.

CARBÓ, H.M., Apostila Aço Inoxidável - Aplicações e Especificação. Núcleo Inox, Acesita, 2001.

CARVALHO, MG, Ávila AF, Van Petten AMVN. Estudo da influência da adição de nanofolhas de grafeno nas propriedades térmicas de nanocompósitos poliméricos. Rev Iberoam Polim 2011; 12(1): 13-22.

CASTRO, A. R. P. D. Impacto da corrosão por CO2 no aço AISI 1020 protegido com revestimentos poliméricos, Dissertação de Mestrado, Programa de Pós-Graduação em Engenharia de Materiais e de Processos Químicos e Metalúrgicos do Departamento de Engenharia de Materiais, DEQM, da Pontifícia Universidade Católica do Rio de janeiro, PUC-RJ, RJ, 2017.

CASTRO NETO A H, Guinea F, Peres N M, Novoselov K S and Geim A K (2009) Rev. Mod. Phys. 81109.

CASTRO NETO, A. H. Tecnologias do Futuro, Grafeno: Aplicações e oportunidades para o Brasil. Abnee Tec 2013 <http://www.tec.abinee.org.br/2013/arquivos/s23.pdf> acessado em: 12 de fevereiro de 2018.

CHUA C.K, PUMERA M. Chemical reduction of graphene oxide: a synthetic chemistry viewpoint. Chemical Society Reviews. 43 (2014) 291-312.

CIVIERO, E., 2010, Obtenção e Avaliação das Propriedades elétricas de materiais físicas de poliuretano termoplástico com aditivos semicondutores. UNIVERSIDADE FEDERAL DE SANTA CATARINA.

DA SILVA, Delne Domingos; DOS SANTOS, Wyllian Ficagna; PEZZIN, Sérgio Henrique. Nanocompósitos de matriz epoxídica com reforços produzidos a partir do grafite natural. 2013.

DE LIMA, D.B "Variações do Grafeno: uma Abordagem Ab-initio de Novas Estruturas Bidimensionais", 2012, USP: São Paulo. 
DIZAJI, Azam Khodadadi; MORTAHEB, Hamid Reza; MOKHTARANI, Babak. Preparation of supported catalyst by adsorption of polyoxometalate on graphene oxide/reduced graphene oxide. Materials Chemistry and Physics, v. 199, p. 424-434, 2017.

DING, J. N. et al. The influence of temperature, time and concentration on the dispersion of reduced graphene oxide prepared by hydrothermal reduction. Diamond and Related Materials, v. 21, p. 11-15, 2012.

DRAGO, R. S. Physical Methods in Chemistry. $2^{\text {nd }}$ edition. Saunders College Publishing, 1992.

DRESSELHAUS M.S, JÓRIO A., HOFMANN M., DRESSELHAUS G., SAITO R. Perspectives on carbon nanotubes and graphene Raman spectroscopy. Nano Lett. 10 (2010) 751-758.

DU X. S., XIAO M., MENG Y. Z., European Polymer Journal 40 (2004) 1489-1493.

ECKMANN, Axel et al. Raman study on defective graphene: Effect of the excitation energy, type, and amount of defects. Physical Review B, v. 88, n. 3, p. 035426, 2013.

EDWARDS, R. S., COLEMAN, K. S., Graphene synthesis: relationship to applications. Nanoscale, v. 5, p.38-51, 2013.

FÁBIO KRÄNKEL, Seção de Marketing da WEG Tintas Ltda.

FAZENDA, J. M. et al. Tintas e vernizes. São Paulo: Edgard Blücher, 2005.

FERNANDES, F.; MARIANO, R.; GNECCO, C.; Tratamento de Superfície e Pintura. Instituto Brasileiro De Siderurgia/Centro Brasileiro da Construção em Aço: Rio de Janeiro, 2003.

FERREIRA, M. et al. Propriedades mecânicas de epóxis utilizadas no recobrimento interno de oleodutos e gasodutos. Polímeros: Ciência e Tecnologia, v. 12, n. 3, 2002.

FERREIRA, E. H. M. Uso da Espectroscopia Raman na metrologia de materiais, 6o Congresso Brasileiro de Metrologia, 2011.

FIDALGO, A. D. C. Caracterização de tinta aditivada com grafeno Avaliação do desempenho anticorrosivo. 2017. Trabalho de Conclusão de Curso. (Graduação em Engenharia em Nanotecnologia) - Pontifícia Universidade Católica do Rio de Janeiro. Orientador: Ivani de Souza Bott. FIEDLER, B. et al. Fundamental aspects of nano-reinforced composites. Composites science and technology, v. 66, n. 16, p. 31153125, 2006. 
FRAUCHES-SANTOS, $C$. et al. A corrosão e os Agentes Anticorrosivos. Revista Virtual de Química, v. 6, n. 2, p. 293-309, 2013.

FREIRE, K. R. R, Avaliação do Desempenho de Inibidores de Corrosão em Armaduras de Concreto. Dissertação (Mestrado em Engenharia e Ciência dos Materiais) Universidade Federal do Paraná, Curitiba, 2005.

GARNICA, D. J. F. Síntese e Caracterização do grafeno por CVD Catalítico em filmes finos de Ni e Cu . São Paulo, 2017. 109p.

GEIM K.A, NOVOSELOV K.S. The rise of graphene. Nature Materials 6 (2007) 183-191.

GEMELLI, E. ; Corrosão de Materiais Metálicos e sua Caracterização, 1a. ed.; LTC: Rio de Janeiro, Brasil, 2001.

GENTIL, V.; Corrosão. LTC - Livros Técnicos e Científicos Editora: Rio de Janeiro, 2007.

GNECCO, C.; MARIANO, R.; FERNANDES, F. Tratamento de superfície e pintura. Rio de Janeiro: IBS/SBCA, 2003.

GOJNY, F. H. et al. Carbon nanotube-reinforced epoxy-composites: enhanced stiffness and fracture toughness at low nanotube content. Composites science and technology, v. 64, n. 15, p. 2363-2371, 2004.

GONZÁLEZ F.G, SOARES B.G. Determination of the epoxide equivalent weight of epoxy resins based on diglycidyl ether of bisphenol A (DGEBA) by proton nuclear magnetic resonance, Polymer Testing 22 (2003) 51-56.

GUO, B.; JIA D.; FU W.; QIU Q.; Polym. Degrad. Stab. 2003, 79, 521. dd

HACK, R. Nanocompósitos Poliméricos Multifuncionais Reforçados com Grafeno. Dissertação de mestrado, Universidade do Estado de Santa Catarina, 2013.

HARB, S. V. Desenvolvimento de revestimentos siloxano-PMMA reforçados por nanotubos de carbono, óxido de grafite e óxido de grafite reduzido para aplicações anticorrosivas. $2015.74 \mathrm{f}$. Dissertação (mestrado) - Universidade Estadual Paulista Júlio de Mesquita Filho, Instituto de Quimica., 2015.

JIANG, T. et al. Enhanced mechanical properties of silanized silica nanoparticle attached graphene oxide/epoxy composites. Composites Science and Technology, v. 79, p. 115-125, 2013. 
JORDAN J, JACOB K. L., TANNENBAUM R, SHARAF M.A., JASIUK I., Mater. Sci. Engin.: A., 393, 1 (2005).

KAMAT P. V. The Journal of Physical Chemistry Letters 1 (2009) 520527.

KAPPES, M. A. Evaluation of Thiosulfate as a Substitute for Hydrogen. Dissertação - The Ohio State University, 2011.

KARÁSEK, L. et al., 1996, "Percolation Concept: Polymer-Filler Gel Formation, Electrical Conductivity and Dynamic Electrical Properties of Carbon-Black-Filled Rubbers." Polymer Journal, pp. 121-126.

KHOLMANOV IN, CAVALIERE E, CEPEK C, GAVIOLI L. "Catalytic chemical vapor deposition of methane on graphite to produce graphene structures". Carbon. 2010, 48: 1619-1625.

KIM, H., ABDALA, A.A., MACOSKO, C.W., "Graphene/polymer nanocomposites", Macromolecules, v.43, pp. 6515-6530, 2010.

$\mathrm{KOO} \mathrm{JH}$, "Polymer nanocomposites: processing, characterization, and applications". Nueva York, McGraw-Hill, 2006.

KROTO H.W., HEATH J.R., O'BRIEN S.C., CURL R.F., SMALLEY R.E., Nature 318 (1985) 162-163.

KUILLA, T.; BHADRA S.; YAO D.; KIM N. H.; BOSE S.; LEE J. H. Recent advances in graphene based polymer composites. Progress in Polymer Science 2010, 35, 1350.

KUILA, T. et al. Chemical functionalization of graphene and its applications. Progress in Materials Science, v. 57, n. 7, p. 1061-1105, 2012.

LAMMERT T., ROZO L., WHITIER E. Graphene: material of the future, in review. Optical Engineering 2009,10 p.

LI, Q. et al. Ultrahigh thermal conductivity of assembled aligned multilayer graphene/epoxy composite. Chemistry of Materials, v. 26, n. 15, p. 4459-4465, 2014.

LI X., LAU K., YIN Y. Mechanical properties of epoxy-based composites using coiled carbon nanotubes. Composites Science and Technology 68 (2008) 2876-81.

LI J., WONG. P. S., KIM J. K., Materials Science and Engineering. A 483 (2008) 660-663.

LIAO L., LIN Y.-C. , BAO M. ,CHENG R., BAI J., LIU Y., QU Y., WANG K.L., HUANG Y., DUAN X., Nature 467 (2010) 305-308. 
LIU, K.H.; CHEN, S.L.; LUO, Y.F.; JIA, D.M.; GAO, H.; HU, G.J.; LIU, L. Edge-functionalized graphene as reinforcement of epoxy-based conductive composite for electrical interconnects. Compos. Sci. Technol. 2013, 88, 84-91.

LIJIMA S., Nature 354 (1991) 56-58.

LOBO, A. O.; MARTIN, A. A.; ANTUNES, E. F.; TRAVAAIROLDI, V. J.; CORAT, E. J. CARACTERIZAÇÃO DE MATERIAIS CARBONOSOS POR ESPECTROSCOPIA RAMAN. Revista Brasileira de Aplicações de Vácuo, 2005, 24(2), 98-103.

MAGNAN, M. D. C. "Pintura na Proteção Anticorrosiva". Trabalho de Conclusão de Curso - Centro Universitário Estatual da Zona Oeste, Rio de Janeiro, 2011.

MAI Y-W, YU-ZZ (Editores) “Polymer Nanocomposites”. Nueva York, Woodhead Publishing LTDA, 2006.

MAIO, D. , Desenvolvimento de "tinta" com pó de cortiça com desempenho acústico optimizado, Dissertação de Mestrado Integrado em Engenharia Civil, FEUP, 2010.

MALARD L.M, PIMENTA M.A, DRESSELHAUS G., DRESSELHAUS M.S. Raman spectroscopy in graphene. Phys. Rep.473 (2009) 51-87.

MARASCHIN, T. G. Preparação de óxido de grafeno e óxido de grafeno reduzido e dispersão em matriz polimérica biodegradável. 2016. 99 f. Dissertação (Mestrado em Engenharia e Tecnologia de Materiais). Pontifícia Universidade Católica do Rio Grande do Sul. Rio Grande do Sul. 2016 .

MARTíNEZ, L., TORRES, S., GOMES, H., \& SILVA, A. (2013). Nanotubos e Grafeno: Os primos mais jovens na família do carbono. Química, vol 128, 21-27.

MATOS, C. F.; GALEMBECK, F.; ZARBIN, A. J. Multifunctional materials based on iron/iron oxide-filled carbon nanotubes/natural rubber composites. Carbon 2012, 50, 4685-4695.

MIRABEDINI, S.M; KIAMANESH, A. The effect of micro and nano-sized particles on mechanical and adhesion properties of a clear polyester powder coating. Prog. Org. Coat. 2013, 76, 1625-1632.

MORALES-TORRES S., PESTRANA-MARTÍNEZ L.M., FIGUEIREDO J.L., FARIA J.L., SILVA A.M.T. Environ. Sci. Pollut. Res. 19 (2012) 36763687. 
MOREIRA W. , 2009, "Compósitos I”, Abmaco Associação Brasileira de Materiais Compósitos, Brasil, pág 43 e 77.

MORITA, M., ARIZONO, R., YOSHIMOTO, N., EGASHIRA, M. On the electrochemical activation of alkali-treated soft carbon for advanced electrochemical capacitors. Journal of Applied Electrochemistry, 44 (4), 447-453, 2014.

MAINIER, F. B. Material do curso Corrosão e Inibidores. In: Instituto Brasileiro de Petróleo, Rio de Janeiro, Brasil, 2006.

MCALLISTER M.J, LIO J.L, ADAMSON D.H, SCHIEPP H.C, ABDALA A.A, LIU J. et al. Single sheet functionalized graphene by oxidation and thermal expansion of graphite. Chem Mater. 19(18), (2007) 4396404.

NAIR, R. R. et al. Fine structure constant defines visual transparency of graphene. Science 320, 1308 (2008).

NAYAK, P.K.; HSU, C.J.; WANG, S.C.; SUNG, J.C.; HUANG, J.L. Graphene coated Ni films: A protective coating. Thin Solid Films 2013, $529,312-316$

NETO, A. H.; GUINEA, F.; PERES, N. M. R.; NOVOSELOV, K. S.; GEIM, A. K. The electronic Properties os Graphene. Reviews of Modern Physiscs. Vol 81, no 1, pp. 109-162, 2009.

NGUYEN, D. A. et al. Morphological and physical properties of a thermoplastic polyurethane reinforced with functionalized graphene sheet. Polymer International, v. 58, n. 4, p. 412-417, 2009.

NORMA ISO20340 "Paints and Varnishes - Performance requirements for protective paint systems for Offshore and related structures" (2009).

NOVOSELOV, K. S. et al. Electric field effect in atomically thin carbon films. Science, v. 306, n. 5696, p. 666-669, 2004.

NOVOSELOV, K. S. et al. Two dimensional atomic crystals. Proc. Natl Acad. Sci. USA 102, 10451-10453 (2005).

NOVOSELOV, K. S. et al. A roadmap for graphene. Nature, v. 490, n. 7419, p. 192-200, 2012.

NUNES, L. P. LOBO, ALFREDO CARLOS O. Pintura Industrial na Proteção Anticorrosiva. 3ª ed. Rio de Janeiro: Editora Interciência, 2007. OAKES, L., WESTOVER, A., MARES, J. W., CHARTTERJEE, S., ERWIN, W. R., BARDHAN, R., Weiss, S. M., Pint, C. L. Surface engineered porous silicon forstable, high performance electrochemical supercapacitors. Scientific Reports 3, Article number: 3020, 2013. 
O'BREIN, M.; NICHOLS, B. CVD synthesis and characterization of graphene thin films. Army Research Laboratory, MD 20783-1197, ARL-TR-5047 (2010).

OLIVEIRA, J. L.; SOUZA, W.; DA SILVA, C. G. Mattos; OR; Quintela, JP; Solymossy, V. Revestimentos anticorrosivos para tanques de armazenamento de petroquímicos. Revista Petro Química, v. 319, p. 75, 2009.

PANNONI, F. D. Manual de proteção de estruturas. São Paulo: Gerdau Açominas, 3, 2015. Disponível em: $<$ www.gerdau.com/br/pt/produtos/catalogos-e-manuais $>$. Acesso em: 22 de Março 2018.

PARDINI, L.C. e Peres, R.J.C. - Polímeros: Ciência e Tecnologia, p.32$42, \mathrm{VI}(1996)$.

PARK M.J, LEE J.K, LEE B.S, LEE Y.W, CHOI I.S, LEE S. Covalent modification of multiwalled carbon nanotubes with imidazolium based ionic liquids: effect of anions on solubility. Chem Mater 18 (2006) 1546-51.

PASTRANA-MARTÍNEZ L., Morales-Torres S., V. Likodimos, J.L. Figueiredo, J.L. Faria, P. Falaras, A.M.T. Silva, Applied Catalysis B: Environmental 123-124 (2012) 241-256.

PASTRANA-MARTÍNEZ, Luisa; Morales-Torres,Sergio; Gomes, Helder; Silva, Adrián (2013) - Nanotubos e grafeno: os primos mais jovens na família do carbono!. QUÍMICA. 128, p. 21-27.

PEREIRA, Neuma das M. et al. Graphene oxide-ionic liquid composite electrolytes for safe and high-performance supercapacitors. Electrochimica Acta, v. 259, p. 783-792, 2018.

PETRIE E.M. Epoxy Adhesive Formulations. McGraw-Hill Chemical Engineering EUA (2006).

PIPER, H.; BARBOSA, J. D. V.; MELO, P.D.S.; SILVA, E.; AZEVEDO, J. $B$. Influência do processo de cura nas características mecânicas e térmicas de revestimentos poliméricos a base de resina epóxi/ $8^{\circ}$ Congresso Brasileiro de Engenharia de Fabricação. Salvador (2015);

PIRES G., D.S. PEREIRA. , N.L. DIAS FILHO, G.D. VECCHIA.2005.Caracterização Físico-Química e Mecânica do Sistema Éster de Silsexquioxano/ Resina Epóxi Dgeba/ Dietilenotriamina.

POTHEN, L.; CHAN, C. H.; THOMAS, S. Natural Rubber Materials, Volume 2-Composites and Nanocomposites. Royal Society of Chemistry. 
POTTS, J. R. et al. Graphene-based polymer nanocomposites. Polymer, v. 52, n. 1, p. 5-25, 2011.

POURBAIX, M. Lições de corrosão electroquímica. $3^{\text {a }}$ ed., Bruxelas, CEBELCOR, 1987.

POURHASHEM, Sepideh et al. The effect of polycrystalline graphene on corrosion protection performance of solvent based epoxy coatings: Experimental and DFT studies. Journal of Alloys and Compounds, v. 764, p. 530-539, 2018.

PRASAI, D.; CARLOS TUBERQUIA, J.; HARL, R.R.; JENNINGS, G.K.; BOLOTIN, K.I. Correction to graphene: Corrosion-Inhibiting coating. ACS Nano 2012, 6, 1102-1108.

RAFIEE, Mohammad A. et al. Enhanced mechanical properties of nanocomposites at low graphene content. ACS nano, v. 3, n. 12, p. 3884-3890, 2009.

RAFIEE, M.A., LU, W., THOMAS, A.V., et al., "Graphene nanoribbon composites", ACSNano,v. 4, pp. 7415-7420, 2010.

RAJABI M., RASHED G.R., ZAAREI D. Assessment of graphene oxide/epoxy nanocomposite as corrosion resistance coating on carbon steel Corros. Eng. Sci. Technol. (2014)

RIBEIRO H. Síntese e caracterização de compósitos nanoestruturados a base de nanofolhas de grafeno quimicamente modificadas. Preparação, Estudo da Estrutura e Propriedades FísicoQuímicas. Tese de doutorado/UFMG 2015.

ROCHA, Roberta Jachura et al. Revestimentos de alta camada obtidos com a modificação de resinas epóxi novolaca pela reação com organo-siloxano e catálise ácida. Química Nova, v. 40, n. 2, p. 146-153, 2018.

SALA, O. Fundamentos da Espectroscopia Raman e no Infravermelho. São Paulo: Unesp, 1996.

SALEEM, H.; HANEEF, M.; ABBASI, H. Y. Synthesis route of reduced graphene oxide via thermal reduction of chemically exfoliated graphene oxide. Materials Chemistry and Physics, v. 204, p. 1-7, 2018.

SANTOS L. Avaliação da resistividade elétrica do concreto como parâmetro para a previsão da iniciação da corrosão induzida por cloretos em estruturas de concreto. [Tese]. Brasília: Brasilia University; 2006. 
SANTOSH, S.; BHANUREKA, M. Graphene based piezo resistive sensor fabrication and its characterization. Second International Conference on Recent Advances in Science \& Engineering. 2015.

SANTOS, A. C. B. D.; SILVA, D. F. D.; SILVA, D. B. D. Desenvolvimento e Análises de Tintas e Vernizes na Linha de Pulverizados. São Paulo, 2012.

SCHIAVETTO, M. G. Desenvolvimento de revestimentos híbridos do sistema siloxano-PMMA com aplicações anticorrosivas. Dissertação de Mestrado. Universidade Estadual Paulista. "Júlio de Mesquita Filho" UNESP. Instituto de Química. Araraquara-SP, 2009.

SCHMIDT, T. M. Soquetagem de Cabos de Fibra Poliéster com Resina Epoxi.2005.100.f. Dissertação (Mestrado em Engenharia - Tecnologia e Ciência dos Materiais) - Escola de Engenharia, Universidade Federal do Rio Grande do Sul,Porto Alegre.

SCHNIEPP, Hannes C. et al. Functionalized single graphene sheets derived from splitting graphite oxide. The Journal of Physical Chemistry B, v. 110, n. 17, p. 8535-8539, 2006.

SEGUNDO, J. E. D. V. SEGUNDO e E. O. VILAR/ Revista Eletrônica de Materiais e Processos / ISSN 1809-8797 / v. 11, n. 2 (2016) 54-57.

SEGER B., KAMAT P.V. The Journal of Physical Chemistry C 113 (2009) 7990-7995.

SHAH, R. et al. Progression from Graphene and Graphene Oxide to High Performance Polymer-Based Nanocomposite: A Review. Polymer-Plastics Technology and Engineering, v. 54, n. 2, p. 173-183, 2015

SHAN C, YANG H, HAN D, ZHANG Q, IVASKA A, NIU L. Water-soluble graphene covalently functionalized by biocompatible poly-L-lysine. Langmuir 25 (2009) 12030-3.

SHEN Y, LUA A.C. A facile method for the large-scale continuous synthesis of graphene sheets using a novel catalyst. Scientific Reports. 3 (2013) 3037.

SHIN, Y. R. et al. The oxidation mechanism of highly ordered pyrolytic graphite in a nitric acid/sulfuric acid mixture. Carbon, v. 52, p. 493498, 2013.

SILVA, D. D. Produção de reforços a partir do grafite natural para aplicação em nanocompósito poliméricos de matriz epóxi. Dissertação de mestrado, Universidade do Estado de Santa Catarina UDESC, 2011. 
SILVERSTEIN, R.M., WEBSTER, F.X., Identificação espectrométrica de compostos orgânicos, 6 ed. LTC, Rio de Janeiro, 2000.

SIMONI, L. Comportamento Mecânico e Eletroquímico do Aço API 5CT P110 em água do mar Sintética com e sem adição de Na2S2O3. Trabalho de Diplomação em Engenharia da Universidade Federal do Rio Grande do Sul - em fase de elaboração. Porto Alegre, 2014.

SINGH V., D. JOUNG, ZHAI L., DAS S., KHONDAKER S.I., SEAL S., Graphene based materials: Past, present and future, Progress in Materials Science, 56 (2011) 1178-1271.

SOARES, B. G., Ferreira, A. J. B., Camargo Jr., S., 1998, "Condutividade elétrica de misturas de poliestireno/polibutadieno e poliestireno/copolímero em bloco de estireno-butadieno contendo negro de fumo.", Polímeros, v. 8, n. 1, pp. 61-66.

SOARES, Vanessa Pavanelo. Revestimentos poliméricos condutores à base de resina epóxi. 2018. Tese de Doutorado. Universidade Federal do Rio de Janeiro.

SOLDANO C, MAHMOOD A, DUJARDIN E. Produção, propriedades e potencial do grafeno. Carbon. 2010, 48: 2127- 2150.

STOOT, Adam C. et al. Multilayer graphene for long-term corrosion protection of stainless steel bipolar plates for polymer electrolyte membrane fuel cell. Journal of Power Sources, v. 293, p. 846-851, 2015.

TAN, Y. B., LEE, J. M. Graphene for supercapacitor applications. Journal of Materials Chemistry A, 1, 14814-14843, 2013.

TANG L.C, WAN Y.J, YAN D, PEI Y.B, ZHAO L, LI Y.B. et al., The effect of graphene dispersion on the mechanical properties of graphene/epoxy composites. Carbon. 60 (2013) 16-27.

TAVARES, S. C. C. Propriedades elétricas de nanoantena de grafeno. 2015. 82 f. Dissertação (Mestrado) - Universidade Federal do Pará, Instituto de Tecnologia, Belém, 2015. Programa de Pós-Graduação em Engenharia Elétrica.

TERRONES, M. et al. Graphene and graphite nanoribbons: morphology, properties, synthesis, defects and applications. Nano today, v. 5, n. 4, p. 351-372, 2010.

TESTE DE IMERSÃO. Site: <www.corrosionlab.com>. Acesso em fevereiro 2018.

TESTE DE IMERSÃO EM CÉLULA ATLAS. Site $<$ www.chartercoating.com/coating inspection/atlas-cell-test.php>Acessado em: 01 de junho de 2018. 
TIWARI, A.; Singh Raman, R. Durable Corrosion Resistance of Copper Due to Multi-Layer Graphene. Materials 2017, 10, No. 1112.

TRIDAPALLI, C. W. Estudo comparativo de metodologias de ensaios acelerados de corrosão por frestas nas ligas de aço inox AISI 430 e AISI 304. Dissertação. PPEQ Universidade Federal de Santa Catarina, 2011.

UEMOTO, K. L. Influência da Formulação das tintas de base acrílica como barreira contra a penetração de agentes agressivos nos concretos. 1998. Tese de Doutorado. Universidade de São Paulo.

UEMOTO, K. L.; AGOPYAN, V.; IKEMATSU, P. As tintas imobiliárias e o impacto ambiental-Parte II. Encontro Brasileiro de Tecnologia do Ambiente Construído, v. 10, 2004.

UEMOTO, K. L., IKEMATSU, P. e AGOPYAN, V. Impactos ambientais das tintas imobiliárias. Coletanea Habitare: Construção e meio ambiente. Ed. Miguel A. Sattler e Fernando O. R. Pereira. Associação Nacional de Tecnologia do ambiente Construído - ANTAC, Porto Alegre, 2006.

VELMURUGAN R, M. T.P., J. Reinf. Plastics Compos., 28, 17 (2009).

VENTURA, S.; CARNEIRO, N.; SOUTO, A. P.. Acabamento de têxteis multifuncionais com nanocompósitos poliméricos. Nova Têxtil, v. 97, n. 1ㄹ, p. 8-13, 2011.

VÉRGES, G. R.; Estudo do desempenho de Sistemas de Pintura para materiais das Redes de Distribuição de Energia Elétrica situadas em regiões litorâneas. Dissertação de Mestrado, Universidade Federal do Paraná, 2005.

VERKER, R.; GROSSMAN, E.; ELIAZ, N. Erosion of POSS-polyimide films under hypervelocity impact and atomic oxygen: The role of mechanical properties at elevated temperatures. Acta Materialia, v. 57, n. 4, p. 1112-1119, 2009.

ZANG, X., Li, P., Chen, Q., Wang, K., Wei, J., Wu, D., Zhu, H. Evaluation of layer-by-layer graphene structures as supercapacitor electrode materials. Journal of Applied Physics, 115, 024305, 2014.

ZARBIN, A. JG; OLIVEIRA, M. M. Nanoestruturas de carbono (nanotubos, grafeno): Quo Vadis. Química Nova, v. 36, n. 10, p. 15331539, 2013.

ZHANG, Shu-Yong et al. Effect of polymeric structure on the corrosion protection of epoxy coatings. Corrosion Science, v. 44, n. 4, p. 861-869, 2002. 
ZHANG, L. L., ZHOU R., ZHAO, X. S. Graphene-based materials as supercapacitor electrodes. Journal of Materials Chemistry, 20, 59835992, 2010.

ZHANG, Z. et al. Mechanical and anticorrosive properties of graphene/epoxy resin composites coating prepared by in-situ method. International journal of molecular sciences, v. 16, n. 1, p. 22392251, 2015.

ZHU, Y. et al. Exfoliation of graphite oxide in propylene carbonate and thermal reduction of the resulting graphene oxide platelets. ACS Nano, v. 4, n. 2, p. 1227-1233, 2010.

ZHU, Y. W., MURALI, S., STOLLER M.D., VELAMAKANNI, A., PINER, R.D., RUOFF R.S. Microwave assisted exfoliation and reduction of graphite oxide for ultracapacitors Carbon, 48 (2010), p. 2118.

WAN, Yan-Jun et al. Improved dispersion and interface in the graphene/epoxy composites via a facile surfactant-assisted process. Composites science and technology, v. 82, p. 60-68, 2013

WANG Y., CHEN F. B., LI Y. C., WU K. C., Composites: Part B 35 (2004) 111-124.

WEGPOXI BLOCK N 2912 TIPO II. Boletim técnico - tinta líquida. São Paulo, DEZ/ 2016.

WEG TINTAS LTDA. Manual de Preparação de Superfície $<$ http://ecatalog.weg.net/files/wegnet/WEG-preparacao-de-superficie manual portugues-br.pdf> acessado em: 23 de julho de 2018.

WENG W., CHEN Z., WU D. Polymer 44 (2003) 8119-8132.

YANG, Y. et al. Enhancing graphene reinforcing potential in composites by hydrogen passivation induced dispersion. Scientific reports, v. 3, p. 2086, 2013.

YASMIN A., DANIEL I., Polymer, 45, 8211(2004).

$\mathrm{YU}$, A. et al. Ultrathin, transparent and flexible graphene films for supercapacitor application. Applied physics letters, v. 96, n. 25, p. 253105, 2010.

$\mathrm{XU}, \mathrm{C}$. et al. Graphene-based electrodes for electrochemical energy storage. Energy \& Environmental Science, v. 6, n. 5, p. 1388-1414, 2013.

$<$ http://old.weg.net/br/Media-Center/Central-de-Downloads> acessado em: 23 de julho de 2018. 